\title{
HORIZONTES PEDOGENÉTICOS E SUA RELAÇÃO COM CAMADAS HIDRÁULICAS DO SOLO
}

\section{JEAN DALMO DE OLIVEIRA MARQUES}

Engenheiro Agrônomo

Orientador: Prof. Dr. PAULO LEONEL LIBARDI

Dissertação apresentada à Escola Superior de Agricultura "Luiz de Queiroz", Universidade de São Paulo, para obtenção do Título de Mestre em Agronomia, Área de Concentração: Solos e Nutrição de Plantas.

PIRACICABA

Estado de São Paulo - Brasil

Dezembro - 2000 
Dados Internacionais de Catalogação na Publicação (CIP) DIVISÃo DE BIBLIOTECA E DOCUMENTAÇĀO - Campus "Luiz de Oueiroz"/USP

Marques, Jean Dalmo de Oliveira
Horizontes pedogenéticos e sua relação com camadas hidráulicas do solo / Jean Dalmo de Oliveira Marques. - - Piracicaba, 2000.

86 p. : il.

Dissertação (mestrado) - - Escola Superior de Agricultura Luiz de Queiroz, 2000. Bibliografia.

1. Água do solo 2. Condutividade hidráulica do solo 3. Curva de retenção 4.

$\operatorname{CDD} 63 y .432$

Eermitida a copia total ou parcial deste documento desde que citada a fonte -0 autor" 
DEDICO

A meus pais,

João da Costa Marques

Maria Iris de Oliveira Marques

Compartilho

Com meus Irmãos: Linderjane e Alexandre, minha Avó Aria e Tia Iolanda 
GABRIEL VICTOR MARQUES

$\boldsymbol{E}$

JUCIMARY ALMEIDA MARQUES

OFEREÇO 


\section{AGRADECIMENTOS}

A DEUS, por ter me dado a permissão de vencer mais uma etapa da minha vida.

Ao Prof. Dr. Paulo Leonel Libardi, pela orientação no decorrer do trabalho, amizade e todos os ensinamentos ao longo do curso. Muito obrigado.

Aos meus pais e familiares, pelo incentivo em persistir sempre mesmo nos momentos de maior dificuldade.

Ao Prof. Dr. Quirijn De Jong van Lier pelas sugestões e ajuda quando necessário.

Aos Professores: Dr. Miguel Cooper, Álvaro Pires e Julio Cesar pelas sugestões.

Ao Dr. Wenceslau Geraldes Teixeira - EMBRAPA-CPAA, pelos ensinamentos, conhecimentos adquiridos e incentivo no decorrer do curso.

Ao Curso de Irrigação e Drenagem pela concessão do uso do laboratório para realização das análises, em especial ao técnico Gilmar Grigol pela ajuda nas análises.

A Valda Maria Nogueira pelos cuidados, amor e dedicação dispensados a Gabriel Victor Marques, permitindo a realização deste curso.

A todos os amigos da Vila da Pós Graduação da ESALQ pela convivência e amizade durante 1 ano, em especial aos amigos Cláudio Duarte e Dori Nava.

Aos grandes amigos e amigas do Curso de Solos e Nutrição de Plantas, pela amizade, companheirismo, ajuda e incentivo durante o curso, destacando: Claudia 
Teixeira, José Fernandes, Jeane Portela, Glória Mesquita, Marcelo Biassusi (UFRGS), Luciana Castro, Antônio Carlos, Genelício Rocha, Ricardo Romero, Marcia Simonete, Cristiane e Silvia Truffi.

A família Nascimento: Jurandir Noronha, Antônia Paula, Jucimara, Jucilene, Humberto, pelo incentivo e amizade.

Aos amigos do Curso de Física do Ambiente Agrícola: Fábio Marin, Glauco Rolim, Alailson Santiago, Karen Maria e Evandro Righi.

Aos amigos do Curso de Irrigação e Drenagem: Luís CarlosTimn, Luiz Geraldo, Ana Berreta e do CENA: José Ronaldo.

Ao Dr. Alfredo Duarte e Marisa Duarte pela ajuda na chegada a Piracicaba e amizade.

Ao INPA - Instituto Nacional de Pesquisas da Amazônia, na pessoa do Dr. Ari de Oliveira Marques Filho, por ter incentivado a continuar os estudos.

Aos amigos da EMBRAPA-CPAA: Estevão, Luiz Gonzaga e Francis Wagner.

Aos professores do Curso de Física do Ambiente Agrícola: Nilson Villa Nova, Sérgio Moraes, Paulo Sentelhas, Antônio Pereira e funcionários: Ana Maria, Fernando Novello, Francisco Dias, Robinson Tuon, Jorge, Edivaldo Abreu e Vanderlino. Ao Projeto SHIFT, pelos trabalhos realizados e incentivo prestado, em especial a: Gotz Schroth e Johannes Lenhamn.

À CAPES pela concessão da bolsa.

Enfim, a todos aqueles que direta ou indiretamente ajudaram na realização deste trabalho. MUITO OBRIGADO. 


\section{SUMÁRIO}

PÁGINAS

LISTA DE FIGURAS.............................................................................................ii

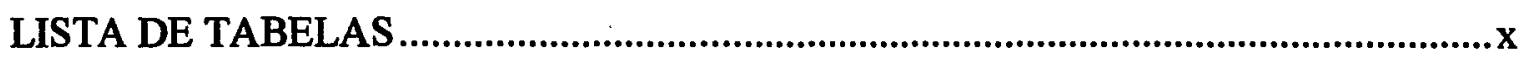

RESUMO ...................................................................................................................

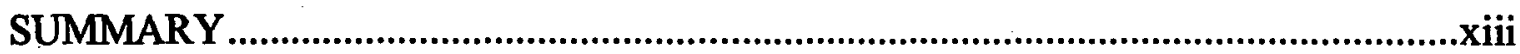

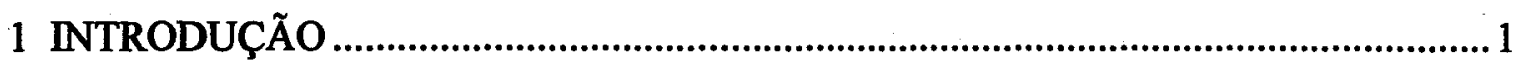

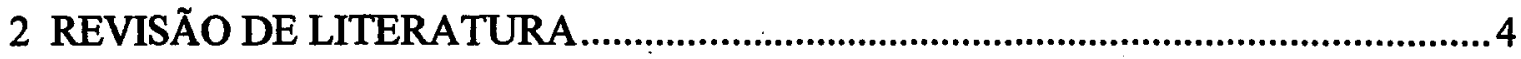

2.1 Conceitos BÁsicos: Horizontes, Camadas e PerfiL de Solo ............................. 4

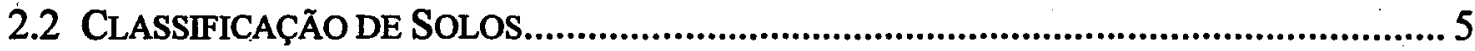

2.3 CARACTERIZAÇÃO MORFOLÓGICA E HIDRÁULICA DO SOLO ...................................... 7

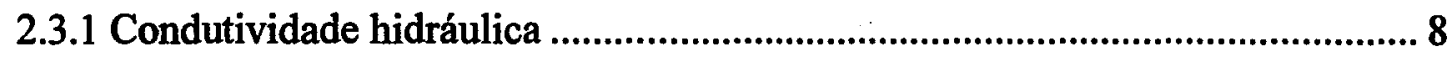

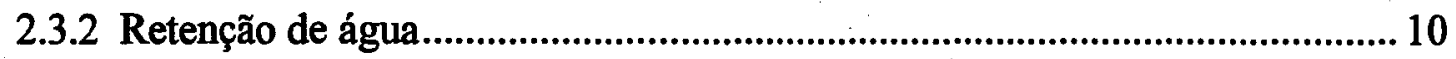

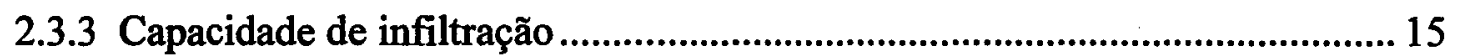

2.4 O ESPAÇO POROSO E SUA RELAÇÃO COM A ÁGUA NO SOLO..................................... 16

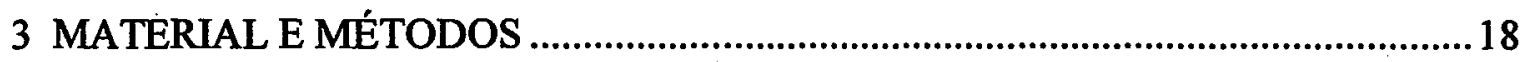

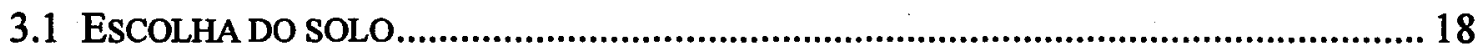

3.2 CARACTERÍSTICAS BÁSICAS dos LATOSSOLOS ................................................... 18

3.3 CARACTERIZAÇÃO DAS ÁREAS EXPERIMENTAIS ESTUDADAS .................................. 18

3.3.1 LATOSSOLO AMARELO Distrófico - LAd ................................................. 19

3.3.2 LATOSSOLO VERMELHO Distroférrico típico: ........................................... 19

3.4 ClASSIFICAÇÃO DOS SOLOS E ANÁLISE MORFOLÓGICA DOS PERFIS........................ 22

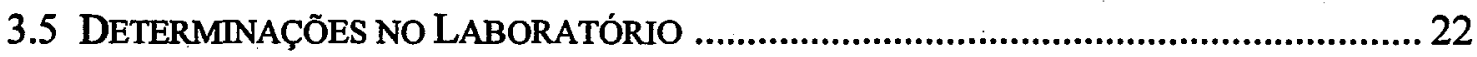

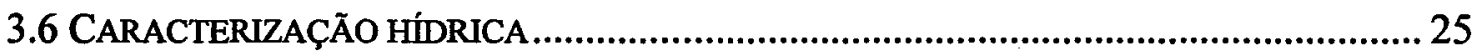

3.6.1 Curva de retenção de água, processo de saturação, umidade e densidade do solo

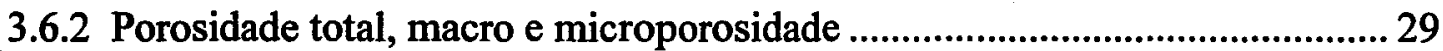

3.6.3 Ajuste das curvas de retenção ............................................................................. 30

3.6.4 Condutividade hidráulica do solo saturado ……............................................. 31 
3.7 AMOSTRAGEM E ANÁliSE ESTATÍSTICA DOS DADOS ......................................... 34

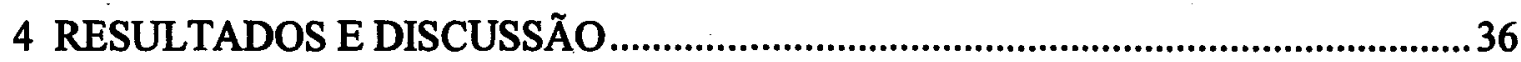

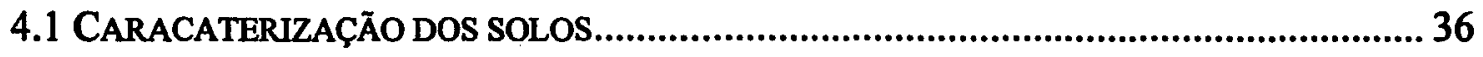

4.1.1 Características morfológicas dos perfis..................................................... 36

4.2 CARACTERIZAÇÃo DE ALGUNS ATRIBUTOS FÍSICOS E QUÍMICOS DOS SOLOS ........... 40

4.3 CONDUTIVIDADE HIDRÁUliCA SATURADA DO SOLO ......................................... 46

4.4 RETENÇÃO DE ÁGUA NOS SOLOS................................................................ 51

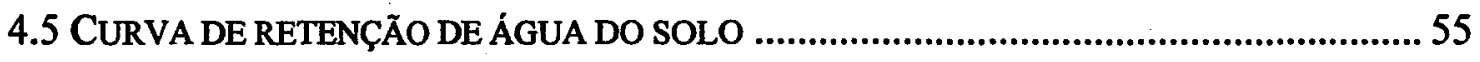

4.6 HoRizontes PedogenÉticos X “CAMAdAS HidRÁUlicas".............................. 59

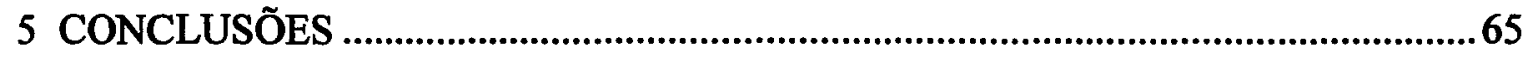

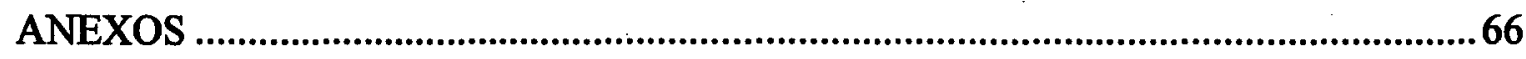

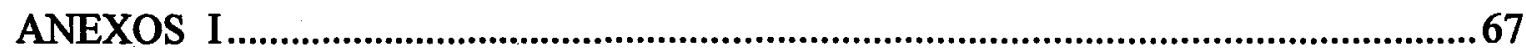

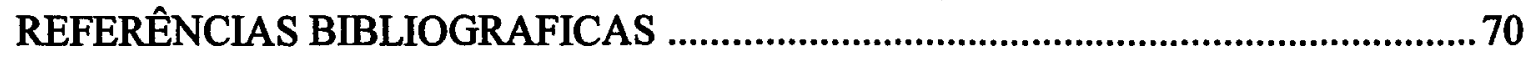




\section{LISTA DE FIGURAS}

PÁgINAS

Figura 1. Localização geográfica das áreas amostradas. 20

Figura 2. Extrato do balanço hídrico climatológico, Thornthwaite \& Mather (1955), calculado com dados médios do período entre 1917 a 1997 das regiões onde foram coletadas as amostras de solo. .21

Figura 3. Perfis dos solos estudados e suas disposições no ambiente: a) LATOSSOLO AMARELO e b) LATOSSOLO VERMELHO 23

Figura 4. Esquema da disposição dos horizontes nos perfis amostrados. 24

Figura 5. Esquema demonstrativo da amostragem realizada para o estudo da curva de retenção de água e condutividade hidráulica saturada dos solos. 26

Figura 6. Processo de saturação das amostras em laboratório, utilizando Frascos de Mariote, para determinação da $\mathrm{K}_{0} \mathrm{e}$ da curva de retenção de água no solo........28

Figura 7. Sistema utilizado para a determinação da condutividade hidráulica do solo saturado em laboratório. .33

Figura 8. Densidade do solo obtida por camadas nos perfis de: a) LAd e b) LVdf........49

Figura 9. Porosidade total, macroporosidade e microporosidade do: a) LAd e b) LVdf. 50 
Figura 10. Comportamento da retenção de água a cada tensão aplicada ao longo das camadas do LATOSSOLO AMARELO Distrófico. 54

Figura 11. Comportamento da retenção de água a cada tensão aplicada ao longo das camadas do LATOSSOLO VERMELHO Distroférrico típico. .54

Figura 12. Curvas de retenção hídrica obtidas para cada camada do LAd. . .57

Figura 13. Curvas de retenção hídrica obtidas para cada camada do LVdf. .58

Figura 14. Diagrama comparativo entre camadas hidráulicas e horizontes pedogenéticos identificados no LAd. .60

Figura 15. Diagrama comparativo entre camadas hidráulicas e horizontes pedogenéticos identificados no LVdf. .61 


\section{LISTA DE TABELAS}

PÁginas

Tabela 1. Distribuição das partículas, densidade dos sólidos e do solo, classe textural e distribuição dos poros nos horizontes dos solos estudados. .43

Tabela 2. Resultados das análises químicas dos perfis de Latossolos estudados. .44

Tabela 3. Resultados do ataque sulfúrico na TFSA das amostras de solo em estudo......45

Tabela 4. Condutividade hidráulica saturada determinada nas camadas selecionadas ao longo dos perfis de solo estudados.

Tabela 5. Valores médios obtidos de umidade volumétrica $(\mathrm{m} 3 \mathrm{~m}-3)$ em diferentes tensões, por camadas, do perfil de LATOSSOLO AMARELO Distrófico. ...52

Tabela 6. Valores médios obtidos de umidade volumétrica $\left(\mathrm{m}^{3} \mathrm{~m}^{-3}\right) \mathrm{em}$ diferentes tensões, por camadas, do perfil de LATOSSOLO VERMELHO Distroférrico típico. 53

Tabela 7. Resultados da análise estatística básica para os valores de condutividade hidráulica saturada em $\mathrm{cm} \mathrm{dia}{ }^{-1}$ do LATOSSOLO AMARELO Distrófico. ..68

Tabela 8. Resultados da análise estatística básica para os valores de condutividade hidráulica saturada em $\mathrm{cm} \mathrm{dia}^{-1}$ do. LATOSSOLO VERMELHO Distroférrico típico. .69 


\title{
HORIZONTES PEDOGENÉTICOS E SUA RELAÇĀO COM CAMADAS HIDRÁULICAS DO SOLO
}

\author{
Autor: JEAN DALMO DE OLIVEIRA MARQUES \\ Orientador: Prof. Dr. PAULO LEONEL LIBARDI
}

\section{RESUMO}

Considerando a hipótese de que a curva de retenção de água e a condutividade hidráulica podem não coincidir com os horizontes pedogenéticos ao longo de um perfil devido aos processos dinâmicos que regem o movimento da solução do solo, foram selecionadas duas áreas de Latossolo com o objetivo de verificar até que ponto há relação entre essas duas propriedades hidráulicas e os horizontes identificados. Em trincheiras abertas em cada área estudada, com dimensões de $2,0 \mathrm{~m} \times 2,5 \mathrm{~m} \times 2,0 \mathrm{~m}$ foram retiradas amostras com estrutura indeformada do perfil $0,00-1,00 \mathrm{~m}$, a cada 0,10 $\mathrm{m}$, não seguindo os horizontes pedogenéticos. Amostras deformadas foram coletadas nos horizontes para caracterização física e química. $O$ método utilizado para determinação da condutividade hidráulica saturada $\left(\mathrm{K}_{\mathrm{o}}\right)$ foi o do permeâmetro de carga decrescente. As curvas de retenção de água foram determinadas por meio de câmaras de pressão com placa porosa e funis de placa porosa. Comparando os resultados obtidos do $\log \mathrm{K}_{\mathbf{o}}$, observou-se que, de modo geral, não houve variações significativas ao longo das camadas estando os valores compreendidos entre 2,22 a 3,20 no LATOSSOLO AMARELO Distrófico (LAd) e entre 1,93 a 3,22 no LATOSSOLO VERMELHO Distroférrico típico (LVdf). Como no caso do $\log \mathrm{K}_{0}$, a curva de retenção de água não seguiu exatamente os horizontes pedogenéticos identificados, sendo que esta propriedade foi a que apresentou maior sensibilidade às variações morfológicas, permitindo identificar, conforme as 10 tensões avaliadas, as seguintes camadas 
hidráulicas: 0,0-0,4 m, 0,4-0,8 $\mathrm{m}$ e 0,8-1,0 m para o LAd e para o LVdf as camadas: 0,00,3 m, 0,3-0,8 m e 0,8-1,0 m. Pelas tendências obtidas, conclui-se que, em solos com grande homogeneidade, nem sempre as propriedades hidráulicas sofrem variações à medida que ocorre transição nos horizontes pedogenéticos, sendo necessário ter precaução quando o objetivo é caracterizar o solo hidraulicamente, pois alguns atributos morfológicos utilizados na identificação de horizontes no campo não são suficientes. 
PEDOGENETIC HORIZONS AS RELATED TO SOIL HIDRAULIC LAYERS

\author{
Author: JEAN DALMO DE OLIVEIRA MARQUES \\ Adviser: Prof. Dr. PAULO LEONEL LIBARDI
}

\title{
SUMIMARY
}

Based on the hypothesis that the water retention curve and the hydraulic conductivity may not match the soil profile pedogenetic horizons, due to the dynamic processes controlling the soil solution movement, two oxisol areas were selected with the objetive of verifying the extent of a relation between these two hydraulic properties and the pedologically identified horizons. The experiment consisted in opening 2,0 $\mathrm{m} \mathrm{x}$ $2,5 \mathrm{~m} \times 2,0 \mathrm{~m}$ pits in each study area, to collect undisturbed soil samples, at every 0,10 $\mathrm{m}$, since the soil surface till $1 \mathrm{~m}$ soil depth, not following the pedogenetic horizons. Disturbed soil samples were also collected from the horizons for the soil physical and chemical characterization. The saturated hydraulic conductivity (Ko) was determined by using the falling decreasing head permeameter method. The retention curve were determined by means of porous plate pressure cells and porous plate funnels. Comparing the results of $\log \mathrm{Ko}$, in general, there were not significant variations along the layers. The values varied from 2,22 to 3,20 in Allic Haplorthox and from 1,93 to 3,22 in Rhodic Haplustox. As in the case of $\log \mathrm{Ko}$, the water retention curve did not also followed precisely the identified pedogenetic horizons and this hydraulic property presented higher sensibility to the morphologic variations; according to the 10 evaluated tensions, the following hydraulic layers could be selected for the Allic Haplorthox: 0,0-0,4 m, 0,40,8 $\mathrm{m}$ and 0,8-1,0 $\mathrm{m}$ and for the Rhodic Haplustox: 0,0-0,3 m, 0,3-0,8 $\mathrm{m}$ and 0,8-1,0 m. From the tendencies, it could be concluded that in soils with great homogeneity, the hydraulic properties do not always suffer variations when there is a transition in the 
pedogenetic horizons of the profile, being necessary to have caution when the objective is to hydraulically characterize the soil, because some morphologic attributes used in the horizons identification in the field are not enough. 


\section{INTRODUÇÃO}

O solo é um meio natural constituído por um material heterogêneo que armazena solução aquosa em seus poros. As propriedades de retenção e de condução dessa solução podem sofrer variações significativas no perfil do solo, sendo necessário a realização de estudos quando o objetivo é caracterizar o solo quanto ao seu comportamento hidráulico.

A caracterização hidráulica do solo é um procedimento complexo, uma vez que a redistribuição, infiltração, evaporação e drenagem da água no solo não são processos contínuos, tornando a sua quantificação e entendimento um grande desafio. Por outro lado, a pedologia também utiliza uma série de critérios básicos utilizados para fins de classificação de solo, que podem indicar mudanças significativas na dinâmica da água.

Os estudos pedológicos procuram separar um perfil em horizontes, sendo estes essenciais na classificação dos solos. A ordenação de perfis em horizontes, apoiada na análise de atributos do solo, permite uma apreciação das diferenças entre os vários solos, proporcionando uma compreensão de suas potencialidades e limitações. Para tanto, são utilizados vários atributos relacionados ao solo como uma maneira de conhecê-lo, sendo a classificação um ordenamento desses atributos em classes mais homogêneas.

A importância deste trabalho reside no fato de levantar um questionamento quanto ao comportamento da dinâmica da água e a divisão de horizontes identificados pedogeneticamente. Esse estudo comparativo surge devido à dificuldade que existe em quantificar o comportamento da água no solo em razão da influência de processos extremamente complexos e até mesmo descontínuos. 
Aliado a esse questionamento, temos que considerar a importância da água nos vários processos pedogenéticos, sendo, portanto, um critério muito útil na identificação dos horizontes, auxiliando na descrição dos fenômenos físico-hídricos do solo.

A utilização de parâmetros hídricos nos trabalhos de caracterização analítica de perfis de solo permite correlacionar esses dados com outras características físicas, químicas e mineralógicas de cada horizonte do perfil, ou do perfil como um todo (Oliveira, 1982). Durante os últimos anos, as propriedades hidrícas têm sido estudadas intensamente tanto em condições de laboratório como de campo. Entretanto, a sua correlação com as propriedades morfológicas do solo ainda necessita de maiores estudos. Inúmeras tentativas têm sido feitas no sentido de definir e estabelecer a relação do movimento da água com os atributos físicos do solo usados no processo de classificação. Nesse caso, a grande dúvida é saber se a água segue rigorosamente os horizontes pedológicos.

Mesmo em um solo que apresenta vários horizontes discriminados pedogeneticamente, o seu comportamento hídrico pode assumir um caráter homogêneo, sendo que o oposto também é possível de ocorrer. Vários estudos relacionam parâmetros morfológicos ao comportamento hidrodinâmico do solo (Bouma et al., 1979; Germann \& Beven, 1981; Bullock \& Mackeague, 1984; Guehl (1984 a,b); Bouma, 1989), assim como correlacionam técnicas computacionais com cores do solo (Anderson \& Bouma, 1973) e condutividade hidráulica saturada com variações na textura e estrutura do solo (Mckeague et al ,1982).

Neste trabalho, pretende-se entender até que ponto um horizonte pedogenético pode caracterizar o comportamento da dinâmica da água no solo. Para isso, os horizontes descritos nos perfis dos solos estudados são comparados com as camadas hidráulicas identificados. Essa suposta "camada hidráulica" é definida pelo comportamento da condutividade hidráulica e da curva característica de retenção de água no solo ( $\phi_{\mathrm{m}}$ vs $\left.\theta\right)$ ao longo do perfil.

Com base nessas considerações foi delineada a hipótese de trabalho na qual assume-se que a retenção de água e condutividade hidraúlica do solo podem não 
coincidir com os horizontes pedogenéticos devido aos processos dinâmicos que regem o movimento da solução no solo. 


\section{REVISÃO DE LITERATURA}

\subsection{Conceitos Básicos: Horizontes, Camadas e Perfil de Solo}

Os fatores de formação são entendidos como agentes atuantes que provocam algum tipo de influência no desenvolvimento dos solos e seus atributos, enquanto que os processos são os caminhos dinâmicos, reações ou mecanismos de carátẹ fisico, químico ou biológico. Esses processos produzem no solo zonas características cuja combinação é particular em cada caso e está correlacionada como os diferentes fatores de formação. São estes processos que conduzem à constituição dos horizontes ou camadas (Buol et al., 1980; Birkeland, 1984; Vieira, 1988). Os processos pedogenéticos condicionados pelos fatores de formação do solo originam diferentes tipos de solos (Jenny, 1941).

Lemos \& Santos (1996) definem horizonte como sendo parte de um perfil de solo geralmente paralela à superfície, resultante da ação de processos pedogenéticos e, camada, como parte do perfil, mas pouco afetada por esses processos (Curi \& Larach, 1993). Uma característica comum a todos os solos é o desenvolvimento de diferentes seções que podem constituir horizontes e/ou camadas que, devido as distintas características e propriedades, podem variar dentro do perfil.

Um perfil de solo é definido como um corte vertical na superfície da terra, que inclui todos os horizontes pedogeneticamente inter-relacionados e também camadas mais profundas, ou mesmo próximas à superfície, que tenham sido pouco influenciadas pelos processos pedogenéticos (EMBRAPA, 1995). Sabe-se que a identificação e designação de horizontes constituem elementos essenciais para a taxonomia de solos, sendo que o desenvolvimento e seqüência dos horizontes e camadas é de suma importância para o estabelecimento e definição das classes de solos (EMBRAPA, 1988). 
Em certos solos, a diferenciação entre horizontes, é bem evidente, enquanto que em outros, somente é possivel através de estudos morfológicos mais detalhados. A identificação dos horizontes diagnósticos é feita através de propriedades morfológicas, fisicas, químicas e mineralógicas, usadas como critérios diferenciais em diversos níveis taxonômicos.

A descrição morfológica de um perfil pode ser feita observando vários outros parâmetros dentre os quais podemos destacar: espessura; arranjamento e número de horizontes; transição entre horizontes; cor e mosqueamentos, textura, estrutura, porosidade, cerosidade, consistência, nódulos ou concreções e pH (SSDS, 1993).

Nos estudos científicos, o estudo de perfis de solo é fundamental, pois além dos atributos físicos, químicos e mineralógicos, a disposição dos horizontes permite estudar a ação dos processos de formação do solo. A água tem participação fundamental na diferenciação dos horizontes de um perfil. A movimentação da água no solo ocasiona o arrastamento de partículas ou de substâncias nela dissolvidas, redistribuindo-as pelo perfil e provocando a formação e transformação nos horizontes.

\subsection{Classificação de Solos}

A Ciência do Solo é dinâmica. O conhecimento pedológico sempre está sendo alterado seja pela evolução conceitual das classes de solos ou pelo advento de novos conhecimentos.

A definição de solo, adotada em diversos sistemas de classificação de todo o mundo, é a de uma coleção de corpos naturais, tridimensionais, dinâmicos, constituídos por materiais minerais e orgânicos, que formam a maior parte do manto superficial das extensões continentais (EMBRAPA, 1997 a; SSDS, 1996), resultado da ação integrada dos fatores de formação do solo.

Classificar um solo é um processo que objetiva organizar cientificamente os conhecimentos necessários nos levantamentos de solo. A classificação utiliza como fundamento básico atributos morfogenéticos dos solos e os chamados horizontes diagnósticos, tornando possível prever seu comportamento pela obtenção de dados 
experimentais (Prado, 1996). Para tanto, é muito importante adquirir informaç̃oes suficientes quanto às características dos solos para que seja possível diferenciá-los.

Segundo Oliveira et al. (1992), os horizontes diagnósticos são atributos utilizados como critérios de formação de classes de solo para identificação dos solos, implicando na combinação de atributos definidos qualitativa e quantitativamente. Logo, cada solo deve satisfazer a exigência de possuir um horizonte diagnóstico.

Muito embora a caracterização do solo seja básica para a sua classificação, inúmeros problemas são encontrados devido à diversidade de critérios adotados para a sua identificação. Os sistemas ou legendas de classificação de solos em todo o mundo adotam conceitos de horizontes diagnósticos, superficiais e subsuperficiais, e propriedades diagnósticas como características chave para a separação de classes de solo. Apesar de ser um fator de grande preocupação nos estudos da Ciência do Solo, não é possivel indicar um Sistema de Classificação de aceitação geral (Dudal, 1990). Cada sistema utiliza parâmetros adequados que melhor classifique os solos existentes no País. Os sistemas diferem de acordo com regiões ou países porque eles estão baseados em conceitos e graus de avaliação diferentes de formação do solo (Kutilek \& Nielsen, 1994).

Dentre os vários sistemas de classificação de solos vingentes, pode-se destacar três principais Soil Taxonomy (Estados Unidos, 1998), WRB (FAO, 1998) e o atual Sistema Brasileiro de Classificação de Solos (EMBRAPA, 1999). Para um melhor conhecimento da evolução histórica e definições dos sistemas de classificação é possivel consultar os trabalhos de (Cline, 1949; Finkl, 1992; Porta et al., 1994; FAO, 1998; Bockheim \& Gennadiyev, 2000; Nachtergaele et al., 2000;) entre outros.

O sistema proposto pela WRB (FAO, 1998) leva em consideração uma legenda de mapas de solos do mundo, a partir do qual se atinge uma classificação de solos (Driessen \& Dudal, 1991).

O sistema americano de classificação de solos (Soil Taxonomy) é bem diferente em estrutura e nomenclatura, sendo considerado o mais bem elaborado. Para classificar o solo requer um conhecimento em campo, por meio de perfis, que permitam uma correta identificação e detalhada descrição dos horizontes diagnósticos. Define 
exatamente os horizontes e as características morfológicas como a base da definição de todas as unidades de solo, sendo completada com a identificação do regime térmico $\mathrm{e}$ hídrico (Porta et al., 1994).

Percebe-se que a classificação de solos está em constante processo de desenvolvimento. $\mathrm{O}$ enquadramento de solos nas respectivas classes pode ser melhorado e mais acessível com a utilização dos estudos envolvendo a água no solo, traduzindo-se como uma forma auxiliar na classificação pedológica. Nesse contexto o estado energético da água no solo afeta continuamente as propriedades do solo devido a sua influência sobre a intemperização, formação, friabilidade e permeabilidade, retenção de água entre outros.

\subsection{Caracterização morfológica e hidráulica do solo}

Quando o objetivo é caracterizar um solo hidraulicamente, considera-se quatro propriedades básicas: condutividade hidráulica, curva de retenção de água, infiltração e difusividade. Para auxiliar na descrição de perfis são utilizadas classes de drenagem, que permitem inferir uma noção sobre a capacidade de drenagem, permeabilidade e retenção de água do solo, sendo portanto, de grande importância.

Libardi \& Reichardt (1973) realizaram pesquisas sobre características hídricas de cinco solos de São Paulo e enfatizaram a importância da curva de retenção, condutividade hidraúlica e difusibilidade da água no solo, afirmando que essas grandezas são dependentes da geometria do meio poroso, compactação e umidade do solo. Afirmaram ainda que estudos dessa natureza trazem boas perspectivas para a análise do movimento da água no solo.

Vários trabalhos procuram correlacionar os atributos morfológicos do solo como textura, estrutura, cor e porosidade à movimentação da água (Beven \& Germann, 1982; Bouma et al., 1989), pois alguns, particularmente aqueles pertinentes à estrutura, podem utilizar ferramentas morfológicas para predizer o comportamento hídrico do solo (Cooper, 1999) e explicar algumas variações entre as propriedades hidráulicas medidas no campo e aquelas determinadas em laboratório (Sharma \& Uehara, 1968; Keng \& Lin, 1982; Field et al., 1984). Por outro lado, quando o objetivo é avaliar a influência da 
textura (Cosby et al., 1984; Haverkamp \& Parlange, 1986; Wosten \& van Genuchten, 1988) e estrutura (Bouma et al., 1979; Beven \& Germann, 1982; Mckeague et al., 1982; Solins \& Radulovich, 1988; Lin et al., 1999) na dinâmica da água são utilizados horizontes heterogêneos quanto a esses dois atributos sendo, ainda, necessário mais informações quanto ao estudo da dinâmica da água em perfis de solos homogêneos.

Para o próposito deste trabalho, faz-se necessário caracterizar as três principais formas de estudar o solo do ponto de vista hidráulico, salientando os conceitos básicos, métodos e utilização dessas propriedades, as quais serão apresentadas a seguir:

\subsubsection{Condutividade hidráulica}

A condutividade hidráulica do solo é uma propriedade de grande importância nos estudos relacionados ao sistema solo - planta. Libardi (2000) define condutividade como a propriedade que expressa a facilidade com que um fluído é transportado através de um meio poroso.

Também conhecida como coeficiente de permeabilidade, a condutividade hidráulica poder ser considerada como um dos parâmetros mais importantes no manejo da água no solo, sendo de larga aplicação nos projetos de drenagem (Klute, 1965). Portanto, quanto maior for o valor dessa propriedade, maior será a facilidade com que a água se movimentará no solo, sendo que o seu valor máximo ocorre quando o solo está saturado, denominando-se condutividade hidráulica saturada (Libardi, 2000).

A condutividade saturada é uma das propriedades do solo que depende fisicamente do sistema poroso do solo, ocasionando dificuldades na sua quantificação (Kutilek \& Nielsen, 1994). Os métodos mais utilizados para determinação da condutividade hidráulica saturada e não saturada podem ser classificados como métodos de laboratório e campo, respectivamente. Dentre os métodos de laboratório, salienta-se o permeâmetro de carga constante e de carga decrescente (Youngs, 1991); e de campo, o método do perfil instantâneo (Hillel et al., 1972).

Millar (1978) argumenta que as medições de condutividade no laboratório são adequadas quando são utilizadas amostras não alteradas e com o propósito de estudar a influência da variabilidade do solo e seus atributos no movimento da água. 
Richards (1931) foi o primeiro a apresentar um método de determinação da condutividade hidráulica. Seu método constitui em utilizar uma pequena coluna de solo entre duas placas porosas de cerâmica, mantendo um gradiente de potencial constante entre as extremidades da coluna por meio de colunas de água. Uma vez atingida a condição de equilibrio dinâmico, a condutividade hidráulica é estimada por meio da equação de Darcy.

Várias metodologias já foram apresentadas para a determinação da condutividade hidráulica. Em função da dificuldade encontrada e da estreita relação que apresenta com outras propriedades do meio poroso, vários trabalhos foram realizados, como é o caso de Childs \& Collins-George (1950), Marshall (1958), Millington \& Quirq (1960), Anderson \& Bouma (1973) e Mualem (1976), que desenvolveram equações matemáticas para o cálculo da condutividade hidraúlica sob condições de não saturação, a partir por exemplo da distribuição do tamanho de poros. A partir dai, muitas pesquisas vêm sendo desenvolvidas, já que essa propriedade tem um papel fundamental na determinação da umidade ideal para o bom desenvolvimento das plantas. Dentre elas, podemos citar o de Ellies et al. (1997) que descrevem a funcionalidade do sistema poroso, englobando propriedades tais como: quantidade, tamanho, morfologia, continuidade e orientação dos poros.

Outro parâmetro importante e que tem sido utilizado para a determinação da condutividade hidráulica em função da umidade do solo é a curva de retenção de água no solo, como bem atestam os trabalhos de Marshall (1958); Millington \& Quirk (1959); Campbell (1974); Van Genuchten (1980) e Kosugui (1981). Germann \& Beven (1981), através da curva de retenção da água no solo, estabeleceram estimativas do volume de macroporos em amostras de horizontes superficiais de dois solos.

\subsubsection{Atributos do solo relacionados com a Condutividade Hidráulica}

A condutividade hidráulica depende das propriedades do fluído e do material poroso. Como o meio poroso de interesse é o solo, salienta-se como importante a distribuição do tamanho e forma das partículas, tortuosidade, superfície específica, 
distribuição do tamanho dos poros e umidade (Libardi, 2000). O material poroso apresenta geometria variável de solo para solo devido a alterações na forma, direção e largura dos poros (Reichardt, 1996), consequentemente, promovendo variações na estrutura (Anderson \& Bouma, 1973; Bouma, 1981). Portanto, a condutividade hidráulica é muito influenciada pelo arranjamento dos poros, sendo que um aumento na densidade do solo significa diminuição do tamanho dos poros e, como consequência, diminuição da condutividade (Hillel, 1971)

A compactação também influência a condutividade hidráulica do solo. Numa situação de solo saturado, a água se encontra retida nos macroporos através de tensões baixas. Assim, a macroporosidade é responsável pelo movimento da água, pois está relacionada ao volume de macroporos (Ahuja et al., 1984). Se ocorrer compactação no solo, acarretará diminuição dos macroporos, ocasionando maior retenção de água. No caso de solo não saturado, a compactação originará aumento do número de microporos $\mathrm{e}$ a água tenderá a ser retida sob altas tensões, proporcionando uma diminuição na condutividade.

Quando um fluído atravessa a amostra de solo por longos períodos de tempo, ou quando a amostra fica muito tempo submersa, diversos processos biológicos, químicos e físicos podem ocorrer no sistema, mudando a característica hidráulica (Klute, 1965). Nesse sentido, a viscosidade é a propriedade mais relevante do fluído que afeta a condutividade hidráulica (Libardi, 2000). Tanto a viscosidade como a densidade da solução do solo dependem da temperatura, pressão, concentração de sais solúveis e teor de água no solo (Reichardt, 1996).

\subsubsection{Retenção de água}

O solo é um sistema aberto, dinâmico, constituído por três fases distintas: sólida (matriz do solo), líquida (solução aquosa) e gasosa (ar do solo). As interações entre essas fases influenciam o estado energético com que a água se movimenta no solo (Libardi, 2000). 
Com a caracterização do movimento da água através das curvas de retenção é possível realizar avaliações importantes sobre as características do solo e seu comportamento hidráulico. Libardi (2000) salienta que a retenção da água no solo pode ser explicada por dois processos: capilaridade e adsorção. Essas duas forças que operam na matriz do solo para a retenção da água são denominadas de forças mátricas. No primeiro, a retenção ocorreria nos microporos dos agregados, sendo associado a uma interface curva ar-água. No segundo processo, a retenção ocorre nas superfícies dos sólidos do solo como filmes presos a ela.

A capilaridade atua na retenção de água dos solos na faixa úmida, quando os poros se apresentam razoavelmente cheios de água. Quando o solo seca, os poros vão se esvaziando e filmes de água recobrem as partículas sólidas. Nestas condições, o fenômeno de adsorção passa a dominar a retenção. A energia de retenção da água nestas condições é muito maior e, por isso, grandes quantidades de energia são requeridas para se retirar esta água do solo (Reichardt, 1987).

Trềs mecanismos principais são propostos para explicar a adsorção: (i) a superficie das partículas minerais de argila, coberta com átomos de oxigênio e grupos de oxidrilas negativamente carregados, cria ao redor das mesmas um campo elétrico que atrai as moléculas de água, devido à sua natureza dipolar, (ii) os pares de elétrons não compartilhados do átomo de oxigênio das moléculas de água são atraídos por cátions trocáveis que podem estar adsorvidos sobre a superficie de argila, ou seja, os cátions retidos na superfície das argilas ocasionam também a adsorção das moléculas de água; (iii) as moléculas de água podem ainda ser atraídas às superficies sólidas pelas forças de London-van der Waals (Libardi, 2000).

O estudo da retenção de água é feito através de um gráfico que relaciona a umidade do solo com o potencial mátrico denominado de curva de retenção da água no solo.

Childs (1940) afirma que as curvas de retenção de água se destacam quanto ao estudo do comportamento da água no solo devido às informações que são possíveis de obter, principalmente, quanto à disponibilidade de água para as plantas. Além disso, essas curvas permitem estimar o nível que o teor de água no solo pode atingir sem afetar 
o desenvolvimento das plantas. A obtenção das curvas de retenção de água nos solos é fundamental em diversas áreas de estudo da Ciência do Solo, por ser um estudo da dinâmica da água e das relações hídricas do sistema solo-planta-atmosfera. Exemplo prático de sua utilidade é que com os dados da curva é possível calcular a difusividade capilar versus o potencial mátrico (Black et al., 1969; Black et al., 1970; Millar, 1975) e solucionar problemas relacionados a irrigação já que permite conhecer a variação do potencial de água no solo disponível às plantas (Correa, 1984).

A curva característica de água pode ser construída a partir de medidas experimentais e/ou equações empíricas. A influência da umidade do solo sobre o potencial mátrico pode ser avaliado a partir de três formas: Tensiômetro, Funil de Haines e Câmara de pressão de Richards. Todas utilizam uma placa porosa separando a(s) amostra(s) em um recipiente contendo uma solução de mesma concentração que a da(s) amostra(s) de solo. As curvas são determinadas após estabelecer uma série de pontos de equilíbrio entre a umidade das amostras e um volume de água com potencial conhecido. O sistema solo-água, representado pela amostra, está em contato hidráulico com o volume de água através da placa porosa.

A curva de drenagem, iniciada a partir da saturação completa da amostra, é denominada curva inicial de drenagem (Klute, 1986). À medida em que a água é removida, o potencial diminui (mais negativo) e a umidade da amostra se aproxima de um limite chamada umidade residual. A curva principal de molhamento é obtida a partir do umedecimento da amostra e inicia quando a mesma está com um baixo teor de água, muitas vezes na umidade residual. À medida em que o solo vai umedecendo e o potencial mátrico se aproximando de zero, o conteúdo de água da amostra se aproxima de um valor denominado saturação $\left(\theta_{0}\right)$, inferior à umidade de saturação $(\theta$ s). Devido à presença de ar aprisionado, geralmente $\theta_{0}$ varia de $0.8 \mathrm{~s}$ à $0.9 \mathrm{~s}$.

O método de laboratório é um dos mais utilizados para determinar a retenção de água, o qual utiliza amostras com estrutura indeformada retiradas com anéis volumétricos que, geralmente, têm diâmetros de $0,05 \mathrm{~m}$ à $0,15 \mathrm{~m}$ e altura $0,01 \mathrm{~m}$ à 0,05 . Salter \& Willians (1965) e Hill \& Sumner (1967) concluíram que a determinação da retenção de água no solo deve ser realizada com amostras tendo estrutura indeformada, 
pois estas representam melhor as condições de campo. Assim, não ocorre grande perturbação da estrutura do solo, mantendo-se a amostra em condições mais próximas do seu estado natural.

Os equipamentos utilizados para determinar as curvas são de dois tipos: tensão e pressão. Conforme Klute (1986), nos equipamentos que utilizam sucção, as amostras ficam em contato hidráulico com o volume de água através da placa porosa. A amostra fica submetida à pressão atmosférica e a pressão na massa de água é reduzida a níveis subatmosféricos, devido à redução de carga hidráulica. Assim, a água flui da amostra até atingir o equilíbrio hidráulico.

Na câmara de pressão, as amostras de solo, após serem colocadas na superficie da placa de cerâmica, são saturadas juntamente com a placa. Por conseguinte, o conjunto é colocado no interior da câmara e, então, uma determinada pressão é aplicada, fazendo a solução se mover do solo para um pequeno reservatório sob a placa. Essa solução goteja no tubo de saída até parar quando atinge uma condição de equilíbrio.

\subsubsection{Atributos do solo relacionadas com a Retenção da água}

Existem atributos do solo que podem exercer grande influência no comportamento da curva de retenção de água em um solo. Os trabalhos realizados salientam opiniões diversificadas quanto aos atributos que realmente causam interferência na curva de retenção, dentre os quais é possível citar: textura, porosidade, estrutura, mineralogia e granulometria. A preocupação em estudar os diversos aspectos que interferem na retenção vem aumentando e vários trabalhos podem ser destacados.

Salter \& Williams (1965), Sharma \& Uehara (1968) e Reeve et al. (1973), destacam que a retenção de água no solo é afetada por uma série de fatores, como a distribuição relativa do tamanho, a forma e o arranjo das partículas do solo.

A retenção de água no solo está relacionada à distribuição e à forma dos poros, que, por sua vez, são influenciadas pela textura, contéudo e qualidade da matéria orgânica, e pela disposição dos componentes sólidos formando os agregados (Hillel, 1971; Baver et al., 1973). Da mesma forma Klute (1986), Reichardt (1987) e Jorge \& 
Prado (1988); comentam que a textura, juntamente com a estrutura, são atributos que influenciam diretamente na retenção da água pelo solo.

A estrutura do solo é utilizada para descrever o solo no que se refere ao arranjo, orientação e organização das partículas sólidas. É uma condição natural do material na qual as suas partículas primárias (argila, silte e areia) encontram-se arranjadas em agregados; estes, por sua vez diferem em forma, tamanho, estabilidade e capacidade de adesão entre si.

Letey (1991) cita que a maior parte dos pesquisadores na área da Ciência do Solo têm interesse nas relações existentes entre a estrutura do solo e alguns processos como os de transferência hídrica e gasosa. A estrutura, para alguns, parece ser o principal fator que controla vários processos dentro do solo, em particular os processos de transferência da água. Robain \& Curmi (1986) mostraram que, apesar de dois horizontes pedogenéticos serem caracterizados pelos mesmos constituintes, a estrutura dos mesmos era diferente, ocasionando variações nas curvas de retenção. Da mesma forma, Grimaldi \& Boulet (1989) mostraram que os principais horizontes dos solos da Guiana, bem diferenciados do ponto de vista estrutural, também apresentavam comportamento hidrodinâmico peculiar.

Segundo Rivers \& Shipp (1978) e Hillel (1982), o teor de água retido a baixas tensões depende do efeito da capilaridade e da porosidade. Nesta faixa, o potencial mátrico da água é mais dependente das forças capilares do que de adsorção. Por outro lado, a retenção a altas tensões é devida ao incremento na adsorção, sendo menos influenciada pela estrutura e mais pela textura e superfície específica do material sólido do solo. Consequentemente, quanto maior o conteúdo de argila, maior a retenção de água a uma dada tensão, sendo a inclinação da curva mais gradual. Outros estudos como o de Petersen et al. (1968) indicam que, a baixas tensões, a matéria orgânica tem um efeito indireto na retenção de água devido à sua influência na agregação das partículas sólidas do solo e, a altas tensões, tem uma atuação direta em função de sua elevada superfície específica e capacidade de adsorção. A matéria orgânica favorece a agregação do solo e a formação de poros grandes, os quais retêm pouca água a $0,033 \mathrm{mPa}$ e acima 
de $1,5 \mathrm{mPa}$, havendo uma tendência de aumentar a retenção conforme aumente o teor de carbono orgânico.

Salter \& Williams (1965) admitem que outros atributos do solo como a granulometria interferem diretamente na retenção de água. De modo geral, solos com textura grosseira tem maior proporção de macroporos, sendo bem drenados e arejados. Por outro lado, os de textura mais fina tem drenagem e aeração inferior aos arenosos, porém, a porosidade total é bem maior.

\subsubsection{Capacidade de infiltração}

A infiltração consiste na penetração da água no solo pela sua superficie, no sentido vertical, podendo ser influenciada pelos atributos intrínsecos do solo e pelo modo como a água atinge a superficie. Depois que a água penetra no solo, esta é perdida lentamente e distribuída, via capilaridade, devido à ação dos poros pequenos (Kretzschmar et al. 1994). A capacidade de infiltração de água representa a vazão máxima por unidade de área e por unidade de tempo capaz de atravessar a superficie do solo, sendo normalmente expressa $\mathrm{em} \mathrm{mm} \mathrm{h}^{-1}$ (Villela \& Mattos, 1975).

Assim, o movimento da água no solo no sentido vertical é regido basicamente pelas forças correspondentes aos potenciais mátrico e gravitacional (Clemmens, 1983; Reichardt, 1987). No início da infiltração, o potencial mátrico é o mais importante e, ao longo do tempo, destaca-se o potencial gravitacional (Gish \& Starr, 1983). Entretanto, quando o movimento da água ocorre por meio de poros grandes, o potencial mátrico é desprezível e o gravitacional constitui o principal componente de força que governa a infiltração vertical (Germann \& Beven, 1981).

\subsubsection{Atributos do solo relacionadas com a Capacidade de Infiltração}

As causas mais importantes de variação na infiltração se relacionam às propriedades do solo (Cauduro \& Dorfman, 1988), da água e dos métodos utilizados no seu estudo. 
Assim, o manejo da camada superficial (Gish \& Starr, 1983), as camadas subsuperficiais (Scopel et al., 1978), umidade inicial (Philip, 1957), porosidade (Germann \& Beven, 1981), estrutura (Baver, 1961) e textura (Duffy et al., 1981) são as principais causas de variação na infiltração da água no solo. Com relação a água, destaca-se a sua qualidade (Agassi et al., 1981) e temperatura (Moore, 1941).

\subsection{O espaço poroso e sua relação com a água no solo}

O meio poroso exerce grande influência no processo de retenção da água no solo, sendo de grande importância conhecer a distribuição dos poros. A distribuição de poros na matriz do solo desempenha papel fundamental nas relações entre as fases sólida, líquida e gasosa, com marcada influência nos processos pedogenéticos e potencialidade agrícola das glebas (Manfredini et al., 1984). Essa distribuição condiciona o comportamento hídrico do solo, podendo ser utilizada para caracterizar e quantificar as propriedades físico-hídricas (Guerif, 1987).

Vários são os trabalhos que procuram relacionar a influência do espaço poroso no movimento da água (Jarvis et al., 1991; Lin et al., 1997), já que a porosidade governa os regimes de água e ar, cuja combinação cria condições favoráveis ou não para as plantas. A importância do estudo das diferenças de porosidade reside no fato que todos os processos que concorrem para uma melhoria das condições da massa do solo envolvem o movimento da água no espaço poroso do solo (Drozhzhina \& Vasil'chikova, 1984). Para um conhecimento minucioso da permeabilidade da água no solo, da capacidade de retenção, e da extensão na qual a zona das raízes é suprida com ar, devese diferenciar a porosidade total, de acordo com o diâmetro (Vomocil, 1965). Os poros do solo são representados por cavidades de diferentes tamanhos e formas, determinados pelo arranjamento de partículas sólidas. Muitas definições têm sido usadas para classificar os diferentes tamanhos dos poros. Inúmeros conceitos tem surgido no sentido de estabelecer um padrão no tamanho da distribuição dos poros, considerando a geometria e a configuração do espaço poroso. 
Segundo Castle \& Kredzorn (1973) os poros podem ser divididos em não capilares (macroporos), que não retêm água contra a força da gravidade, e os capilares (microporos), que são capazes de armazenar água a tensões superiores à força da gravidade. Libardi (2000) por outro lado, cita a classificação de Koorevaar et al. (1983), a qual divide os poros em a) macroporos, com diâmetro superior a $100 \mu \mathrm{m}$, e cujas funções seriam a de promover a aeração do solo e a condução da água durante a infiltração b) mesoporos, com diâmetro entre 30 e $100 \mu \mathrm{m}$, nos quais a condução de água se processaria durante a redistribuição e c) microporos, com diâmetro inferior a 30 $\mu \mathrm{m}$, que atuariam na armazenagem e nos quais a água apresentaria movimento muito lento.

Sabe-se que a microporosidade é a principal responsável pela retenção da água, enquanto que a macroporosidade, deixa a água gravitacional fluir com facilidade, passando os espaços a serem preenchidos com ar. Bouma et al. (1977) afirmam que nos microporos, em função do diâmetro muito reduzido, a água circula lentamente devido à ação das forças capilares. Os microporos são portanto os responsáveis pela retenção e redistribuição da água no solo.

A existência de uma porosidade interna (intra-agregado) e outra externa aos microagregados (interagregado) foi verificado por Sharma \& Uehara (1968), que estudaram a influência das porosidades intra $\mathrm{e}$ interagregados na retenção hídrica de dois Oxissols do Havaí. Os autores atribuíram a perda rápida de água nas baixas tensões e o maior volume hídrico armazenado nas tensões mais elevadas, às porosidades inter e intraagregados, respectivamente. Da mesma forma Kertzmann (1996) afirma que a água retida dentro dos microagregados de um Latossolo Roxo pode ser extraída do solo apenas com tensões muito elevadas, devido ao diminuto diâmetro dos poros, o que a torna praticamente indisponível para as plantas. No entanto, trata-se de um teor de água sempre presente no solo, conferido-lhe uma umidade permanente, mesmo que reduzida. 


\section{MATERIAL E MÉTODOS}

\subsection{Escolha do solo}

Cerca de $60 \%$ dos solos do território brasileiro são ocupados por Latossolos, constituindo-se no grupamento de maior expressão geográfica no País (estimativa a partir de mapa esquemático, Resende et al., 1988).

Quando se estuda um perfil de solo de um Latossolo, uma maior homogeneidade na cor ao longo das seções torna mais difícil a separação dos horizontes e, ainda, caracterização hídrica do mesmo.

Por esta razão, utilizou-se nesse estudo esse grupamento de solo, já que em alguns casos a caracterização morfológica depende da experiência do profissional que a executa.

\subsection{Características básicas dos Latossolos}

Esses solos são profundos, podendo ultrapassar $30 \mathrm{~m}$ de profundidade, bem a acentuadamente drenados, de textura média a muito argilosa, apresentando horizonte $\mathrm{B}$ latossólico intemperizado, caracterizado pela quase total ausência de minerais primários facilmente intemperizáveis e/ou de minerais de argila 2:1, e pela concentração residual de sesquióxidos, argila do tipo 1:1 e minerais primários resistentes ao intemperismo (EMBRAPA, 1981; Radambrasil, 1983; Camargo et al., 1987; Carvalho et al., 1988).

\subsection{Caracterização das áreas experimentais estudadas}


As amostras de solos estudadas foram provenientes de dois Estados distintos: Amazonas e São Paulo (Figura 1). Procurou-se coletar amostras de diferentes materiais de origem e representativos de classe, com o intuito de realizar uma comparação entre as camadas hídricas e pedogenéticas. Dessa forma, os solos selecionados foram:

\subsubsection{LATOSSOLO AMARELO Distrófico - LAd}

As amostras do LAd foram coletadas na Estação Experimental da EMBRAPA - Centro de Pesquisa Agroflorestal da Amazônia Ocidental, situada a $30 \mathrm{~km}$ ao norte de Manaus $\left(2^{\circ} 52^{\prime}\right.$ de latitude Sul e $59^{\circ} 59^{\prime}$ de longitude Oeste, com $50 \mathrm{~m}$ de altitude). As médias das temperaturas máximas e mínimas mensais são de $32^{\circ} \mathrm{C}$ e $22^{\circ} \mathrm{C}$, respectivamente. $O$ clima nessa região é do tipo Af, na classificação de Koppen, caracterizado por apresentar precipitação média anual é de $2420 \mathrm{~mm}$, com um máximo de $295 \mathrm{~mm}$ mensais, de março a abril, e um mínimo de $105 \mathrm{~mm}$ mensais, de agosto a setembro (EMBRAPA, 1984)

Nos ecossistemas de terra firme da Amazônia, esses solos são, juntamente com os Podzólicos, os mais representativos da região, sendo altamente intemperizados e com fortes limitações nutricionais, mas com propriedades físicas adequadas para o uso agrícola (Radambrasil, 1975).

\subsubsection{LATOSSOLO VERMELHO Distroférrico típico:}

As amostras do LVdf foram coletadas em a área cultivada com cana-de-açúcar localizada a $3 \mathrm{~km}$ em linha reta a partir da antiga rodovia Piracicaba - Santa Bárbara D'Oeste, lado direito, no município de Piracicaba - SP. O município se localiza na latitude $22^{\circ} 44^{\prime}$ Sul e longitude Oeste $47^{\circ} 34^{\prime}$, com altitude de $546 \mathrm{~m}$. O clima da região é do tipo Cwa, segundo a classificação de Koppen, mesotérmico úmido, subtropical, em que a temperatura do mês mais frio não excede $18^{\circ} \mathrm{C}$ e do mês mais quente é maior que $22^{\circ} \mathrm{C}$ (Brasil, 1969). 


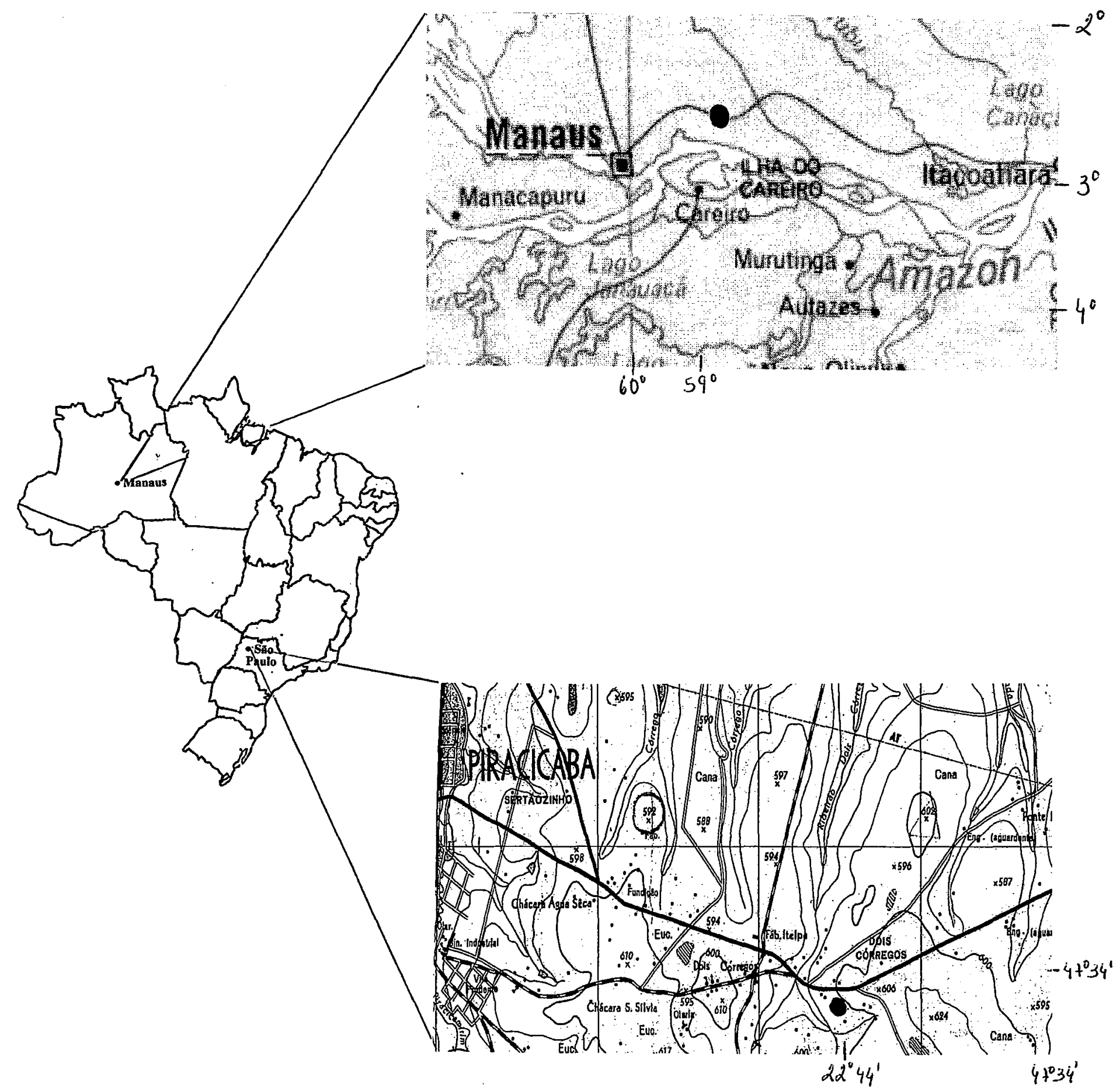

Figura 1. Localização geográfica das áreas amostradas. 
Apresenta uma temperatura média anual de $21,1^{\circ} \mathrm{C}$ com precipitação média anual de $1278 \mathrm{~mm}$, sendo cerca de $1.000 \mathrm{~mm}$ de outubro a março, e $278 \mathrm{~mm}$ de abril a setembro (Sentelhas et al., 1998).

Nas Figuras 2 (a e b) é possível observar a variação sazonal do clima nos locais estudados.

a) Manaus

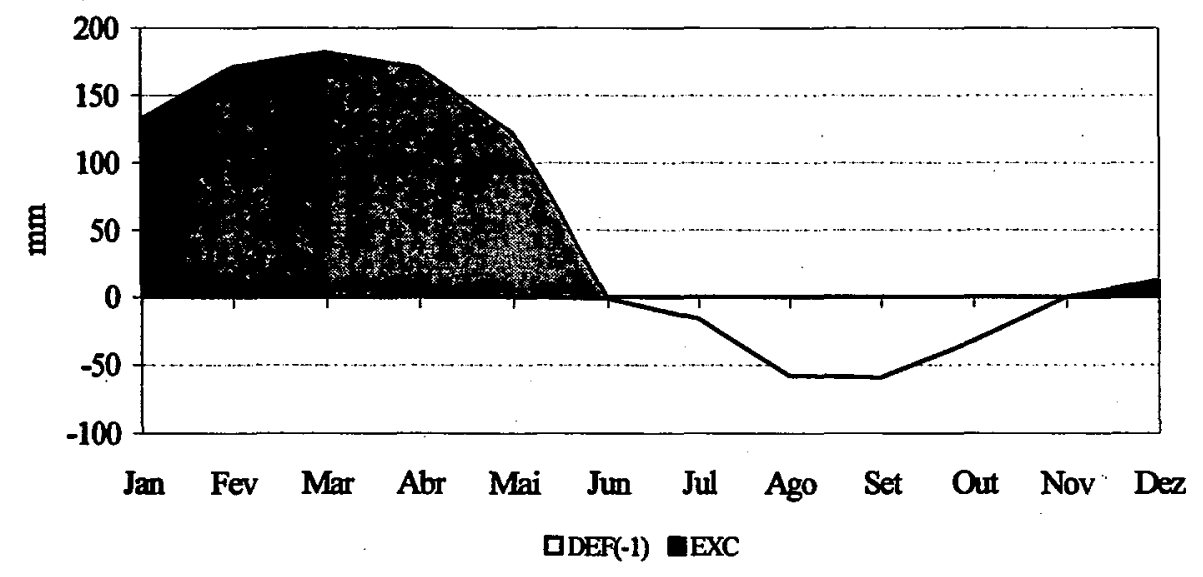

b) Piracicaba

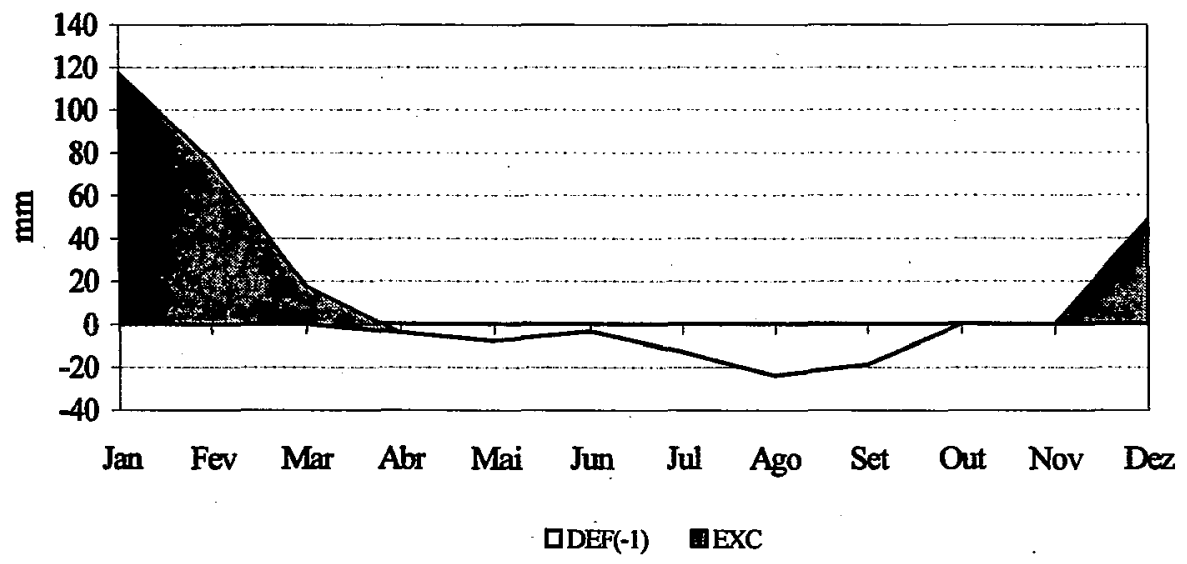

Figura 2. Extrato do balanço hídrico climatológico, Thornthwaite \& Mather (1955), calculado com dados médios do período entre 1917 a 1997 das regiões onde foram coletadas as amostras de solo.

FONTE: Departamento de Física e Meteorologia - ESALQ/USP. 


\subsection{Classificação dos solos e análise morfológica dos perfis}

Para a classificação e caracterização física e química dos solos das áreas amostradas foram abertas trincheiras com dimensões de $2,0 \mathrm{~m} \times 2,5 \mathrm{~m} \times 2,0 \mathrm{~m} \mathrm{e}$ coletadas amostras deformados por horizontes.

As descrições morfológicas dos solos estudados foram realizadas conforme Lemos \& Santos (1996) e as classificações com base na norma estabelecida pela EMBRAPA (1999).

Os perfis dos solos estudados são apresentados na Figura 3 a (LATOSSOLO AMARELO Distrófico) e $3 \mathrm{~b}$ (LATOSSOLO VERMELHO Distroférrico típico). Observa-se que são solos pertencentes a diferentes sistemas de uso e manejo agrícola, submetidos ao cultivo de um sistema agroflorestal e de um plantio cana-de-açúcar, respectivamente.

Para estudar o comportamento hidráulico ao longo das seções dos perfis foram considerados os horizontes existentes até a faixa de $1,0 \mathrm{~m}$ de profundidade, perfazendo um total de 04 horizontes por perfil de solo (Figura 4).

\subsection{Determinações no Laboratório}

As análises físicas e químicas foram realizadas nos laboratórios da EMBRAPA - CPAA e no Departamento de Ciência do Solo da ESALQ/USP.

Amostras com estrutura deformada foram coletadas ao longo dos horizontes em sacos plásticos com aproximadamente $0,3 \mathrm{~kg}$ de solo para as determinações físicas e químicas. A densidade do solo $\rho\left(\mathrm{kg} \mathrm{m}^{-3}\right)$ foi determinada a partir de amostras indeformadas, utilizando anéis volumétricos. A determinação da densidade dos sólidos ps $\left(\mathrm{kg} \mathrm{m}^{-3}\right)$ foi realizada pelo método do picnômetro conforme EMBRAPA (1997 b).

A análise granulométrica foi realizada segundo Gree \& Bauder (1986), utilizando $0,05 \mathrm{~kg}$ de solo, como dispersante solução aquosa de hexametafosfato de sódio puro $\left(6 \mathrm{~kg} \mathrm{~m}^{-3}\right)$ e hidróxido de sódio $\left(4 \mathrm{~kg} \mathrm{~m}^{-3}\right)$ e agitação lenta durante 16 horas. 
a)
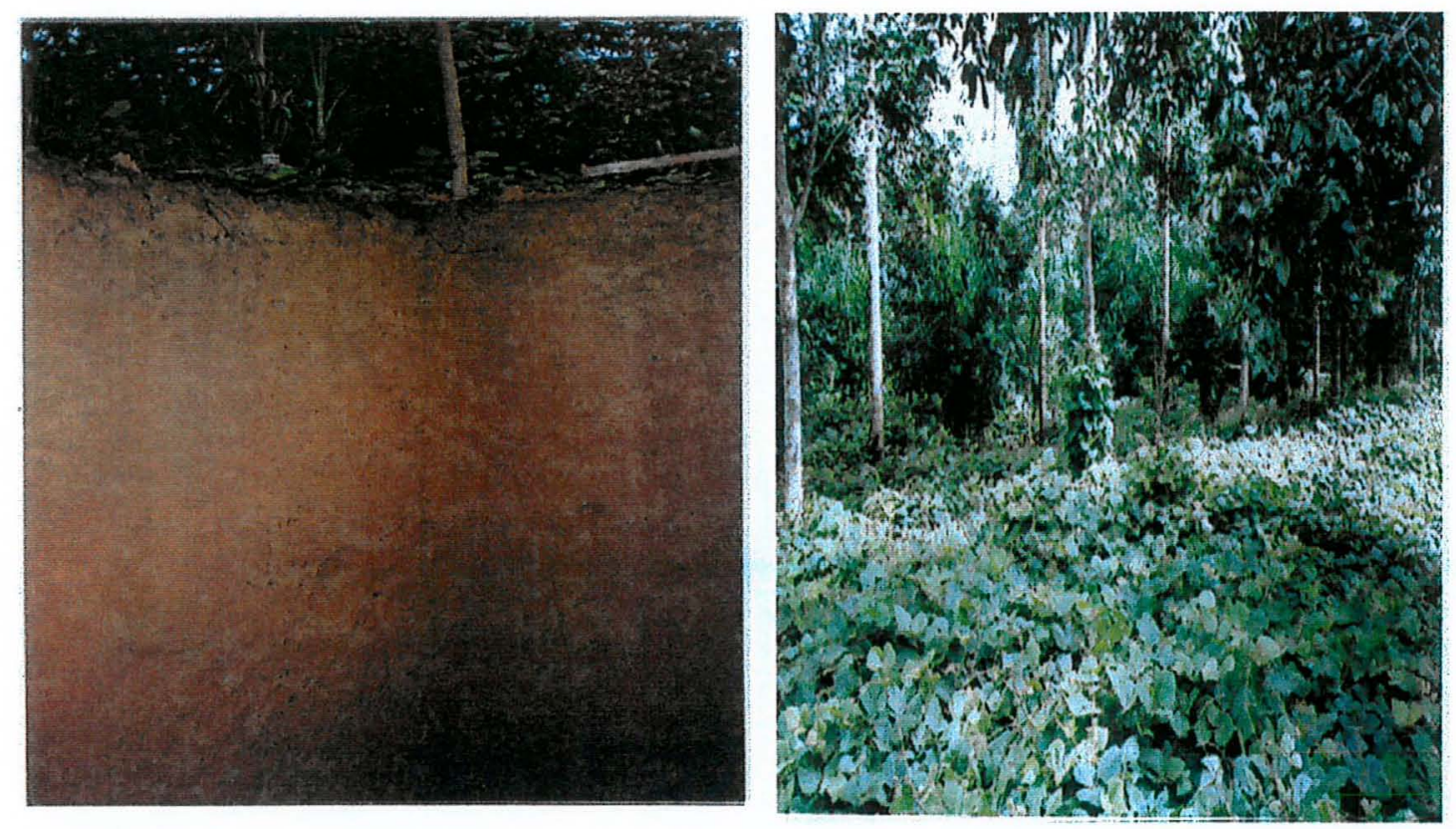

b)
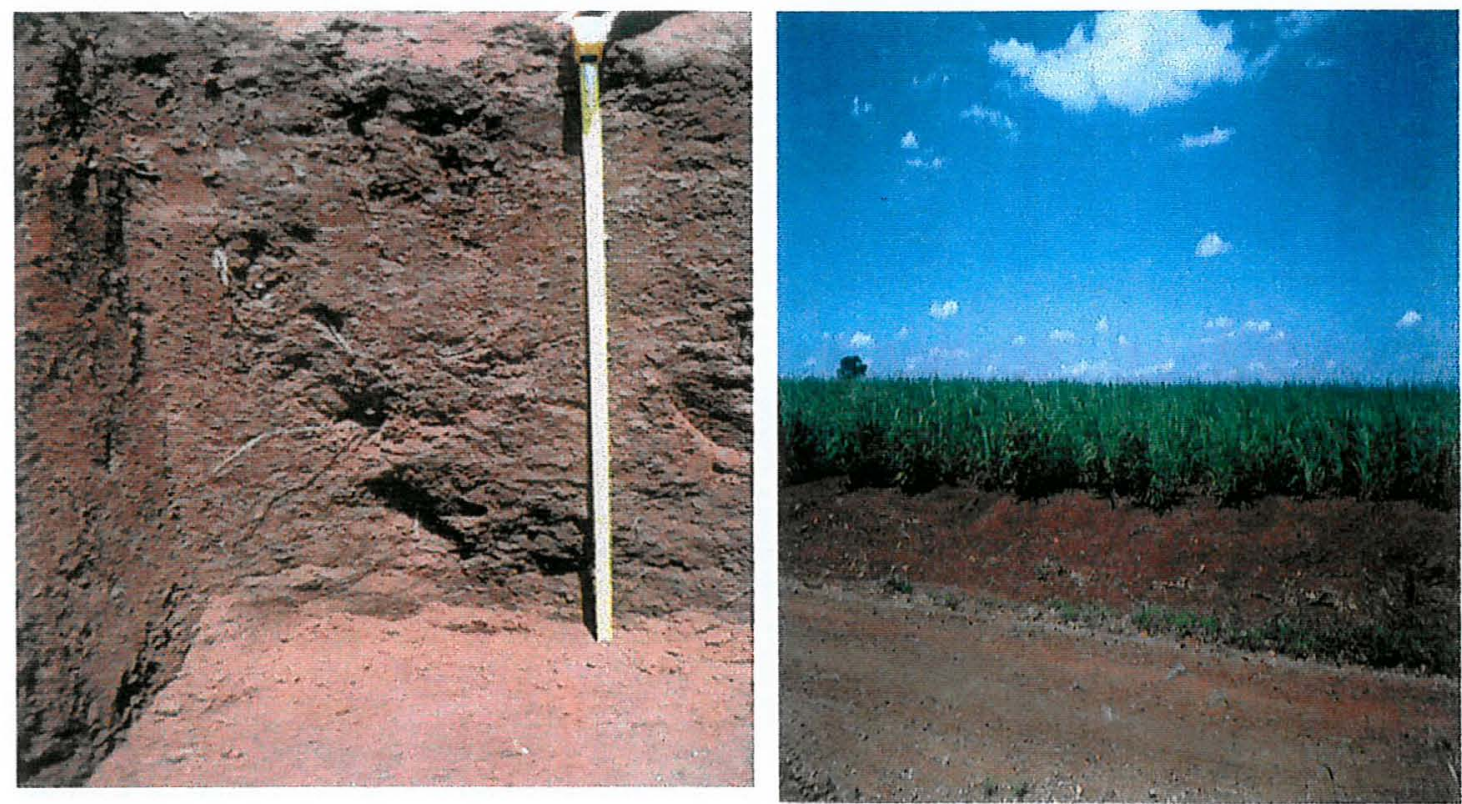

Figura 3. Perfis dos solos estudados e suas disposições no ambiente: a) LATOSSOLO AMARELO e b) LATOSSOLO VERMELHO. 


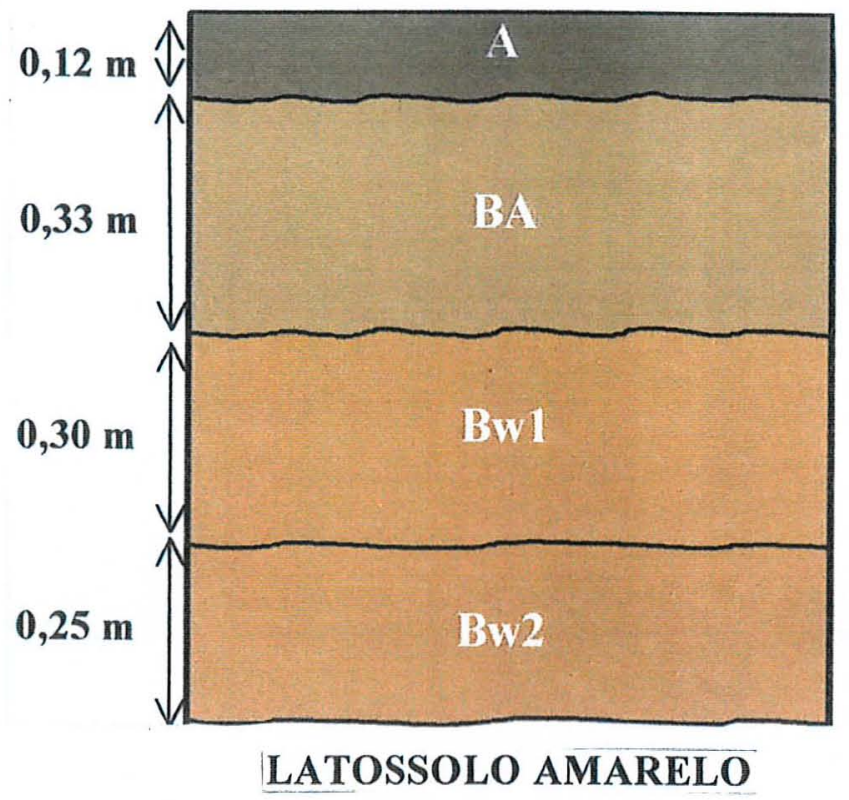

Escala $0,1 \mathrm{~m}$

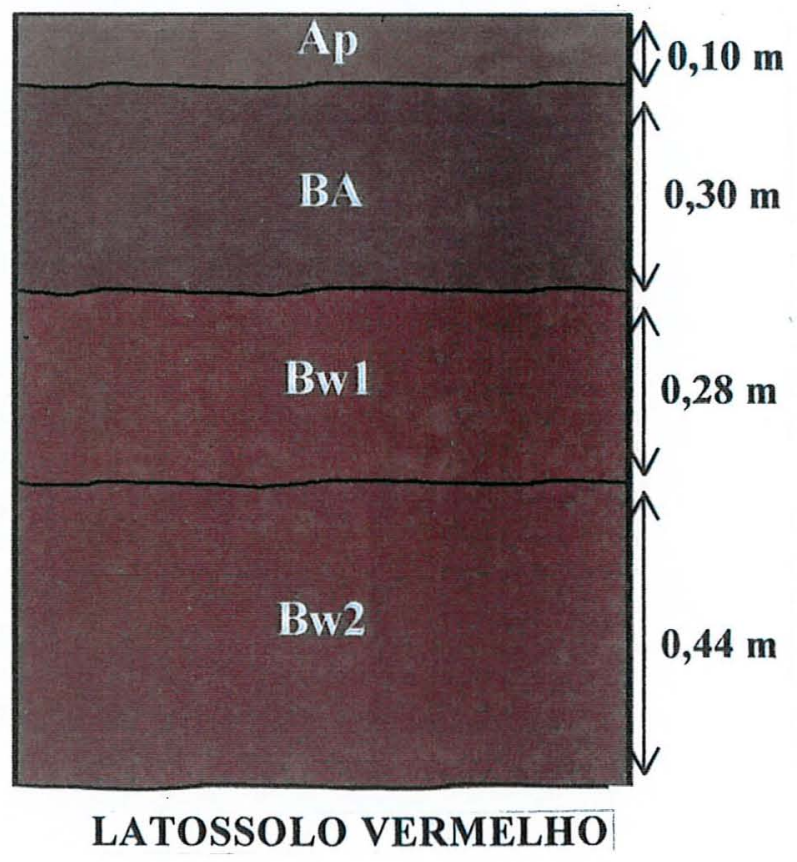

Figura 4. Esquema da disposição dos horizontes nos perfis amostrados. 


\subsection{Caracterização hídrica}

A caracterização hídrica dos solos e identificação das possíveis camadas hidráulicas foi realizada nos perfis descritos anteriormente. Para avaliar a dinâmica da água nos perfis estudados, utilizou-se a curva de retenção e a condutividade hidráulica do solo saturado.

\subsubsection{Curva de retenção de água, processo de saturação, umidade e densidade do solo}

O estudo da retenção de água foi realizado a partir de amostras com estrutura deformada e indeformada, perfazendo um total de 100 amostras.

As amostras indeformadas foram coletadas utilizando-se um amostrador de solo tipo Uhland, com anéis volumétricos, de $0,05 \mathrm{~m}$ de altura e $0,04 \mathrm{~m}$ de diâmetro. A cada $0,10 \mathrm{~m}$, a partir da superfície do solo, foram coletadas 5 amostras indeformadas até atingir $1 \mathrm{~m}$ de profundidade, sem considerar os horizontes pedogenéticos previamente descritos (Figura 5). Após coletados, os anéis volumétricos foram acondicionados em papel alumínio para evitar perdas de umidade, sendo conduzidas ao laboratório para análise. No preparo das amostras foi utilizada uma faca dentada, para retirada do excesso de terra de cada extremidade dos cilindros. Em seguida, em cada cilindro foi colocado um pano na parte inferior para evitar perdas de material e do contato do solo com o mata borrão da mesa de tensão e placa porosa da câmara de pressão de Richards. A saturação das amostras foi feita com gotejador de Mariotte, lentamente e no sentido ascendente, utilizando água destilada e deareada, baseado em Moraes (1991), tendo o objetivo de expulsar $o$ ar contido no interior dos poros da amostra. $O$ gotejamento ocorreu durante 24 horas, período no qual a água atingiu o topo das amostras. As amostras ainda permaneceram imersas por mais 24 horas para que toda as bolhas de ar remanescentes pudessem ser eliminadas. (Figura 6).

Cada uma dessas cinco repetições coletadas foram submetidas as tensões de 1 , $2,4,10,30,50,100,500,1500 \mathrm{Kpa}$. 


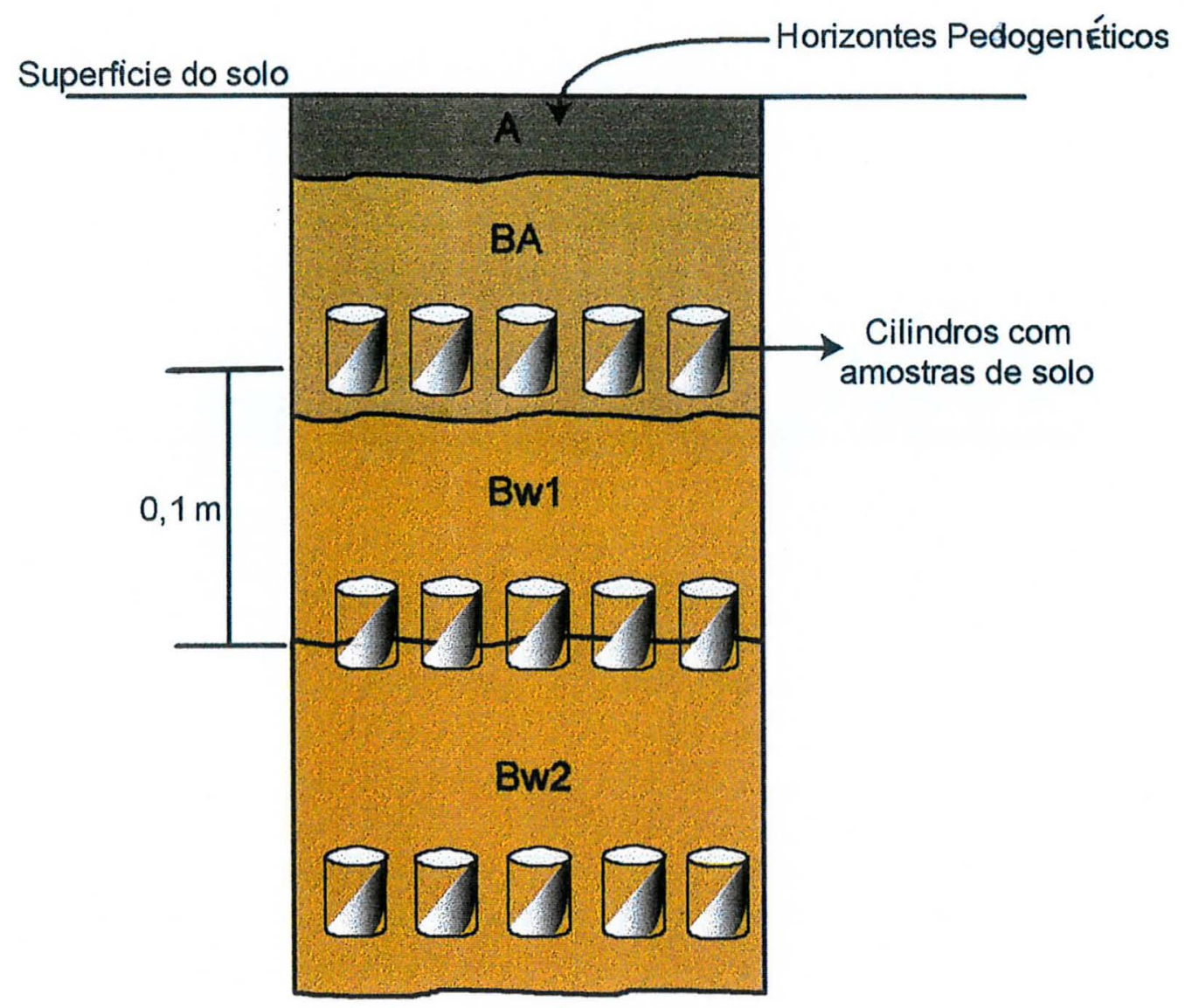

Escala $0,1 \mathrm { m } \longdiv { 0 , 1 \mathrm { m } }$

Figura 5. Esquema demonstrativo da amostragem realizada para o estudo da curva de retenção de água e condutividade hidráulica saturada dos solos. 
Os equipamentos utilizados na determinação da curva de retenção foram a mesa de tensão (EMBRAPA, 1997 b) com a qual foram obtidas as tensões de 1,2 e $4 \mathrm{kPa}$ e as câmaras de pressão (Richards \& Fireman, 1943) para as tensões de 10, 30, 50, 100, 500 e $1500 \mathrm{kPa}$. O tempo médio gasto nas tensões baixas de 1, 2 e $4 \mathrm{kPa}$ foi de três dias. Nos demais pontos: $10,30,50,100,500$ e $1500 \mathrm{kPa}$, o tempo de permanência das amostras dependeu da estabilização de drenagem, que variou conforme a tensão aplicada. Ao final da aplicação de cada tensão, momento em que atingem a drenagem máxima de água contida nos poros, as amostras foram devidamente pesadas para a determinação da massa de solo úmido $(\mathrm{m}, \mathrm{kg})$ e recolocadas no aparelho para atingirem um novo ponto de equilíbrio.

Após a aplicação da tensão de $100 \mathrm{kPa}$ as amostras indeformadas foram secas em estufa a $105^{\circ} \mathrm{C}$, por um período de 24 horas, para a determinação da massa de sólidos $\left(\mathrm{m}_{\mathrm{s}} \mathrm{kg}\right)$. Com essa informação foi realizado o cálculo da umidade gravimétrica $\left(\mathrm{U}, \mathrm{kg} \mathrm{kg}^{-1}\right)$ e umidade volumétrica $\left(\theta, \mathrm{m}^{3} \mathrm{~m}^{-3}\right)$ para determinação do conteúdo hídrico (Gardner, 1986; Hendrickx, 1990) e da densidade do solo $\left(\rho, \mathrm{kg} \mathrm{m}^{-3}\right)$ a partir das seguintes equações:

$$
\begin{gathered}
\rho=\frac{m_{s}}{v} \\
U=\frac{m-m_{s}}{m_{s}} \\
\theta=\rho_{r} \cdot U
\end{gathered}
$$

sendo:

$\rho=$ densidade do solo $\left(\mathrm{Kg} \mathrm{m}^{-3}\right)$;

$\rho_{\mathrm{r}}=$ densidade relativa do solo $\left(=\rho / \rho_{\mathrm{a}}\right)$;

$\rho_{\mathrm{a}}=$ densidade da água no solo $\left(\mathrm{Kg} \mathrm{m}^{-3}\right)$; 

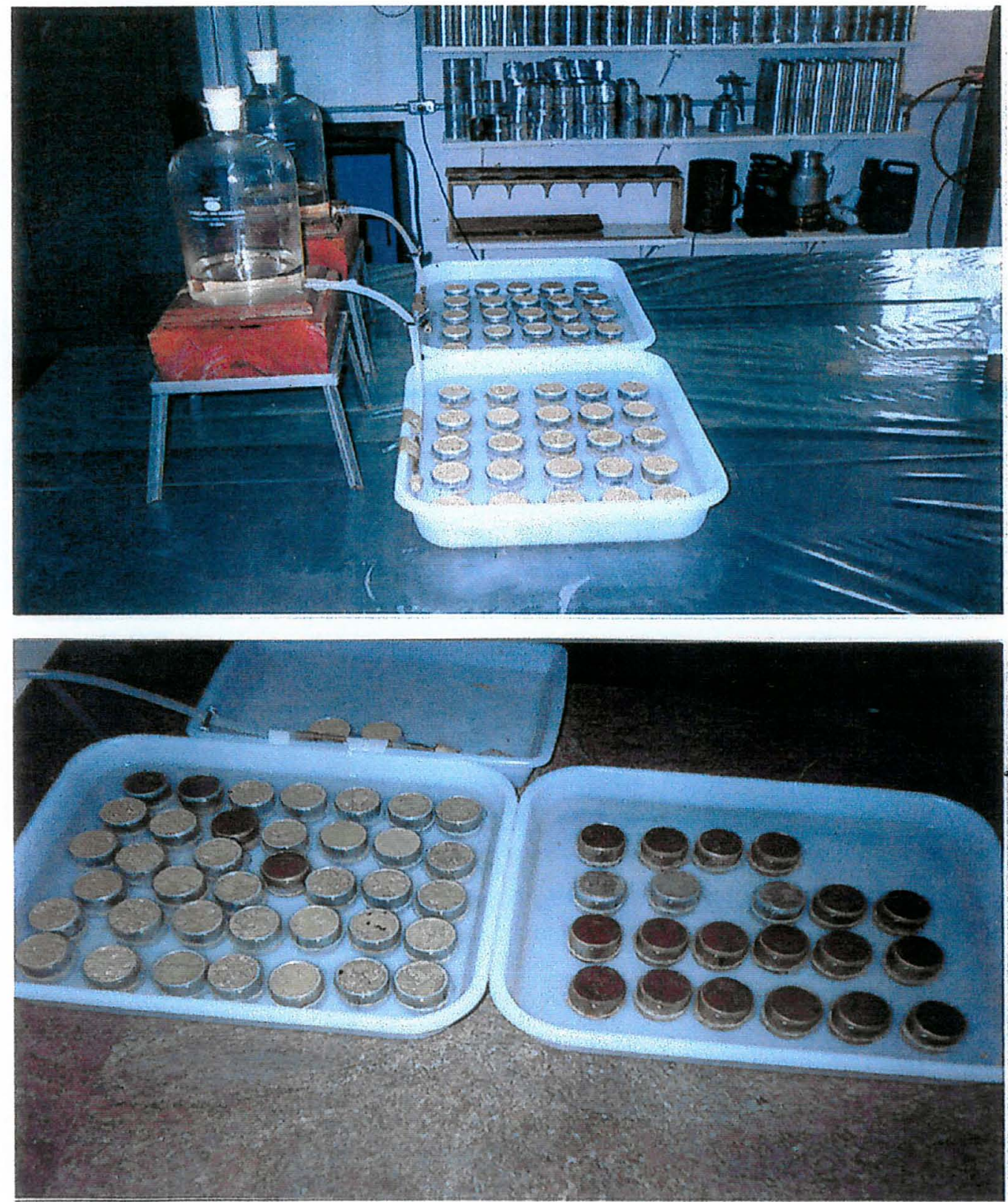

Figura 6. Processo de saturação das amostras em laboratório, utilizando Frascos de Mariote, para determinação da $\mathrm{K}_{0}$ e da curva de retenção de água no solo. 


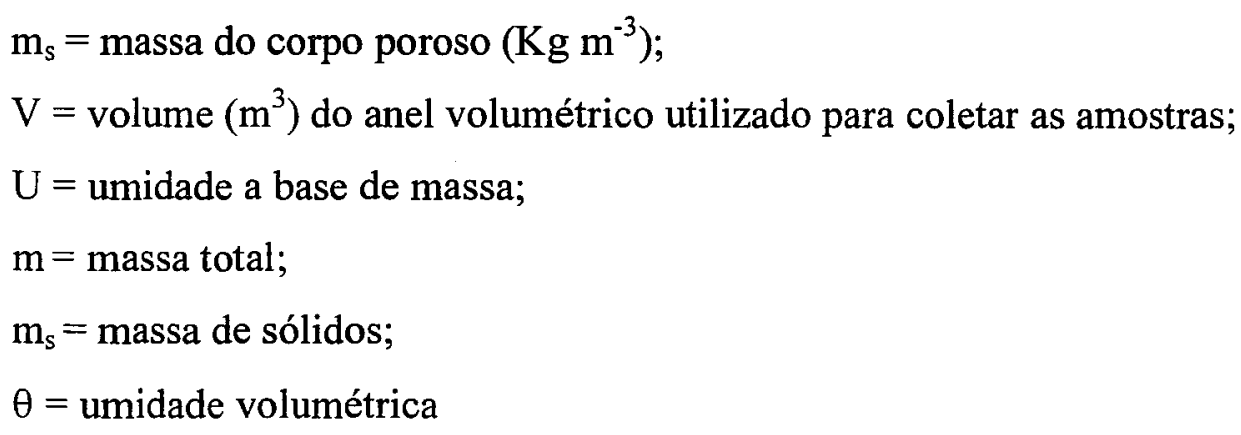

A preparação das amostras deformadas consistiu em retirar as amostras indeformadas já secas dos cilindros volumétricos, desestruturando-as com um rolo de madeira e passando em peneiras de $2 \mathrm{~mm}$ de $\phi$, sendo em seguida colocadas em sacos plásticos devidamente identificados. Essas amostras foram saturadas diretamente em placa porosa, dentro de cilindros de borracha com $0,05 \mathrm{~m}$ de diâmetro e $0,01 \mathrm{~mm}$ de altura. Com o auxílio de uma pipeta, foi possível elevar lentamente o nível da água nas amostras. Após as amostras atingirem a saturação, foram submetidas às tensões de $500 \mathrm{e}$ $1500 \mathrm{kPa}$ para obtenção das umidades gravimétricas nesses potenciais. Com o auxílio de uma espátula foi possível colocar as amostras em placa porosa, bem como retirá-las. Após retiradas, as amostras foram colocadas em recipientes já tarados para obtenção da sua massa úmida e depois conduzidas a estufa para a obtenção da sua massa seca. Posteriormente, a umidade volumétrica foi obtida pela equação 3.

\subsubsection{Porosidade total, macro e microporosidade}

A determinação da distribuição dos poros por tamanho foi obtida a partir das amostras utilizadas para a obtenção das curvas de retenção e condutividade hidráulica do solo saturado.

Sabendo-se que o limite de separação entre macro e microporos é referido para as tensões 6 e $10 \mathrm{kPa}$, considerou-se como porosidade capilar aquela que o solo apresenta depois de submetida a uma tensão de $10 \mathrm{kPa}$.

O cálculo da porosidade total foi feito pela seguinte equação: 


$$
P t=\left(1-\frac{\rho}{\rho_{s}}\right) \times 100
$$

sendo:

$\mathrm{Pt}=$ porosidade total $(\%)$

$\rho_{\mathrm{s}}=$ densidade dos sólidos $\left(\mathrm{kg} \mathrm{m}^{-3}\right)$;

$\rho=$ densidade do solo $\left(\mathrm{kg} \mathrm{m}^{-3}\right)$;

A macroporosidade foi determinada através da equação:

$$
\mathrm{M} \%=\left(\theta_{\mathrm{s}}-\theta_{\mathrm{m}}\right) \times 100
$$

sendo:

$\mathrm{M} \%$ = macroposidade (\%)

$\theta_{\mathrm{s}}=$ umidade volumétrica considerando o solo saturado $\left(\mathrm{m}^{3} \mathrm{~m}^{-3}\right)$

$\theta_{\mathrm{m}}=$ umidade volumétrica retida a $10 \mathrm{kPa}\left(\mathrm{m}^{3} \mathrm{~m}^{-3}\right)$

A microposidade foi determinada pela diferença entre a porosidade total e a macroposidade.

\subsubsection{Ajuste das curvas de retenção}

Com os valores das umidades associadas às suas respectivas tensões foram obtidos os ajustes conforme os parâmetros empíricos da equação proposta por van Genuchten (1980):

$$
\theta=\theta_{r}+\frac{\theta_{s}-\theta_{r}}{\left[1+\left(\alpha\left|\phi_{m}\right|\right)^{n}\right]^{m}}
$$


sendo $\theta$ a umidade volumétrica $\left(\mathrm{m}^{3} \mathrm{~m}^{-3}\right), \theta_{\mathrm{r}}$ a umidade residual $\left(\mathrm{m}^{3} \mathrm{~m}^{-3}\right), \theta_{\mathrm{s}}$ a umidade de saturação $\left(\mathrm{m}^{3} \mathrm{~m}^{-3}\right), \phi_{\mathrm{m}} \mathrm{o}$ potencial mátrico $(\mathrm{kPa})$ e $\alpha, \mathrm{m}$ e $\mathrm{n}$ os parâmetros empíricos da equação.

O ajuste das curvas de retenção foi feito com a utilização do programa computacional SWRC desenvolvido por Dourado Neto et al. (1990). No ajuste, $\theta_{\mathrm{s}}, \theta_{\mathrm{r}}$, $\alpha$ e $m$ foram estimados por regressão e $n$ foi considerado função de $m$, isto é, $m=1-1 / n$

\subsubsection{Condutividade hidráulica do solo saturado}

A metodologia utilizada para a determinação da condutividade hidráulica do solo saturado foi a do permeâmetro de carga decrescente (Hendrickx, 1990; Youngs, 1991). Esse método é semelhante ao permeâmetro de carga constante, sendo que a única diferença é o decréscimo da carga hidráulica conforme a infiltração da água através da amostra. Construção detalhada de aparelhos usualmente destinados a tal determinação está contida nos trabalhos de (Klute \& Dirksen, 1986; Klute, 1965).

Para esta determinação foram utilizadas as mesmas amostras destinadas à curva de retenção. A determinação da condutividade hidráulica foi realizada em laboratório. Os cilindros volumétricos foram inseridos em um dispositivo previamente construído composto por um tubo de vidro transparente colado a um módulo de encaixe para os cilindros (Figura 7).

As amostras foram, inicialmente, saturadas. O processo de saturação seguiu os mesmos procedimentos utilizados na curva de retenção de água descrito no item 3.3.2. Após saturadas foram imediatamente retiradas da bandeja e encaixadas no dispositivo para evitar a perda de água. Em seguida, o módulo contendo a amostra foi submerso em um recipiente contendo água destilada e deareada, no intuito de manter os poros saturados. Assim, era possível visualizar a formação do nível de água no tubo de vidro cuidando para evitar percolação de água ao longo da parede interna do tubo.

Antes do início das medidas foi delimitado dois pontos no tubo de vidro $\left(\mathrm{H}_{1} \mathrm{e}\right.$ $\mathrm{H}_{2}$ ) de forma que fosse possível acompanhar os seus respectivos tempos $\left(t_{1}\right.$ e $\left.t_{2}\right)$. As medidas de condutividade eram iniciadas a partir do momento que a água era colocada 
no tubo de vidro. Com isso, a queda do nível de água de $\mathrm{H}_{1}$ para $\mathrm{H}_{2}$ era acompanhada e associada ao tempo no qual a água passava em cada ponto, obtendo-se o fluxo de água no solo em um determinado intervalo de tempo $(\Delta t)$, o qual variava em função das amostras no perfil. Cada amostra de solo foi submetida a três medições.

Assim, para calcular a condutividade hidráulica saturada, utilizou-se a seguinte equação, seguindo dedução feita por Libardi (2000)

$$
K_{o}=\frac{a L}{A \Delta t} \ln \left[\frac{H_{1}-H^{\prime}}{H_{2}-H^{\prime}}\right]
$$

sendo:

$\Delta t=t_{2}-t_{1}$ intervalo de tempo para o nível de água no tubo de vidro cair de $\mathrm{H}_{1}$ para $\mathrm{H}_{2}$;

A = área da secção transversal da coluna de solo;

$\mathrm{L}=$ comprimento da amostra de solo;

$\mathrm{a}=$ área da secção transversal do tubo de vidro onde se mede $\mathrm{H}$;

$\mathrm{H}_{1}$ e $\mathrm{H}_{2}$ representam potenciais totais da amostra, os quais foram fixados em dois pontos no tubo e mantidos constantes ao longo das medições;

$H^{\prime}=$ carga hidráulica na superfície da amostra

$h^{\prime}=$ altura compreendida entre a base do recipiente com água e o cilindro contendo a amostra de solo. 


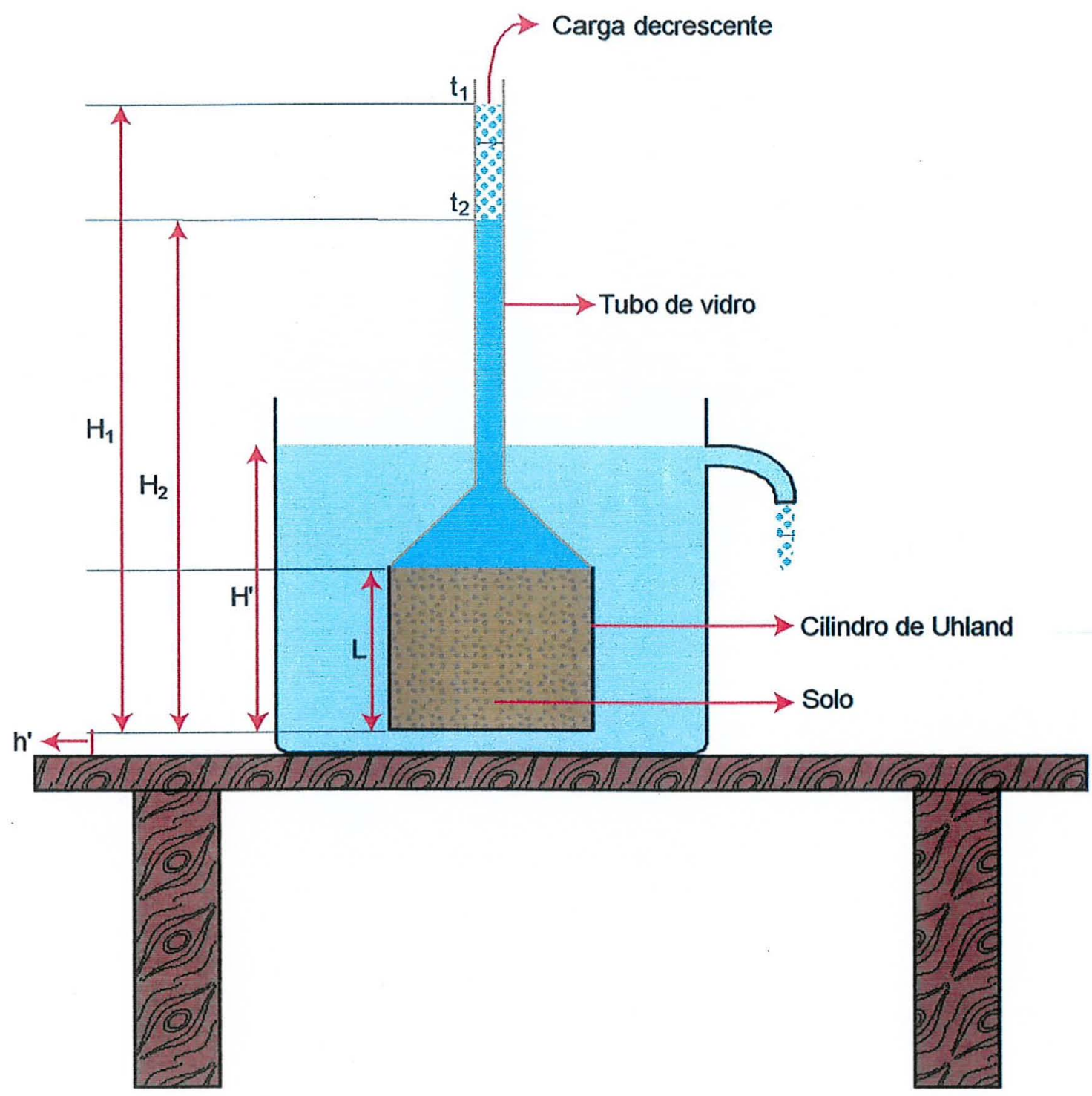

Figura 7. Sistema utilizado para a determinação da condutividade hidráulica do solo saturado em laboratório. 
Considerando que a distribuição da condutividade hidráulica normalmente é log-normal (Tietje \& Hennings, 1996; Logsdon \& Jaynes, 1996), a média da condutividade hidráulica saturada $\left(\mathrm{K}_{0}\right)$ em cada seção dos perfis estudados foi obtida a partir da média aritmética do logaritmo. Segundo Starr (1990) a transformação logarítmica é necessária para reduzir as variações nos dados de $\mathrm{K}_{0}$, mas os valores dos coeficientes de variação podem ainda permanecer elevados.

\subsection{Amostragem e análise estatística dos dados}

Um dos grandes problemas da utilização da estatística clássica é a necessidade de ter amostras independentes e dados que apresentem distribuição normal. Entretanto, em determinadas análises nem sempre ocorre tal situação, principalmente, quando se trata de estudos que envolvem retenção de água e condutividade hidráulica do solo.

Silva (1988), estudando variabilidade espacial do solo, ressalta que há muito tempo os pesquisadores da ciência do solo têm procurado desenvolver técnicas mais adequadas de amostragem do solo, preocupando-se em encontrar a melhor forma de analisar os dados estatisticamente. Nesse sentido, um dos aspectos que merece atenção é a questão da dependência e independência de amostras em profundidade, pois pode ser considerada como um fator limitante em muitas áreas da ciência do solo. Talvez a melhor alternativa para solucionar esse tipo de problema seja coletar amostras admitindo independência entre si e não levando em consideração a sua posição no perfil. Portanto, para a análise dos dados obtidos, considerou-se as camadas estudadas como variáveis independentes visto que as amostras foram submetidas às mesmas condições de saturação em laboratório, inteiramente ao acaso, sob condições controladas (item 3.6.1.), evidenciando assim a casualização dos dados. Outro fator a ser considerado sobre a independência das camadas é que o estudo não foi feito no campo, portanto, não envolveu fluxo de água ao longo do perfil. Além disso, o objetivo do trabalho foi estudar uma propriedade não inerente ao solo, mas o comportamento da água no solo.

A análise da homogeneidade ou heterogeneidade da água nos perfis de solo foi realizada com o auxílio de análise de variância e aplicação do teste de Tuckey ao nível 
de $5 \%$ de probabilidade para a comparação das médias das umidades volumétricas em cada potencial mátrico aplicado ( $\theta$ vs $\left.\phi_{\mathrm{m}}\right)$.

No que se refere à curva de retenção, o critério utilizado para considerar camadas hidraulicamente semelhantes consistiu em delimitar até que camada a umidade em função da tensão aplicada diferiu ou não estatisticamente $(P<0,05)$ no sentido vertical do perfil. Quando houve interferência na continuidade da seqüência da umidade, admitiu-se a interrupção da camada hidráulica e o surgimento de outra. Adotou-se a existência da camada hidráulica de transição que foi considerada como pertencente a duas camadas simultaneamente, sendo equivalente aos horizontes transicionais do solo que indicam características intermediárias entre um horizonte precedente e um subsequente. Assim, foi possível elaborar as Figuras 14 e 15 apresentadas no item resultados e discussão, a partir das análises estatísticas contidas nas Tabelas 5 e 6.

O programa computacional utilizado para a realização das análises estatísticas foi o SAS - Statistical Analitical Systems (SAS, 1985). 


\section{RESULTADOS E DISCUSSÃO}

\subsection{Caracaterização dos solos}

\subsubsection{Características morfológicas dos perfis}

Estas informações serão apresentadas a seguir à exceção das análises físicas e químicas que estão no item 4.2.

LATOSSOLO VERMELHO Distroférrico típico

\section{DESCRIÇÃO GERAL}

CLASSIFICAÇÃO SOIL TAXONOMY: Rhodic Haplustox

CLASSIFICAÇÃO FAO: Rhodic Ferralsol

LOCALIZAÇĀO, MUNICÍPIO, ESTADO E COORDENADAS: Estrada da Itelpa, Tecnal Ferramentaria, Piracicaba - SP. Acesso pela antiga rodovia Piracicaba - Santa Bárbara D'Oeste.

SITUAÇÃO, DECLIVE E COBERTURA VEGETAL SOBRE O PERFIL: Topo de encosta, apresentando $0-3 \%$ de declividade, erosão laminar.

\section{ALTITUDE: $600 \mathrm{~m}$}

MATERIAL ORIGINÁRIO: Lavas basalticas com intercalações de arenitos, siltitos; soleiros e diques de diabásio

LITOLOGIA E FORMAÇÃO GEOLÓGICA: Formação Serra Geral - Grupo São Bento

PEDREGOSIDADE: Não Pedregosa

ROCHOSIDADE: Não Rochosa 
RELEVO LOCAL: Plano

RELEVO REGIONAL: Suave Ondulado

EROSÃO: Laminar

DRENAGEM DO PERFIL: Bem drenado

USO ATUAL (formas de vegetação, excluindo a primária): Área sem vegetação predominante, somente tendo plantio abundante de cana-de-açucar.

CLIMA: Cwa, na classificação de Koppen, mesotérmico, úmido, subtropical, com inverno seco, temperatura do mês mais frio não excede $18^{\circ} \mathrm{C}$ e dos mês mais quente é maior que $22^{\circ} \mathrm{C}$. Temperatura média anual é de $21,1^{\circ} \mathrm{C}$ e a precipitação média anual de aproximadamente $1250 \mathrm{~mm}$.

\section{DESCRIÇÃO MORFOLÓGICA DO PERFIL}

Ap - 0,00-0,10 m, vermelho acinzentado, (10R 4/3, úmido); muito argilosa; moderada blocos subangulares médio a grande se desfazendo em muito pequeno e pequeno; dura; firme, muito plástico e muito pegajoso; transição gradual e plana; bem drenado; raízes do tipo fasciculada com diâmetro inferior a $5 \mathrm{~mm}$; porosidade 1 $2 \mathrm{~mm}$ (poros muito pequenos) e comuns.

BA - 0,10-0,40 m, vermelho escuro acinzentado, (10R 3/4, úmido); muito argilosa; moderada blocos subangulares grande; dura; firme; muito plástico e muito pegajoso; cerosidade fraca e pouca; transição difusa e plana; bem drenado; raízes do tipo fasciculada com diâmetro inferior a $5 \mathrm{~mm}$, porosidade $1-2 \mathrm{~mm}$ (poros muito pequenos) e comuns.

Bw1 - 0,40-0,68 $\mathrm{m}$, vermelho escuro, (10R3/6, úmido); muito argilosa; fraca blocos subangulares média a grande; dura; firme; muito plástico e muito pegajoso; transição difusa e plana; acentuadamente drenado; raízes do tipo fasciculada, 
poucas, com diâmetro inferior a $5 \mathrm{~mm}$; porosidade $1-2 \mathrm{~mm}$ (poros muito pequenos e pequenos) e comuns.

Bw2 - 0,68 - 1,12 m, vermelho escuro, (10R 3/6, úmido); muito argilosa; fraco blocos subangulares pequeno a médio se desfazendo em microagregados de grau forte; ligeiramente duro; friável; muito plástico e muito pegajoso; transição difusa e plana; acentuadamente drenado; raízes do tipo fasciculada, com diâmetro inferior a $5 \mathrm{~mm}$, poucas; porosidade $1-2 \mathrm{~mm}$ (poros muito pequenos e pequenos) e comuns.

\section{OBSERVAÇÕES:}

- Presença de carvão no perfil;

- Horizonte BA compactado;

- Predomínio de microestrutura globular em todo o perfil; compactação nos primeiros $0,30 \mathrm{~m}$ causou modificação na estrutura, tornando os microagregados menos perceptiveis.

\section{LATOSSOLO AMARELO Distrófico}

\section{DESCRIÇÃO GERAL}

CLASSIFICAÇÃO SOIL TAXONOMY: Allic Haplorthox

CLASSIFICAÇÃO FAO: Xanthic Ferralsol

LOCALIZAÇÃO, MUNICÍPIO, ESTADO E COORDENADAS: Estrada AM - 010 que interliga o Município de Manaus a Itacoatiara, Estado do Amazonas, área de estudos do Projeto SHIFT.

SITUAÇÃo, DECLIVE E COBERTURA VEGETAL SOBRE O PERFIL: Perfil situado em uma área plana de um Sistema Agroflorestal com as especies de Cupuaçu, 
Urucum, Castanha e Pupunha, apresentando declividade de $1 \%$ sem erosão evidente, tendo como cobertura de solo a Puerária phaseoloides.

ALTITUDE: $50 \mathrm{~m}$

MATERIAL ORIGINÁRIO: Sedimentos argilosos

LITOLOGIA E FORMAÇÃo E FORMAÇÃo GEOLÓGICA: Terciário Formação Manaus

PEDREGOSIDADE: Não Pedregoso

ROCHOSIDADE: Não Rochoso

RELEVO LOCAL: Plano

RELEVO REGIONAL: Plano

EROSÃO: Praticamente nula

DRENAGEM DO PERFIL: Bem drenado

USO ATUAL: Área utilizada com sistema agroflorestal

CLIMA: Af, na classificação de Koppen, úmido, tropical, caracterizado por apresentar precipitação média anual de $2420 \mathrm{~mm}$. Médias de tempepratura máxima e mínima são de $32^{\circ} \mathrm{C}$ e $22^{\circ} \mathrm{C}$, respectivamente.

\section{DESCRIÇÃO MORFOLÓGICA DO PERFIL}

A - 0,00-0,12 m, bruno, (10YR 4/3, úmido), argilosa; moderada blocos subangulares pequeno a médio; ligeiramente duro; friável; plástico e pegajoso; transição gradual e plana; bem drenado; raízes do tipo fasciculada com diâmetro inferior a $5 \mathrm{~mm}$; porosidade $2-5 \mathrm{~mm}$ (poros pequenos) e comuns.

BA- 0,12-0,45 m, amarelo, (10YR 7/6, úmido), muito argilosa; fraca blocos subangulares pequeno a médio; macia; friável; plástico e pegajoso; transição difusa e plana; bem drenado; raízes do tipo fasciculada com diâmetro inferior a 5 $\mathrm{mm}$; porosidade 1 - $2 \mathrm{~mm}$ (poros muito pequenos) e comum. 
Bwl - 0,45 - 0,75 m, amarelo, (10YR 7/8, úmido), muito argilosa; fraca blocos subangulares pequeno a médio; macio; friável; plástico e muito pegajoso; transição difusa e plana; bem drenado; raizes do tipo fasciculada com diâmetro inferior a $5 \mathrm{~mm}$; porosidade $1-2 \mathrm{~mm}$ (poros muito pequenos) e comum.

Bw2 - 0,75 - 1,00 m, amarelo, (10YR 7/8, úmido), muito argilosa; fraca blocos subangulares pequeno; macio; friável; plástico e muito pegajoso; transição difusa e plana; bem drenado; raízes do tipo fasciculada com diâmetro inferior a $2 \mathrm{~mm}$; porosidade $1-2 \mathrm{~mm}$ (poros muito pequenos) e comum.

\section{OBSERVAÇÕES:}

- Presença de cupins em todo o perfil, em maior intensidade até 0,45 m;

- Presença de canais com raízes em decomposição nos horizontes A e BA

\subsection{Caracterização de alguns atributos físicos e químicos dos solos}

Neste item são apenas apresentados e discutidos algumas características básicas dos solos em estudo.

As Tabelas 1, 2 e 3 apresentam os resultados das análises físicas e químicas realizadas.

A análise granulométrica (Tabela 1) revelou que os solos apresentam uma certa homogeneidade na distribuição do tamanho de partículas ao longo do perfil, havendo um aumento em profundidade do teor de argila no $\mathrm{LA}\left(0,59 \mathrm{~kg} \mathrm{~kg}^{-1}\right.$ a $\left.0,73 \mathrm{~kg} \mathrm{~kg}^{-1}\right)$ e uma pequena redução não expressiva no $\operatorname{LVdf}\left(0,71 \mathrm{~kg} \mathrm{~kg}^{-1}\right.$ a $\left.0,67 \mathrm{~kg} \mathrm{~kg}^{-1}\right)$. Com essa distribuição, observa-se que o LVd apresenta a mesma classe textural em todos os horizontes descritos (m. argilosa), mas o LAd apresentou textura argilosa no horizontes superficial (Tabela 1).

Ainda na Tabela 1 , os valores referentes à densidade das partículas mostram pequenas variações dentro de cada solo estudado, apresentando valores médios de 2560 
$\mathrm{kg} \mathrm{m}^{-3}$ e $2530 \mathrm{~kg} \mathrm{~m}^{-3}$ para o LAd e LVdf, respectivamente. Tal comportamento também foi observado para a densidade do solo com médias de $1060 \mathrm{~kg} \mathrm{~m}^{-3}$ (LAd) e $1290 \mathrm{~kg} \mathrm{~m}^{-3}$ (LVdf).

Analisando os resultados de análise química (Tabela 2), observa-se que o pH em $\mathrm{H}_{2} \mathrm{O}$ do LAd varia entre 4,07 a 4,23 não havendo muita variação entre os horizontes e caracterizando o caráter extremamente ácido deste solo. O LVdf apresentou caráter moderamente ácido, variando de 5,8 a 6,8, conforme EMBRAPA (1999).

$O$ teor de matéria orgânica decresce em profundidade tanto no LAd quanto no LVdf, sendo que o maior teor ocorre no horizonte Ap (Tabela 2). O maior conteúdo de M.O. na superfície do LAd, deve-se à incorporação de resíduos vegetais decorrentes do sistema agroflorestal, garantindo uma decomposição mais lenta deste material, já que não está sujeito ao efeito de alta temperatura e processo erosivo. No caso do LVdf, onde se observou $36 \mathrm{~g} \mathrm{~kg}^{-1}$ de M.O na superfície, pode estar relacionado à incorporação da palha depois colheita da cana-de-açúcar.

Apesar da matéria orgânica diminuir com a profundidade no LAd (Tabela 2) não foram verificadas grandes variações nos valores de densidade do solo (Tabela 1). $\mathrm{O}$ aumento gradativo do teor de argila (Tabela 1) pode ter influenciado, de certa forma, a falta de variações expressivas da densidade do solo.

Os valores mais elevados de fósforo e soma de bases na superfície desses solos, podem ser atribuídos aos maiores teores de matéria orgânica em superfície e prováveis adubações, refletindo o efeito cumulativo da aplicação desse nutriente.

A capacidade de troca de cátions (T) descresceu em profundidade no LAd, sendo que o valor de $\mathrm{T}$ variou de 110 a $26,9 \mathrm{mmol}_{\mathrm{c}} \mathrm{kg}^{-1}$ de solo. No LVdf, notou-se variação do valor de $\mathrm{T}$ dos horizontes, podendo ser devida à influência da M.O.

Ainda na Tabela 2, observa-se baixa saturação por base (V\%) e alta saturação por alumínio (m) no LAd, fato comum em solos originados desses sedimentos. Esta condição pode limitar o enraizamento das plantas em profundidade. A elevada saturação por alumínio $(>40 \%)$ na camada de $0,2-0,4 \mathrm{~m}$ pode ser um fator restritivo ao crescimento de raízes (Hardy et al., 1990). O LVdf apresentou valores de V\% superiores aos de $\mathrm{m} \%$, sendo reflexo do aumento da soma de bases (SB). 
Verifica-se que os solos apresentam contrastes acentuados quanto aos teores de $\mathrm{Fe}_{2} \mathrm{O}_{3}$. A grande amplitude dos teores de $\mathrm{Fe}_{2} \mathrm{O}_{3}$ variando entre $3,04 \%$ a $4,15 \%$ no LAd e de $21,88 \%$ a $22,88 \%$ no LVdf é reflexo dos diferentes materiais de origem desses solos. Os valores da relação Ki (Tabela 3) variaram de 1,87 a 2,04 nos horizontes do LAd e de 1,46 a 1,51 no LVdf. No caso do $\mathrm{Kr}$, observou-se valores menores $(0,85$ a 0,90$)$ no $L V d f$ quando comparados com o LAd $(1,71$ a 1,87).

Os valores de $\mathrm{Ki}$ e $\mathrm{Kr}$ obtidos indicam a dominância de caulinita sesquioxídica nos solos estudados e uma inexpressiva sub-dominância da gibbsita, sendo o LVdf o mais intemperizado (Resende \& Santana, 1988). 


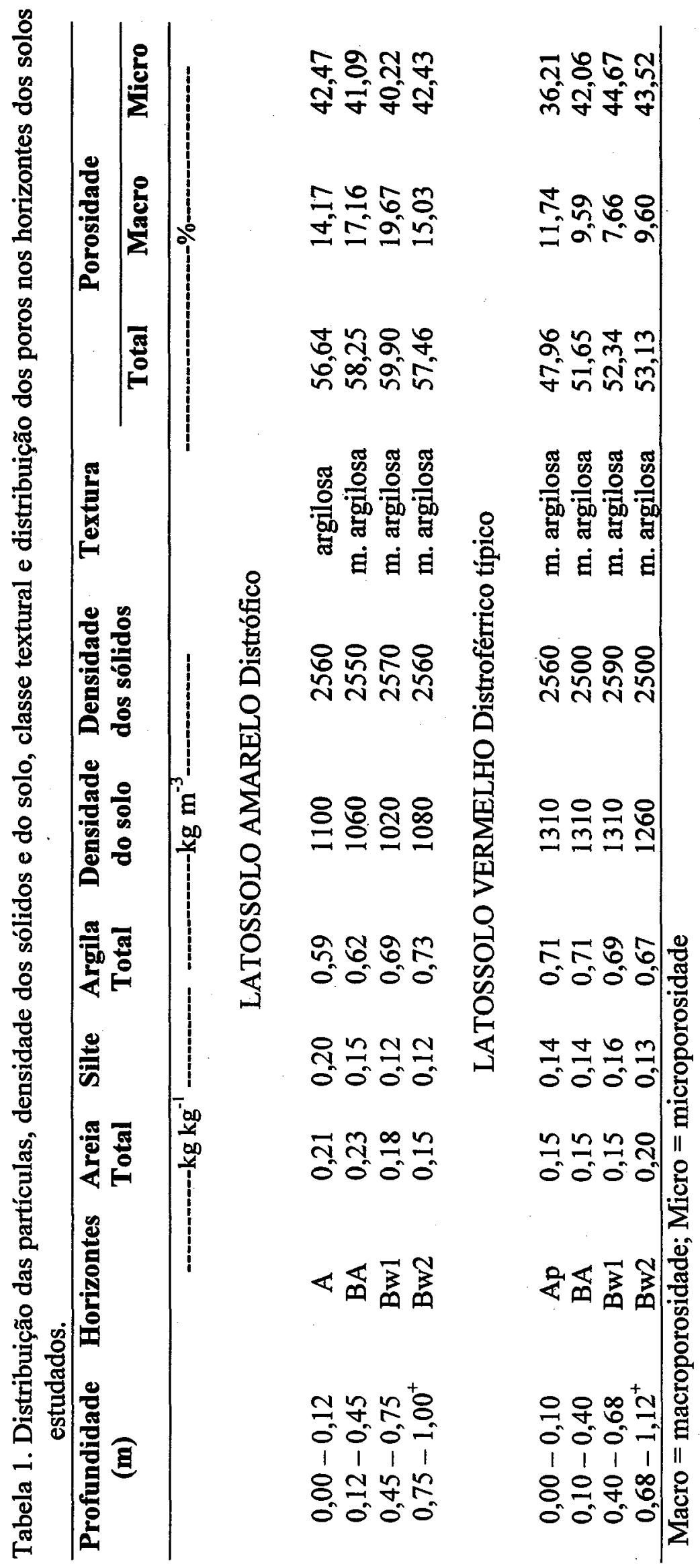




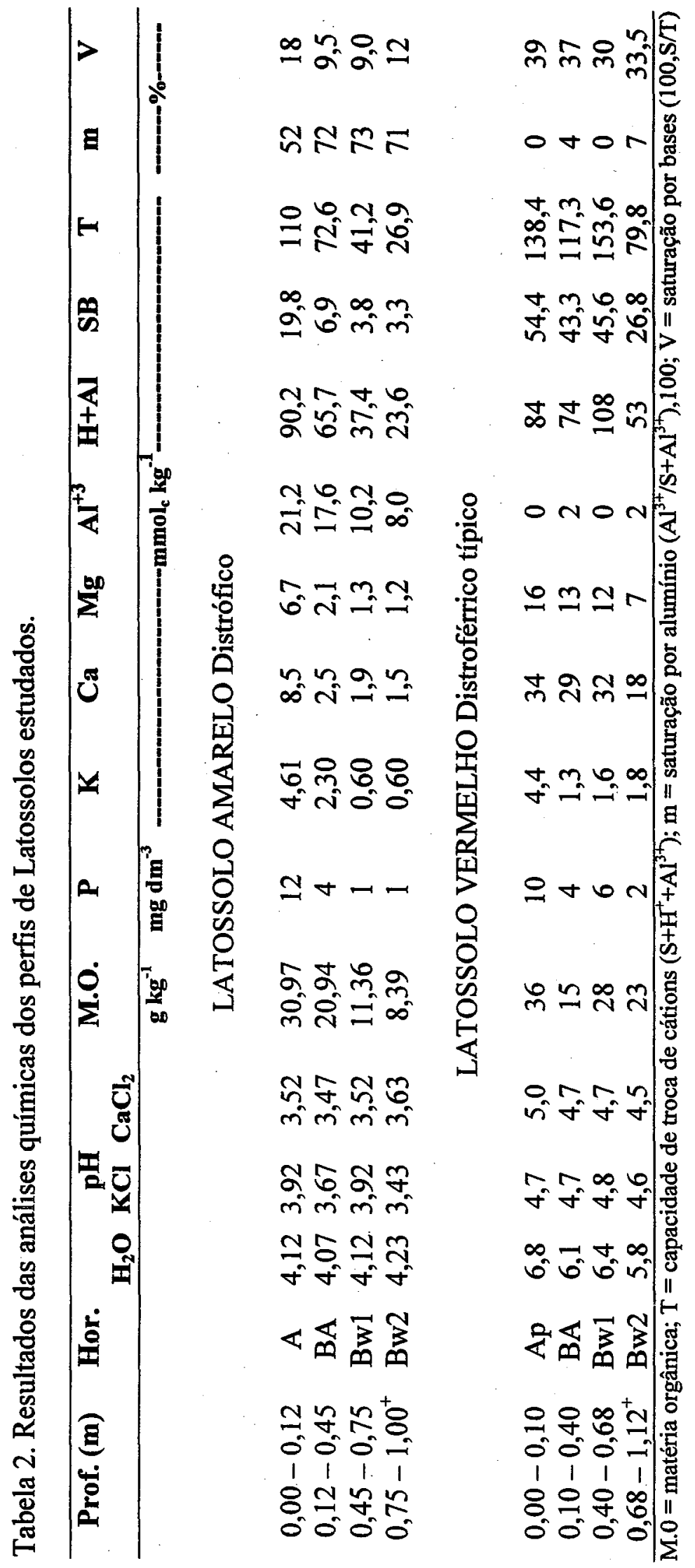




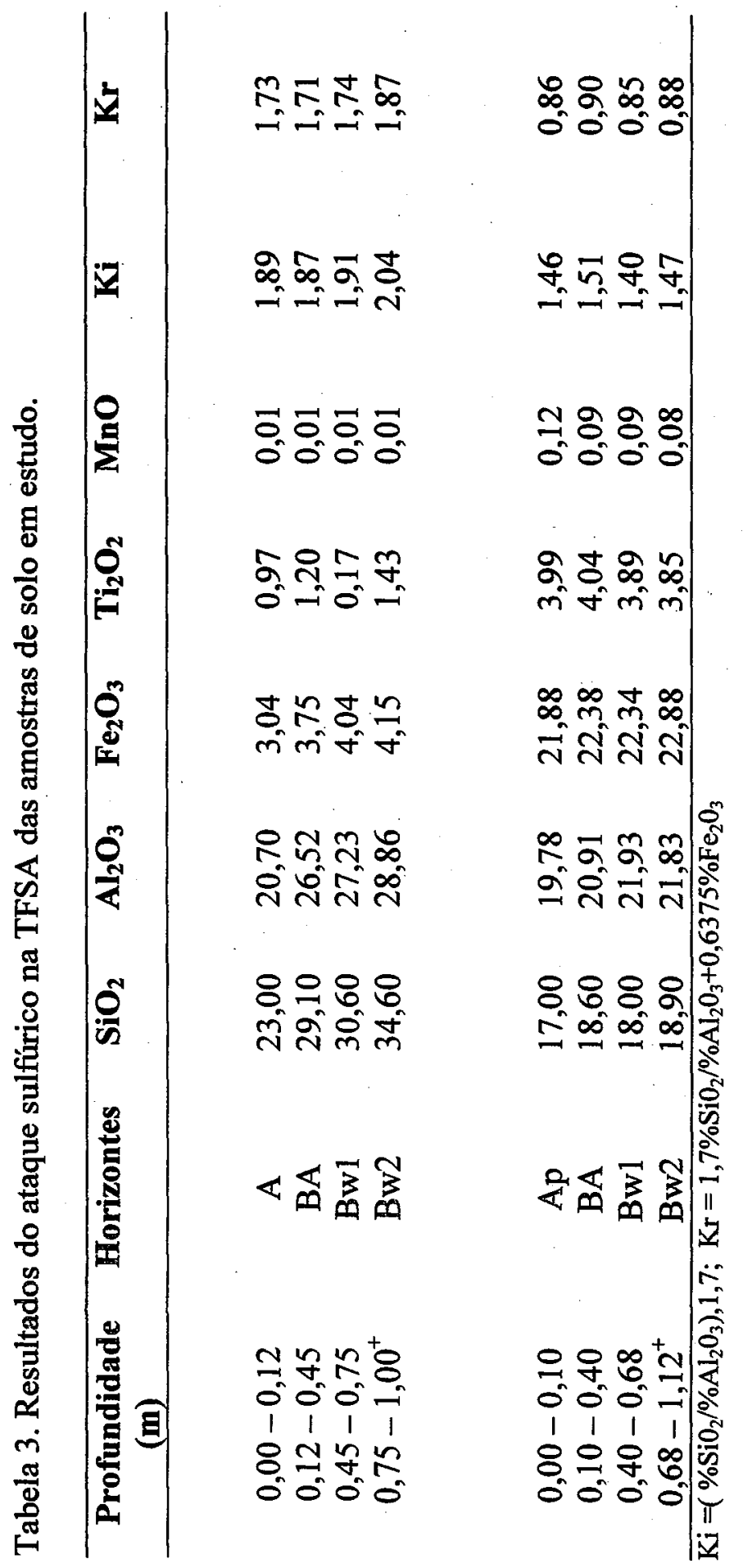




\subsection{Condutividade hidráulica do solo saturado}

Os resultados do logarítmo da condutividade hidráulica saturada $\left(\log \mathrm{K}_{0}\right)$ obtidos em laboratório pelo método de carga decrescente são apresentados na Tabela 4 com os valores de Ko expressos em $\mathrm{cm} \mathrm{dia}^{-1}$. Ressalta-se, que os valores apresentados abaixo foram obtidos a partir da transformação logarítmica dos dados (Jury et al., 1987; Logsdon \& Jaynes, 1996).

Tabela 4. Condutividade hidráulica saturada determinada nas camadas selecionadas ao longo dos perfis de solo estudados.

\begin{tabular}{|c|c|c|c|c|}
\hline \multirow[t]{2}{*}{$\begin{array}{c}\text { Camadas } \\
(\mathrm{m})\end{array}$} & \multicolumn{2}{|c|}{$\log \mathrm{K}_{0}\left(\mathrm{Ko} \mathrm{em} \mathrm{cm} \mathrm{dia}{ }^{-1}\right)$} & \multicolumn{2}{|c|}{$\begin{array}{c}\text { Coeficiente de variação } \\
(\%)\end{array}$} \\
\hline & $\begin{array}{c}\text { LATOSSOLO } \\
\text { AMARELO }\end{array}$ & $\begin{array}{l}\text { LATOSSOLO } \\
\text { VERMELHO }\end{array}$ & $\begin{array}{c}\text { LATOSSOLO } \\
\text { AMARELO }\end{array}$ & $\begin{array}{l}\text { LATOSSOLO } \\
\text { VERMELHO }\end{array}$ \\
\hline $0,0-0,1$ & $2,6240 \mathrm{a}$ & $2,9120 \mathrm{a} \mathrm{b}$ & 15,04 & 14,21 \\
\hline $0,1-0,2$ & $2,6549 \mathrm{a}$ & 2,5902 a b & 26,54 & 18,76 \\
\hline $0,2-0,3$ & $2,5156 a$ & $2,7222 \cdot \mathrm{a} \mathrm{b}$ & 27,03 & 13,20 \\
\hline $0,3-0,4$ & $2,3986 \mathrm{a}$ & $2,2102 \mathrm{a} \mathrm{b}$ & 28,86 & 13,79 \\
\hline $0,4-0,5$ & $2,7798 \mathrm{a}$ & 1,9539 a b & 28,71 & 40,80 \\
\hline $0,5-0,6$ & $3,0630 \mathrm{a}$ & 2,3529 a b & 26,55 & 39,12 \\
\hline $0,6-0,7$ & 3,2051 a & 2,9826 a b & 11,50 & 24,05 \\
\hline $0,7-0,8$ & 3,1725 a & $1,9820 \mathrm{a} \mathrm{b}$ & 8,30 & 25,86 \\
\hline $0,8-0,9$ & $2,5328 \mathrm{a}$ & 3,2228 a & 26,62 & 8,31 \\
\hline $0,9-1,0$ & 2,2229 a & $1,9304 \mathrm{~b}$ & 25,67 & 43,94 \\
\hline
\end{tabular}

Médias obtidas a partir de 05 repetições

Médias seguidas de letras diferentes nas colunas indicam diferença significativa pelo teste de Tukey ao nível de 5\%.

Analisando os valores de $\log \mathrm{K}_{\mathrm{o}}$ obtidos ao longo das camadas para o LAd, observa-se que não houve diferença estatística significativa entre as mesmas, sendo os valores compreendidos entre 2,22 a 3,20. Entretanto, nota-se que há uma tendência para os valores do $\log \mathrm{K}_{0}$ aumentarem a partir de $0,4 \mathrm{~m}(2,77)$ até $0,8 \mathrm{~m}$ alcançando o valor de 3,17. Essa tendência pode ter ocorrido devido aos menores valores da densidade do solo obtidos nessas camadas (Figura 8a) e, como consequiência, maiores valores de porosidade total e macroporosidade (Figura 9a). 
Ainda na Tabela 4, observa-se que os valores do $\log \mathrm{K}_{\mathrm{o}}$ para o LVdf variam de 1,93 a 3,22, apresentando a camada de $0,8-0,9 \mathrm{~m}$ o maior valor de $\log \mathrm{K}_{0}$ com 3,22, seguida pelas camadas $0,6-0,7 \mathrm{~m}(2,98)$ e $0,0-0,1 \mathrm{~m}(2,91)$. Da mesma forma como ocorrido no LAd, esse alto valor do $\log \mathrm{K}_{\mathrm{o}}$ pode ter sido influenciado pela menor densidade $\left(1220 \mathrm{~kg} \mathrm{~m}^{-3}\right.$ )(Figura $8 \mathrm{~b}$ ) e maior macroporosidade (12,39\%) (Figura 9b) dessa camada. Esse $\log \mathrm{K}_{0}$ de 3,22 ocasionou diferença estatística significativa quando comparada com a camada de 0,9-1,0 $\mathrm{m}$ que apresentou o menor $\log \mathrm{K}_{0}(1,93)$, juntamente com as camadas de 0,4-0,5 m e 0,7-0,8 m. Apesar da camada de 0,1-0,2 m ter apresentado um valor de densidade em torno de $1240 \mathrm{~kg} \mathrm{~m}^{-3}$ (Figura $8 \mathrm{~b}$ ) sendo próximo a camada de 0,9-1,0 $\mathrm{m}$, não houve reflexo no $\log \mathrm{K}_{0}$, pois a sua macroporosidade foi menor $(11,86 \%)$.

Percebe-se que o $\log \mathrm{K}_{\mathrm{o}}$ foi sensível a pequenas variações na macroporosidade, apesar da comparação entre camadas não ter apresentado diferença estatística significativa, com exceção da camada de 0,8-0,9 m. Assim, verifica-se que a $\mathrm{K}_{0}$ está relacionada com o volume de macroporos (Ahuja et al., 1984), bem como com variações na estrutura (Anderson \& Bouma, 1973; Bouma \& Anderson, 1973; Bouma; 1981; Crawford, 1994; Ellies et al., 1997). Apesar do $\log \mathrm{K}_{0}$ não apresentar diferença expressiva ao longo da maior parte das camadas nos 2 perfis, é preciso considerar que essa propriedade apresenta um alto coeficiente de variação, ocasionando dificuldades na sua determinação e posteriores interpretações dos resultados. A $\mathrm{K}_{0}$ é sensível a distúrbios na estrutura seja durante a amostragem, transporte e procedimentos no laboratório (Hendricks, 1990). Warrick \& Nielsen (1980) relatam que problemas metodológicos envolvidos na obtenção da condutividade hidráulica saturada, desde o processo de amostragem até a sua determinação em laboratório, são considerados os responsáveis pela elevada variabilidade e grandes desvios entre os valores determinados. Para Kutilek \& Nielsen (1994) a $\mathrm{K}_{0}$ é uma propriedade que apresenta altos coeficientes de variação, as vezes alcançando valores superiores a $100 \%$.

Durante a execução do método para a determinação da $\mathrm{K}_{0}$, observou-se elevadas diferenças de $\mathrm{K}_{0}$ entre as amostras pertencentes à mesma camada, comprovando a dificuldade existente nas determinações dessa propriedade. Entretanto, 
analisando os valores das três leituras realizadas em cada repetição, notou-se que não houve discrepâncias acentuadas dos valores, concluindo-se que o método não apresenta fonte de erro que interfira na análise dos resultados. Em função da variabilidade dos resultados, o volume e o número de amostras são muito importantes, pois têm que representar o sistema poroso em estudo (Lauren et al., 1988; Bouma 1991). Esses mesmos autores admitem ainda que $a \mathrm{~K}_{\mathrm{o}}$ aumenta conforme o volume da amostra.

Mohanty et al. (1998), estudando diferentes metodologias de determinação da $\mathrm{K}_{0}$, consideraram que a mais alta variabilidade proporcionada pelos métodos de laboratório, quando comparados com os de campo (permeâmetro e infiltrômetro) é devida ao volume da amostra e quantidade de macroporos não alterados durante a amostragem. Outro fator importante a considerar é que o solo representa um sistema poroso e contínuo. Assim, coletar amostras em profundidades distintas pode interromper a continuidade dos poros, ocasionando redução dos macroporos de certas camadas e influenciando a obtenção das medidas.

De qualquer maneira, apesar dessas dificuldades na análise da $\mathrm{K}_{0}$ devido a variabilidade de seus valores, a análise do $\log \mathrm{K}_{\mathrm{o}}$ permite inferir a respeito do comportamento do tratamento (no caso as camadas de solo) para essa propriedade, conforme a Tabela 4, pela qual $\log \mathrm{K}_{0}$ não difere estatisticamente de camada a camada. 
a)

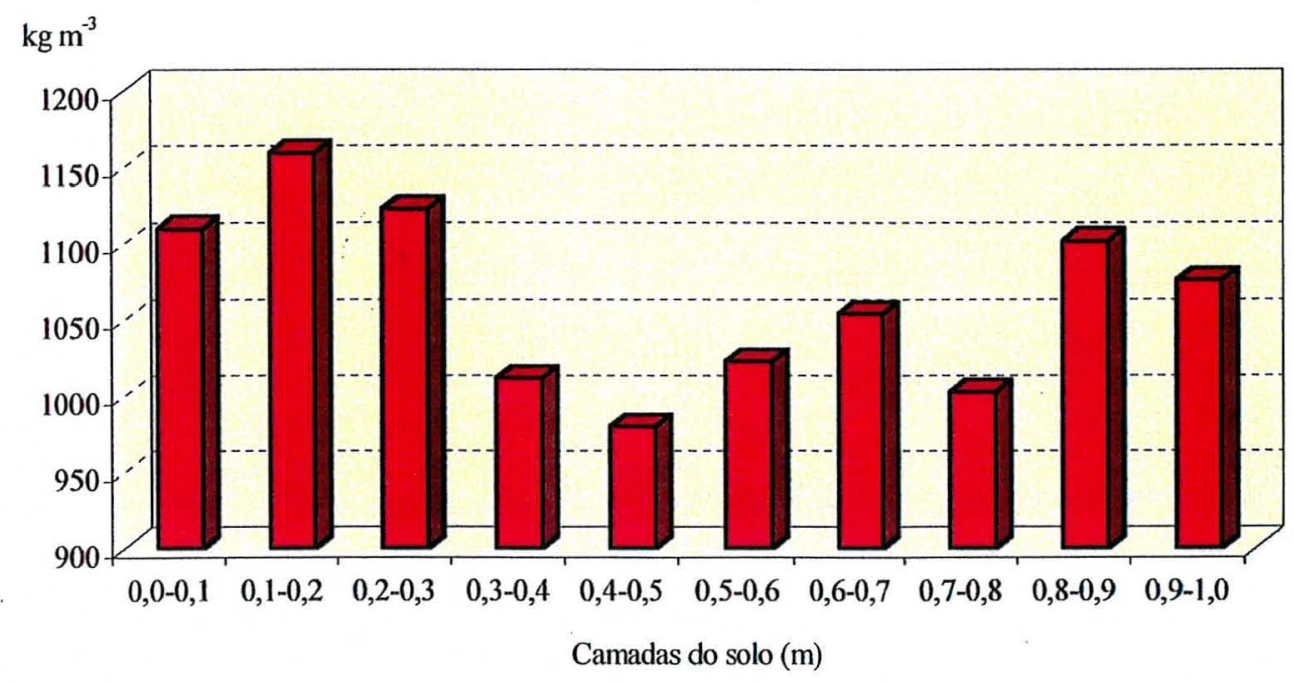

b)

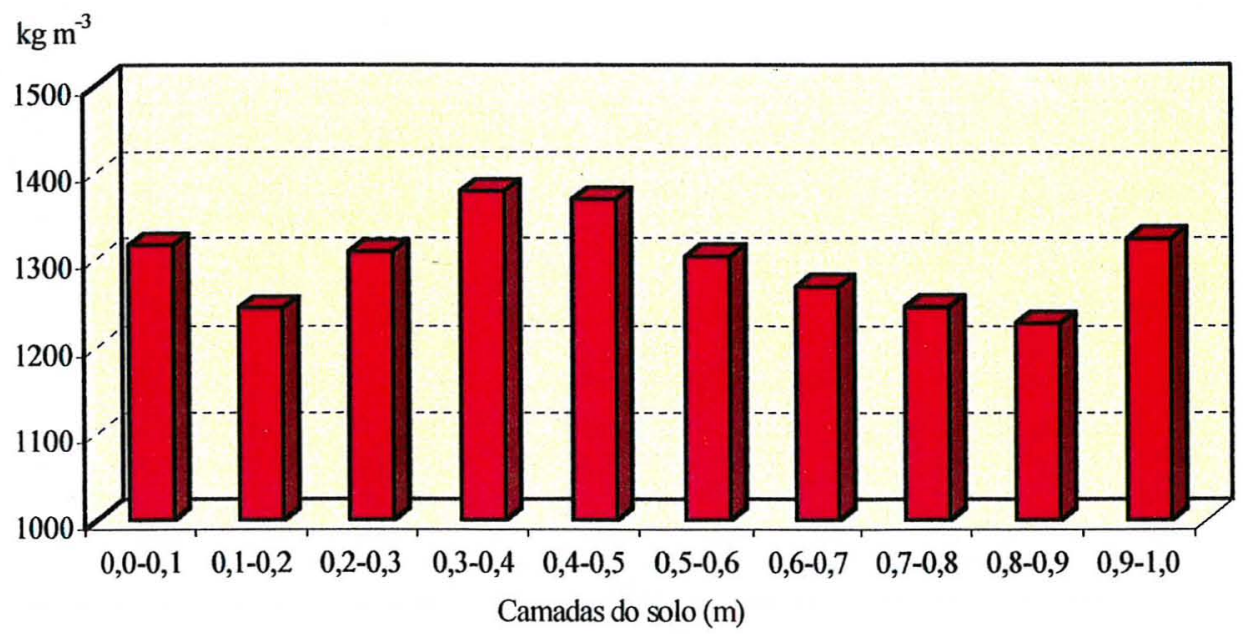

Figura 8. Densidade do solo obtida por camadas nos perfis de: a) LAd e b) LVdf. 
a)

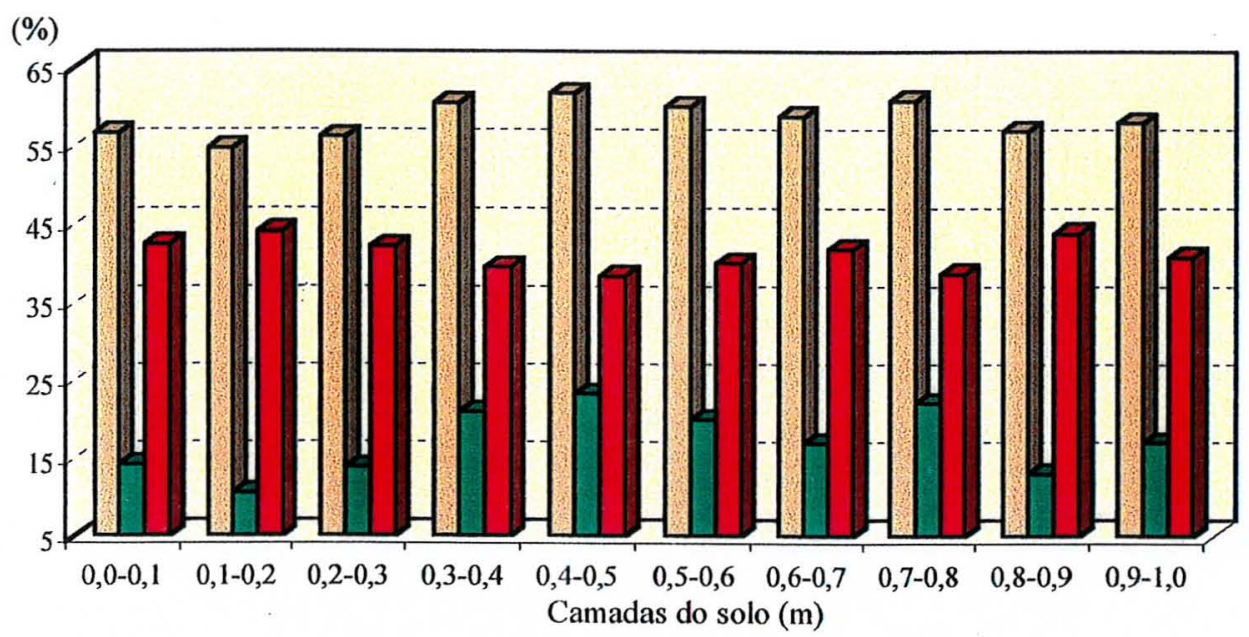

$\square$ Porosidade total $\square$ Macroporosidade $\square$ Microporosidade

b)

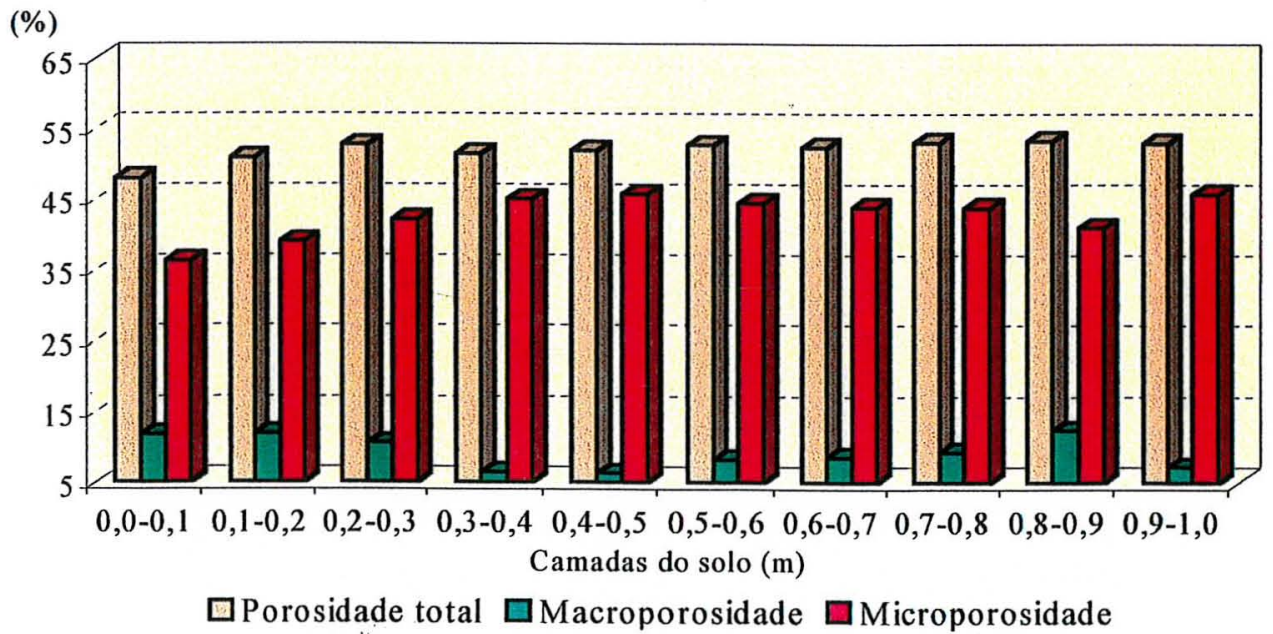

Figura 9. Porosidade total, macroporosidade e microporosidade do: a) LAd e b) LVdf. 


\subsection{Retenção de água nos solos}

Os resultados das umidades volumétricas, a cada tensão aplicada, por camada de solo, obtidas a partir de 05 repetições são apresentadas nas Tabelas 5 e 6.

Analisando a partir dessas tabelas os coeficientes de variação das umidades a cada potencial mátrico, nota-se que as variações podem ser consideradas baixas, indicando pouca variabilidade dos dados e boa precisão.

Nas figuras 10 e 11 é possível visualizar melhor as características genéricas dos solos quanto à retenção de água. Percebe-se que os valores das umidades volumétricas foram relativamente altas em todos os potenciais mátricos avaliados, apresentando uma suave redução com o aumento da tensão. Uma provável explicação para essa tendência pode estar relacionada a maior proporção de microporos aproximadamente (41\%-LAd; 42\%-LVdf) e menor de macroporos nos 2 perfis (17\%-LAd; 6-12\%-LVdf) (Figuras 9 a,b). Assim, os poros grandes perdem a água retida por capilaridade a potenciais elevados, enquanto que os pequenos, retêm água até potenciais baixos adsorvida no sistema coloidal, ocasionando uma alta retenção caso existam em maior proporção (Hillel, 1971). Outros trabalhos desenvolvidos com LVdf ainda atribuem a pequena disponibilidade hídrica desses solos à microagregação (Sharma \& Uehara, 1968), que tem seu desenvolvimento influenciado pela composição mineralógica da fração argila (Tsuji et al., 1975), sendo a água retida dentro dos microagregados extraída apenas à tensões elevadas (Kertzmann, 1996).

Os teores de água nas tensões de 500 e $1500 \mathrm{kPa}$ foram próximos entre si (Tabelas 5 e 6), indicando que a curva de umidade poderia ter sido determinada até o ponto de $500 \mathrm{kPa}$. A pequena variação das umidades entre essas duas tensões pode ser explicada pelos elevados teores de argila, pois conforme Hillel (1982), a textura e a superficie específica influenciam mais diretamente a retenção nessas tensões.

As Tabelas 5 e 6 demonstram que a água retida na capacidade de campo (tensão de $30 \mathrm{kPa}$ ), situou-se entre 0,35 a $0,41 \mathrm{~m}^{3} \mathrm{~m}^{-3}$ para o LAd e entre 0,34 a $0,43 \mathrm{~m}^{3} \mathrm{~m}^{-3}$ para o LVdf, estando a umidade no ponto de murcha permanente (tensão de $1500 \mathrm{kPa}$ ) entre 0,27 a $0,33 \mathrm{~m}^{3} \mathrm{~m}^{-3}$ (LAd) e 0,25 a $0,29 \mathrm{~m}^{3} \mathrm{~m}^{-3}$ (LVdf). 


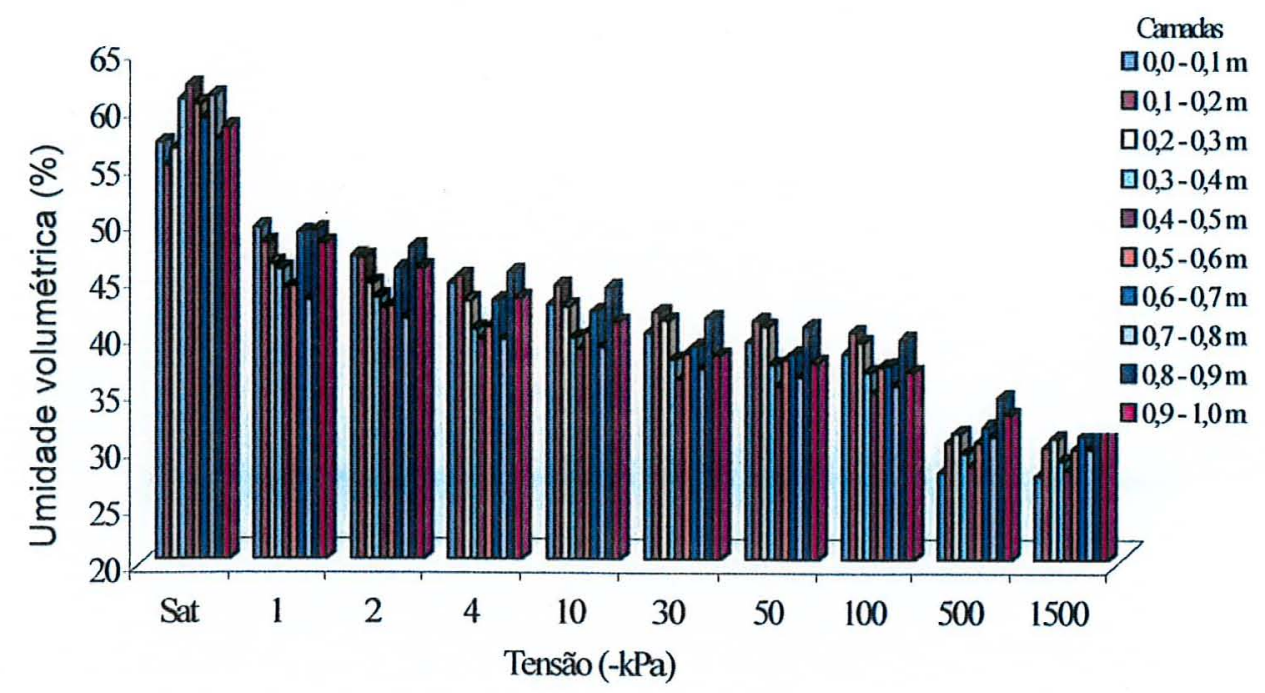

Figura 10. Comportamento da retenção de água a cada tensão aplicada ao longo das camadas do LATOSSOLO AMARELO Distrófico.

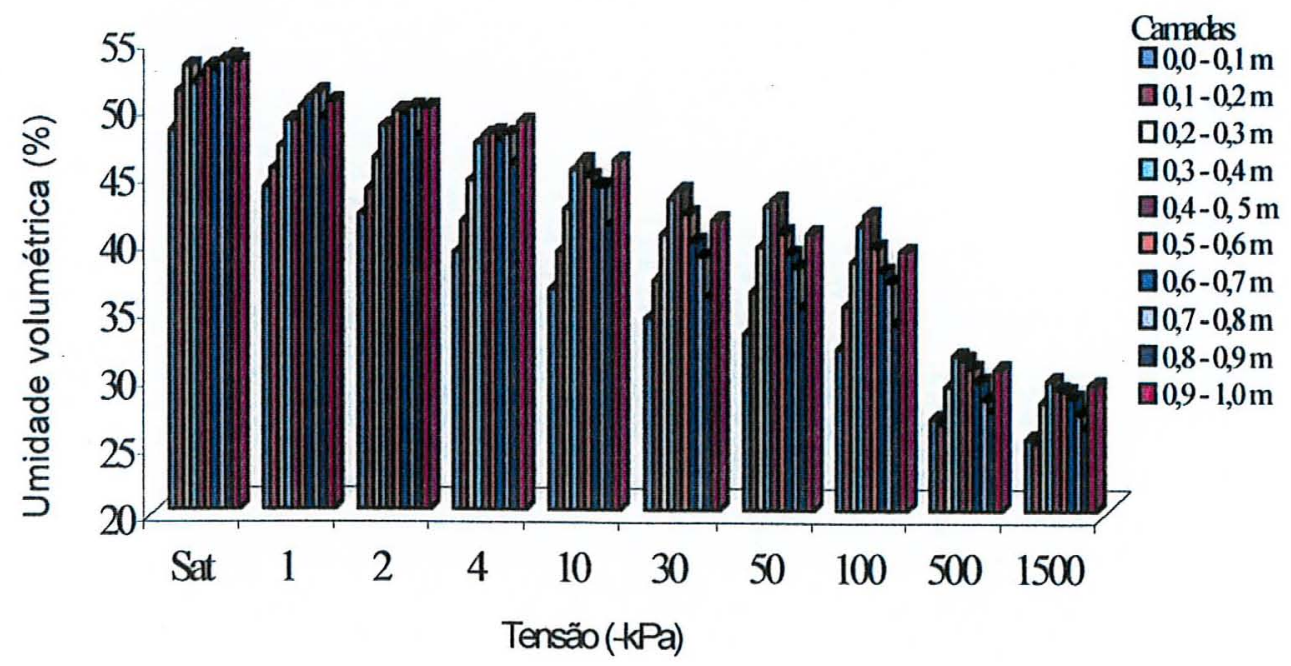

Figura 11. Comportamento da retenção de água a cada tensão aplicada ao longo das camadas do LATOSSOLO VERMELHO Distroférrico típico. 


\subsection{Curva de retenção de água do solo}

As curvas de retenção de água elaboradas para "camadas hidráulicas"dos perfis de solo estudados podem ser visualizadas nas Figuras 12 e 13.

Com os dados contidos nas Tabelas 5 e 6 foi possível elaborar curvas características de retenção de água para cada camada do solo (Figuras 12 e 13), utilizando o ajuste proposto por van Genuchten (1980).

A análise das curvas de retenção possibilitou visualizar melhor a grande semelhança hidráulica das camadas testadas, evidenciando ainda mais a validade dos resultados obtidos e sustentando a hipótese de que os perfis não apresentam características hidráulicas coincidentes com $o$ horizontes pedogenéticos descritos (Figura 4), visto que quanto mais próximas as curvas maior é a indicação de homogeneidade.

No caso do LAd é possivel identificar dois grupos de camadas que apresentam características semelhantes: $0,0-0,1 \mathrm{~m}, 0,1-0,2 \mathrm{~m}, 0,2-0,3 \mathrm{~m}$ e $0,8-0,9 \mathrm{~m}$ (Figura 12) com inclinação mais acentuada, indicando um decréscimo no teor de água conforme o aumento da tensão. Nas camadas $0,3-0,4 \mathrm{~m}, 0,4-0,5 \mathrm{~m}, 0,5-0,6 \mathrm{~m} ; 0,6-0,7 \mathrm{~m}, 0,7-0,8 \mathrm{~m}$ e 0,9-1,0 m (Figura 12), as inclinações das curvas são mais suaves indicando que as perdas de água ocorrem mais lentamente.

No LVdf as camadas $0,0-0,1 \mathrm{~m}, 0,1-0,2 \mathrm{~m}, 0,2-0,3 \mathrm{~m}$ (Figura 13) apresentam curvas similares entre si, tendo maiores inclinações quando comparadas com as curvas apresentadas nas camadas $0,3-0,4 \mathrm{~m}, 0,4-0,5 \mathrm{~m}, 0,5-0,6 \mathrm{~m}$, que a partir da tensão de $1 \mathrm{kPa}$ têm um decréscimo gradativo na umidade, e. com as curvas obtidas nas camadas 0,6-0,7 m, 0,7-0,8 m (inclinação suave), 0,8-0,9 m (inclinação mais suave) e 0,9-1,0 m (inclinação gradual).

Associando as curvas obtidas por camadas aos horizontes, percebe-se que mesmo em um horizonte há variação no comportamento das curvas, tornando a análise por horizontes não recomendada.

Ainda analisando as Figuras 12 a 13, percebe-se que alguns pontos não tiveram um ajuste perfeito pela equação de van Genuchten (1980). Uma provável explicação pode estar relacionada a distribuição da porosidade. Observa-se pelas Figuras 9 a,b que 
no espaço poroso do LAd há o predomínio de duas classes de poros, tendo poucos macroporos e quase que exclusivamente microporos, evidenciando uma distribuição de poros bimodal, concordando com os resultados encontrados por Chauvel et al. (1991) em solos dessa região. Este tipo de distribuição parece também ocorrer no LVdf e deve ser considerada no momento da realização do ajuste das curvas de retenção desses solos (Othmer et al., 1991; Mallants et al., 1997). 


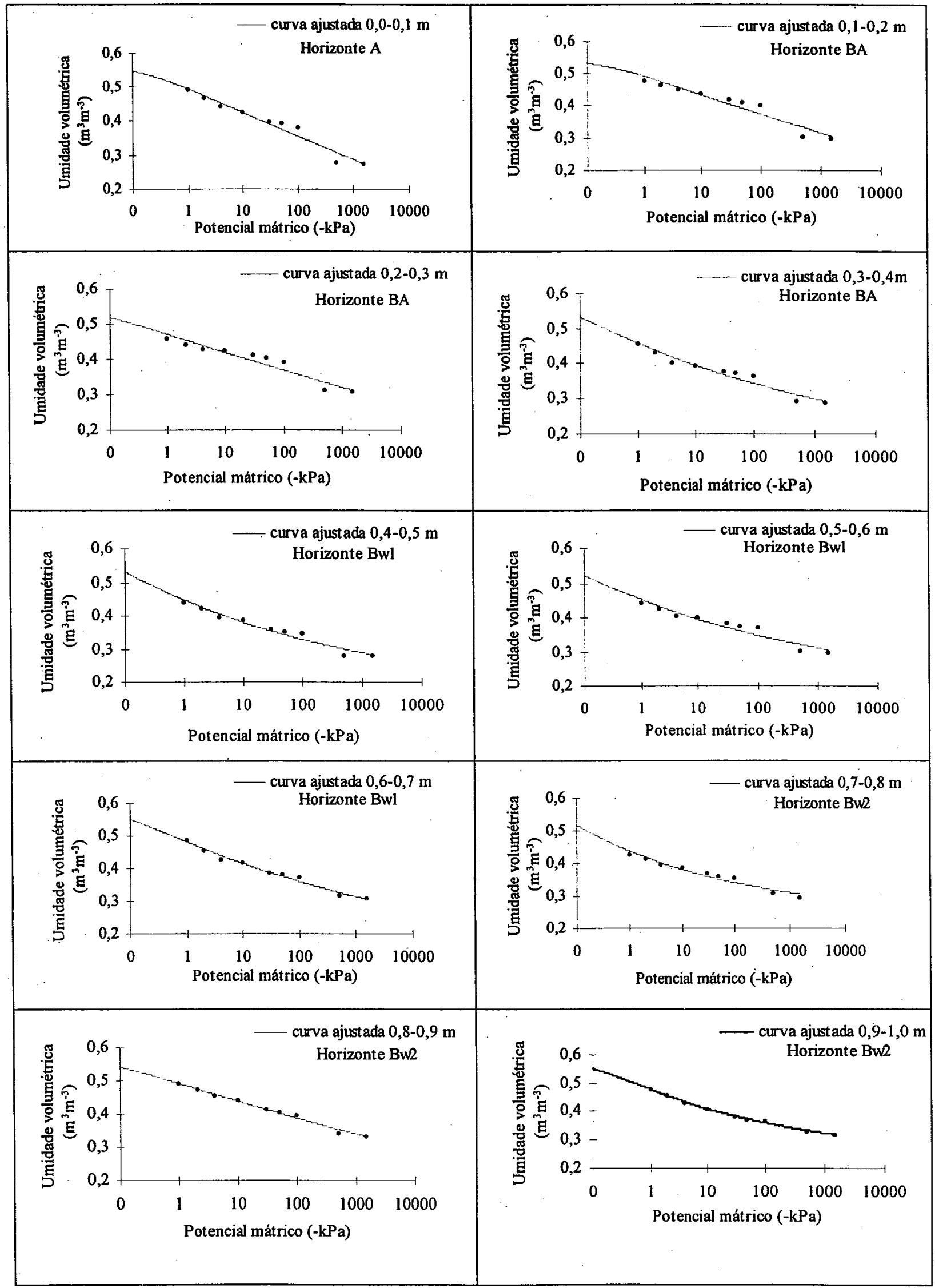




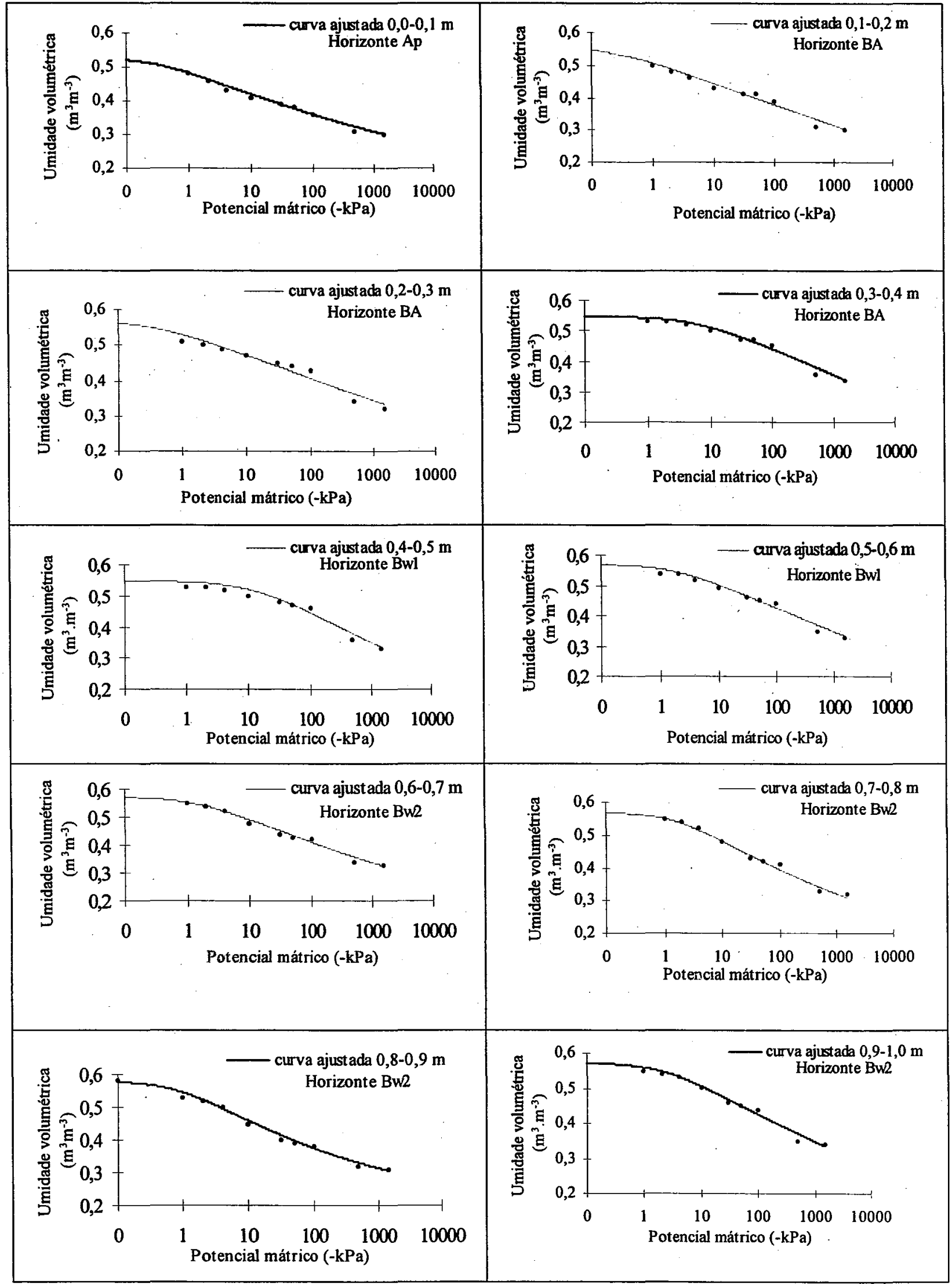

Figura 13. Curvas de retenção hídrica obtidas para cada camada do LVdf. 


\subsection{Horizontes Pedogenéticos x "Camadas Hidráulicas"}

As Figuras 14 e 15 são representações comparativas entre as camadas hidráulicas identificadas e os horizontes pedogenéticos.

Analisando as figuras 14 e 15 , observa-se que as camadas definidas a partir do parâmetro retenção de água não coincidiram com os horizontes pedogenéticos. Os resultados, aqui obtidos, permitem inferir que em solos com grande homogeneidade de cor, como os latossolos, a dinâmica da água nem sempre se altera quando há mudança de horizontes pedogenéticos.

Como os horizontes pedogenéticos dos solos em estudo apresentam em sua maioria classe textural homogênea (Tabela 1), em condição de campo, a cor e a consistência foram os principais critérios morfológicos utilizados para identificação dos horizontes. As figuras 14 e 15 demonstram que esses parâmetros podem conduzir a erros, já que em algumas identificações de horizontes, a própria descrição no campo é subjetiva e rápida. Apesar da descrição morfológica não ter o objetivo de caracterizar hidraulicamente o solo, mas sim fornecer uma noção inicial de atributos, potencialidades e limitações para fins diversos, é comum considerar os horizontes pedogenéticos como um referencial para coleta de amostras destinadas a caracterização hidráulica. Em determinadas situações no campo não é possível complementar de imediato as informações morfológicas com análises físicas, químicas e mineralógicas. Assim, as feições morfológicas podem ou não ser um bom indicativo da dinâmica da água.

$\mathrm{Na}$ Figura 14 (LAd) percebe-se que, somente nas tensões 1,2 e $4 \mathrm{kPa}$, a variação da umidade na camada $0,7-0,8 \mathrm{~m}$ coincidiu com o horizonte pedogenético, sendo sensível a transição Bw1/Bw2. Este comportamento não foi observado no LVdf (Figura 15).

Confrontando os dois parâmetros hidráulicos utilizados no estudo, salienta-se que os resultados das umidades volumétricas (Tabelas 5 e 6) foram mais sensíveis às variações morfológicas do que os valores de $K_{0}$. 


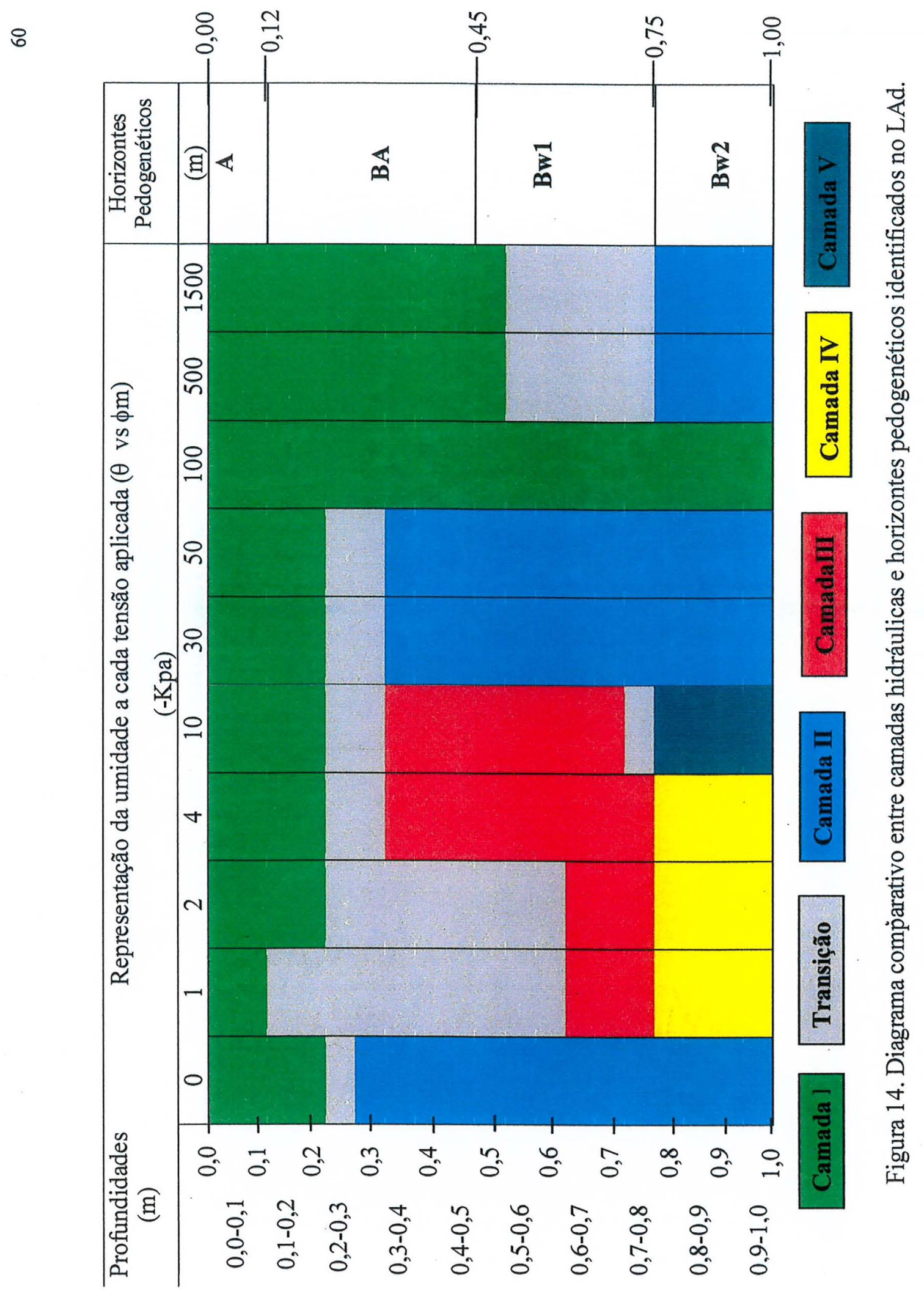




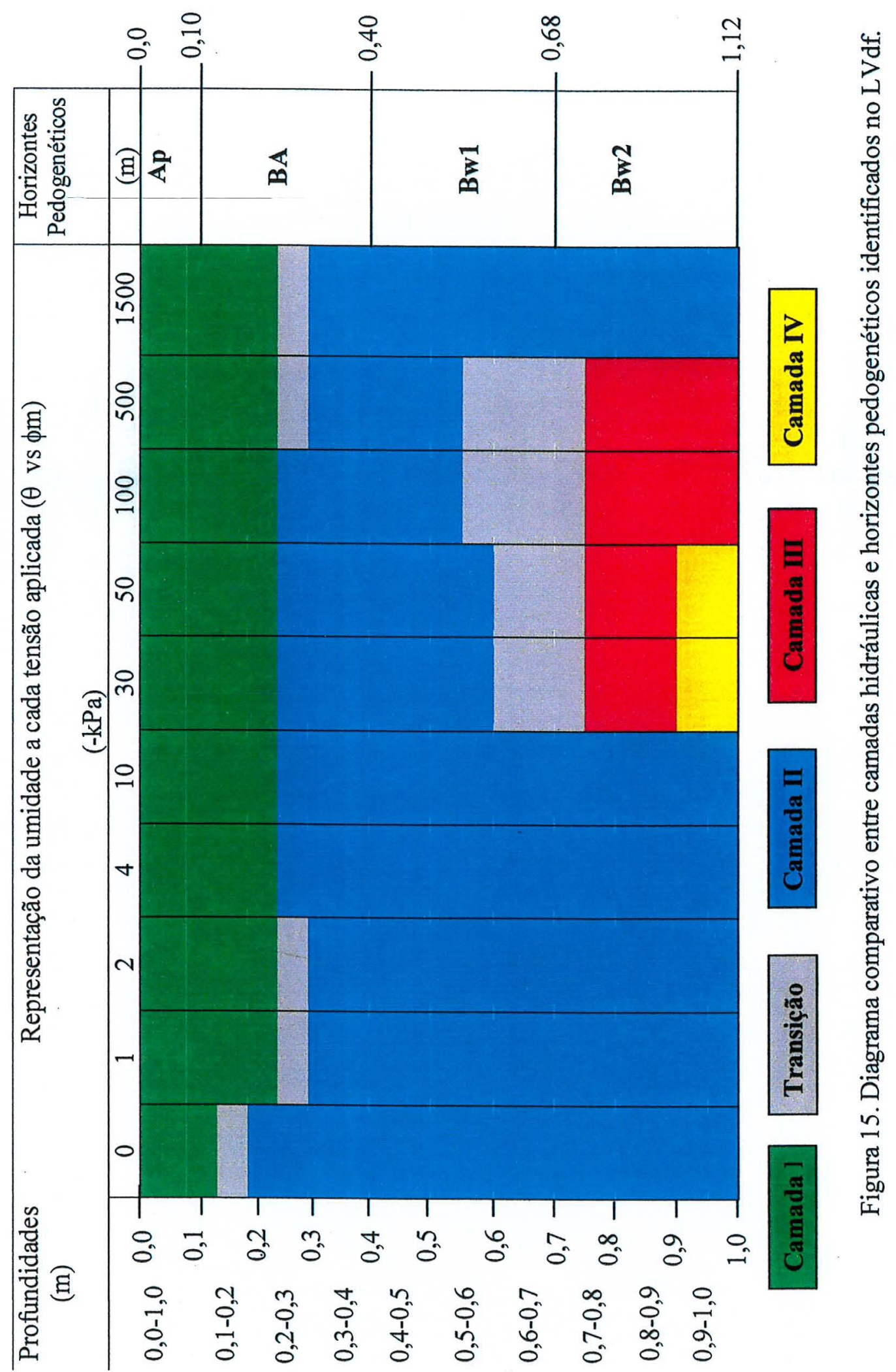


O que se pretende nessa discussão é chamar atenção para algumas correlações que são realizadas envolvendo características hidrodinâmicas e a pedologia, salientando que apesar da identificação de horizontes pedogenéticos ser um procedimento inicial e importante na classificação de solos, é preciso ter cuidado quanto à sua utilização em estudos hidráulicos em perfil de solo.

É indiscutível a grande importância da separação dos horizontes pedogenéticos no processo de classificação, principalmente por ser a principal maneira de realizar levantamento de solos (Prado, 1996). Salienta-se que os vários estudos que relacionam parâmetros morfológicos do solo com o movimento da água (Anderson \& Bouma, 1973; Mckeague et al., 1982; Wosten \& van Genuchten, 1988; Lin et al., 1999) utilizam horizontes heterogêneos do ponto de vista textural e estrutural, abordando de forma específica a influência desses atributos nas propriedades hidráulicas do solo. Nesse caso, espera-se que haja mudanças na umidade conforme variem os horizontes. Entretanto, ainda é necessário realizar mais estudos que evidenciem até que ponto a dinâmica da água em perfis é sensível à variação dos atributos físicos do solo.

Dentre os atributos físicos do solo, a estrutura parece ser o principal fator que controla a dinâmica da água. Variações na estrutura do solo podem afetar o comportamento da curva de retenção mesmo em horizontes pedogenéticos caracterizados pelos mesmos constituintes (Robain \& Curmi, 1986). Entretanto, quando a estrutura não varia muito no solo é preciso considerar outros fatores para identificar os horizontes que podem não alterar significativamente 0 comportamento da curva de retenção no perfil.

Percebe-se pelas Figuras 14 e 15 que, quando os solos apresentam feições morfológicas homogêneas ao longo do perfil, torna-se mais dificil caracterizá-los hidraulicamente. Prevedello (1987), estudando o regime de fluxo de água em solos saturados, salienta que em meios porosos aproximadamente homogêneos, o critério morfológico para identificação dessas camadas nem sempre conduz a resultados satisfatórios.

Embora o critério de divisão do perfil em horizontes demonstre não ser rigorosamente seguido pela dinâmica da água, surge a partir das considerações 
anteriores um importante questionamento: "No caso dos solos estudados, qual seria a melhor maneira de avaliá-los hidraulicamente"? Baseado nas figuras 14 e 15, nota-se que para os referidos solos as amostras não devem ser coletadas nos horizontes, mas sim em camadas.

Seguindo o critério utilizado e considerando o comportamento das umidades nas tensões avaliadas, bem como as curvas de retenção na camadas (Figuras 12 e 13), verifica-se que o LAd (Figura 14) pode ser caracaterizado quanto a dinâmica da água no perfil pela retirada de amostras nas seguintes camadas hidráulicas identificadas: 0,0-0,4 $\mathrm{m}, 0,4-0,8 \mathrm{~m}$ e $0,8-1,0 \mathrm{~m}$. Quanto ao LVdf (Figura 15), tem-se as seguintes camadas: 0,0-0,3 m, 0,3-0,8 m e 0,8-1,0 m.

Como se pode observar, as amostragens podem ser feitas em camadas específicas dentro de cada perfil, representando os pontos onde ocorreu alteração na umidade. No caso da tensão $100 \mathrm{kPa}$ no LAd (Figura 14), observa-se que a amostragem pode ser feita em qualquer camada, pois a umidade não variou ao longo do perfil.

Entretanto, identificar quais camadas devem ser amostradas para posterior caracterização hidráulica não é tarefa fácil, ainda mais em solos com grande homogeneidade morfológica. Nesse caso, apesar da coleta de amostras a cada $0,10 \mathrm{~m}$ de profundidade ser um trabalho desgastante e demorado, parece ser a melhor alternativa para avaliar, em termos hidráulicos, solos com essa característica. Em algumas condições de campo, a partir de determinada profundidade, a própria identificação pedológica se torna mais subjetiva, já que a transição de horizontes é cada vez mais difusa.

Percebe-se que ainda é necessário realizar mais estudos que possibilitem desenvolver uma metodologia para caracterizar, de forma prática e ideal, o comportamento hidráulico de solos que apresentam dificuldade quanto à separação de horizontes. Além disso, é preciso considerar a influência da matéria orgânica na dinâmica da água nas camadas superficiais. Apesar de não ter sido verificado a interferência da M.O. no LAd e LVdf, é comum constatar sua contribuição como agente agregante e modificando as condições estruturais (Feller \& Beare, 1997), principalmente a baixas tensões onde a geometria do espaço poroso é mais importante (Petersen et al., 
1968; Baver et al., 1973). Assim, em solos cujas camadas superficiais sejam conservadas do ponto de vista estrutural, é provável que a condutividade hidráulica e a retenção de água sejam diferentes das outras camadas, sugerindo que também sejam amostradas.

No caso dos solos caracterizados hidraulicamente neste trabalho, pelos valores apresentados na Tabela 2, constata-se que, apesar do maior conteúdo de matéria orgânica no horizonte superficial, os valores mais elevados de densidade do solo obtidos nessas camadas para o LAd (Figura 8 a) indicam uma ligeira compactação refletida na porosidade do solo e, consequentemente, na dinâmica da água. Quanto ao LVdf, os valores de umidade apresentados na Tabela 6 demonstram que, independente da tensão aplicada, as camadas superficais (0,0-0,1 $\mathrm{m}$ e 0,1-0,2 m) apresentaram um menor teor de água. Como se assumiu que $\theta_{\mathrm{s}}=\mathrm{Pt}$ (Tabelas 5 e 6), percebe-se que os valores de porosidade total calculada a partir da densidade do solo e médias da densidade das partículas (Tabela 1), foram menores nas camadas superficais, sendo os valores de macroporosidade maiores (11\%) (Figura 9 b) o que leva a considerar esses parâmetros como os responsáveis pela baixa retenção. 


\section{CONCLUSÕES}

Analisando os resultados obtidos neste trabalho é possível concluir que:

De modo geral, os horizontes pedogenéticos identificados não coincidiram com as camadas hidráulicas obtidas a partir da curva de retenção e condutividade hidráulica saturada;

Em solos com grande homogeneidade, como os Latossolos, nem sempre as propriedades hidráulicas sofrem variações à medida em que ocorre transição entre horizontes pedogenéticos no perfil;

A utilização de alguns atributos morfológicos como textura, cor e consistência comumente utilizados na identificação dos horizontes pedogenéticos, em condições de campo, pode não ser suficiente quando o objetivo é caracterizar o solo hidraulicamente. 


\section{ANEXOS}


ANEXOS I

ESTATÍSTICA DESCRITIVA OBTIDA PARA AS MEDIDAS DA CONDUTIVIDADE HIDRÁULICA SATURADA NAS CAMADAS DE SOLO 


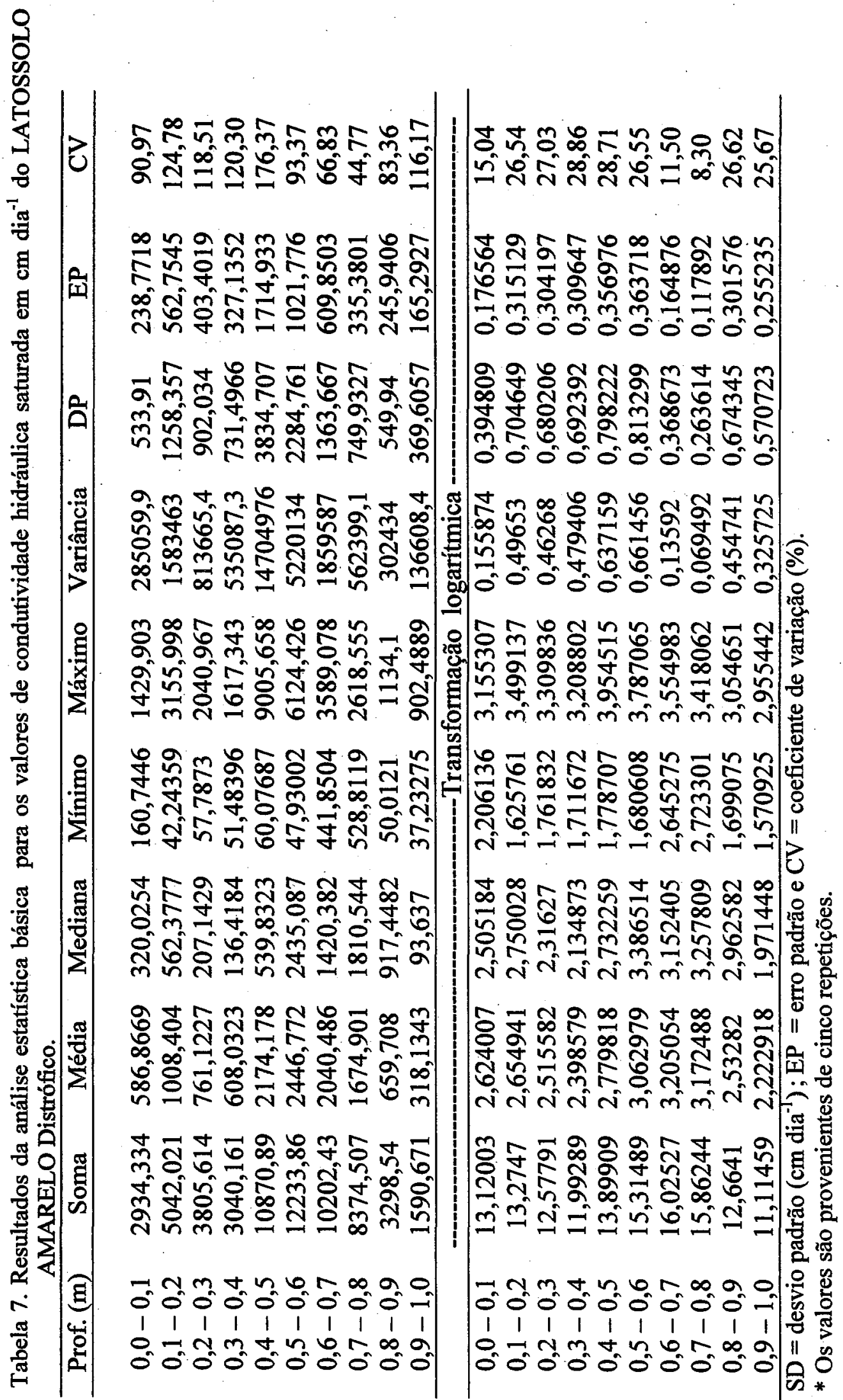




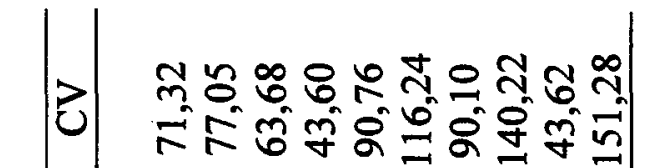

ษกำ

m К쥬

a

กิ๊

马्ञ

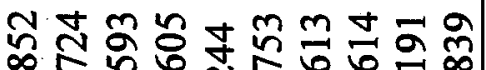

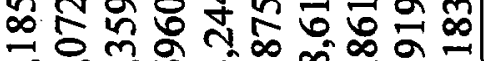

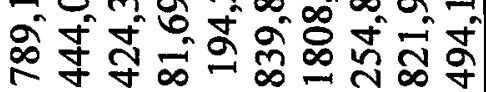

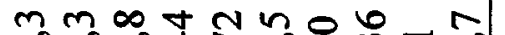

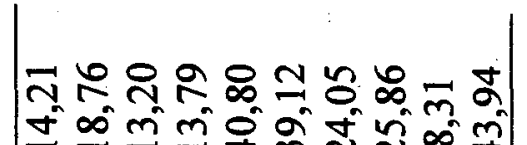

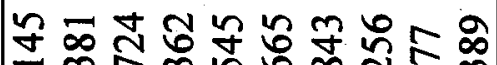
๘ 근은 "ू

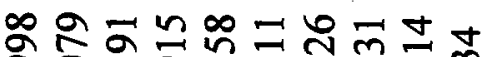
人。ํำ m ఈ

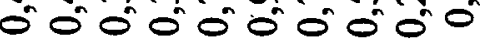
m \&

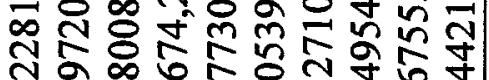
저의

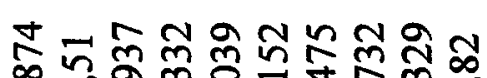

क \% กั

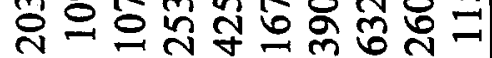

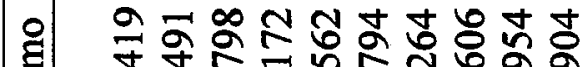
ฮั่

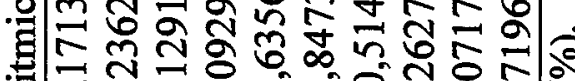

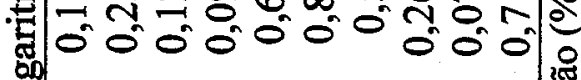

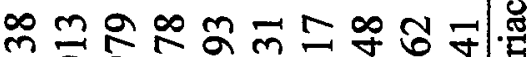

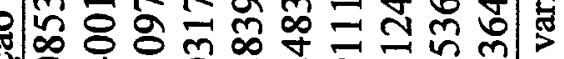
m 寸 ली ली ती ली ली ती mी

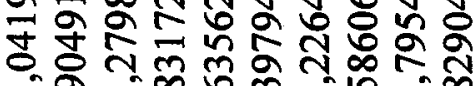

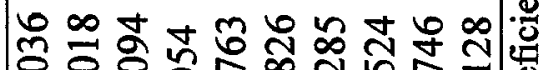
훙ㅎㅇ ₹ ต

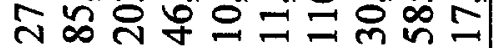
\% 节 क

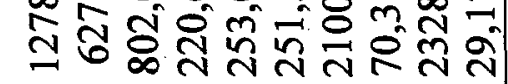

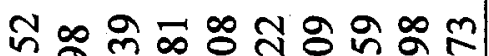
† సे क రิ ชิ 는 तन

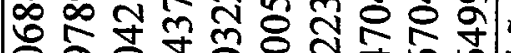
응ㅎㅇ लंतेत ते लीजि

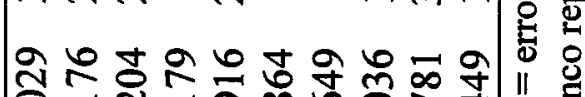

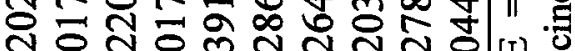
교요을

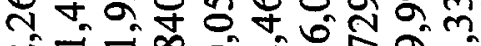

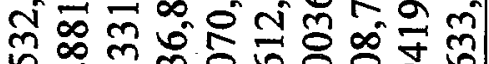
ñ (

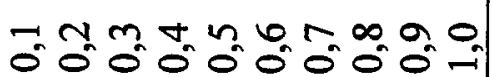

$\pm \infty$ \&

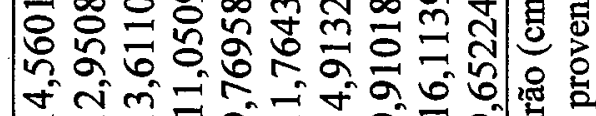

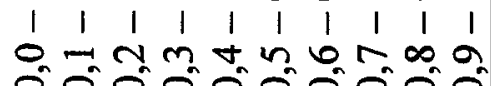

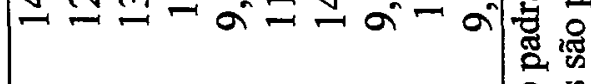
= $\begin{array}{llllllllll}1 & 1 & 1 & 1 & 1 & 1 & 1 & 1 & 1 & 1\end{array}$

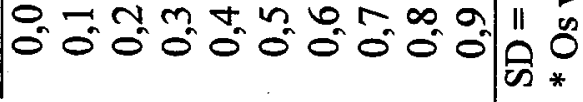




\section{REFERÊNCIAS BIBLIOGRAFICAS}

AGASSI, M; SHAINBERG, I.; MORIN, J. Effect of electrolyte concentration and soil sodicity on infiltration rate and crust formation. Soil Science Society of American Journal, v. 45, p. 848-851, 1981.

AHUJA, L.R.; NANEY, J.W.; GREEN, R.E.; NIELSEN, D.R. Macroporosity to characterize spatial variability of hydraulic conductivity and effects of land management. Soil Science Society of America Journal, v. 48, p. 699-702, 1984.

ANDERSON, J.L.; BOUMA, J. Relationship between saturated hydraulic conductivity and morphometric data of na argilic horizon. Soil Science Society of America Proceedings, v.37, n.3, p.408 - 413, 1973.

BAVER, L.D. Soil physics. New York, 1961. 489p.

BAVER, D.V.; GARDNER, W.H.; GARDNER, W.R. Fisica de suelos. Mexico, Uthea, 1973. 529p

BEVEN, K.; GERMANN, P. Macropores and water flow in soils. Water Resources Research, v. 18, p. 1311-1325, 1982.

BIRKELAND, P.W. Soil and Geomorphology. Oxford University Press, New York EUA, 1984. 
BLACK, T.A.; GARDNER, W.R.; THURTELL, G.M. The prediction of evaporation, drainage and soil water storage for a bare soil. Soil Science Society American Proceedings, v.33, p.655-660, 1969.

BLACK, T.A.; GARDNER, W.R.; TANNER, C.B. Water storage and drainage under a row crop on a sandy soil. Agronomy Journal, v.62, p.48-51, 1970.

BOCKHEIM, J.G.; GENNADIYEV, A.N. The role of soil forming processes in the definition of taxa in Soil Taxonomy and the World Soil Reference Base. Geoderma, v. 95, p. 53-72, 2000.

BOUMA, J. Comment on Micro, meso and macroporosity of soil. Soil Science Society of American Journal, v. 45, p. 1244-1245; 1981.

BOUMA, J. Using soil survey data for quantitative land evaluation. Advance Soil Science, v.9, p.177-213, 1989.

BOUMA, J. Influence of soil macroporosity on environmental quality. Advances in Agronomy, v. 46, p. 1-37, 1991.

BOUMA, J.; ANDERSON, J.L. Relationships between soil structure characteristics and hydraulic conductivity. In BRUCE, R.R. et al. Field soil water regime. Soil Science Society of American. Special Publication, $\mathbf{n}^{0}$ 5, 1973.

BOUMA, J.; JONGERIUS, A; BOHSUMA, O.; LEGGER, A.; SCTROONDERBEER, $D$. The function of different types of macroporos during saturated flow through four swelling soil horizons. Soil Science Society of American. v. 41, p.945-950, 1977. 
BOUMA, J.; JONGERIUS, A.; SCHOONDERBEEK, D. Calculation of saturated hydraulic condutivity of some pedal clay soils using micromorphometric data. Soil Science Society of American Journal, v.43, p. 261-264, 1979.

BRASIL. Ministério de Agricultura. Comissão de Solos. Levantamento de reconhecimento de solos do Estado de São Paulo. Rio de Janeiro, Ministério da Agricultura, CNEPA, 1969. 634p. (Boletim 12).

BULLOCK, P.; MCKEAGUE, J.A. Estimating air-water properties of a soil. C.R. colloque fonctionnement hydrique et comportement des sols, Dijon France, A.F.E.S, p. 55-76, 1984.

BUOL, S.W.; HOLE, F.D.; MAcCRACKEN, R.J. Soil Genesis and classification. The Iowa State University Press, Ames, 1980. 404p.

CAMARGO, M.N.; KAMPF, N.; KLAMT, E. Sistema Brasileiro de Classificação de Solos. Rio de Janeiro: SNLCS/EMBRAPA, 1987. 35p. (Boletim Informativo, 15).

CAMPBELL, G.S. A simple method for determining unsaturated conductivity form moisture retention data. Soil Science, v.117, n.6, p. 311-314, 1974.

CARVALHO, A.P.; LARACH, J.O.I. de.; JACOMINE, P.K.T.; CAMARGO, M.N. Critérios para distinção de classes de solos e de fase de unidades de mapeamento. Normas em uso pelo SNLCS. Rio de Janeiro: SNLCS/EMBRAPA, 1988. 67p. (Documentos, 11).

CASTLE, W.S.; KREZDORN, A.H. Rootstock effects on root distribution and leaf mineral content of 'Orlando' tangelo trees. Proceedings of Florida State Horticultural Society, v.86, p.80-84, 1973. 
CAUDURO, F.A.; DORFMAN, R. Manual de ensaios de laboratório e campo para irrigação e drenagem. Brasília, PRONI/MA, 1988. 216 p.

CHAUVEL, A.; GRIMALDI, M.; TESSIER, D. Changes in soil poro-space distribution following deforestation and revegetation: $\mathrm{Na}$ example from the Central Amazon Basin, Brazil. Forest Ecology and Management, v. 38, p. 259-271, 1991.

CHILDS, E.C. The use of soil moisture characteristics in soil studies. Soil Science. Baltimore, v.50, p.239-252, 1940.

CHILDS, E.C.; COLLINGS-GEORGE, N. The permeability of porous materials. Proceedings of the Royal Society of London. A, v.201, p.392 - 405, 1950.

CLEMMENS, A.J. Infiltration equations for border irrigation models. In: National Conference on Advances in Infiltration. Chicago, American Society of Agricultural Engineers, 1983, p. 266-274.

CLINE, M.G. Basic principles of soil classification. Soil Science, Baltimore, v. 67, p. 81-91, 1949.

COOPER, M. Influência das condições físico-hídricas nas transformações estruturais entre horizontes B latossólico e B textural sobre diabásio. Piracicaba, 1999. 128p. Tese (Doutorado) - Escola Superior de Agricultura Luiz de Queiroz, Universidade de São Paulo.

CORREA, J.C. Caracaterísticas físico-hídricas dos solos Latossolo Amarelo, Podzólico Vermelho Amarelo e Podzol Hidromórfico do Estado do Amazonas. Pesquisa Agropecuária Brasileira, v. 19, p. 347-360, 1984. 
COSBY, B.J.; HORNBERGER, G.M.; CLAPP, R.B.; GINN, T.R. A statistical exploration of the relationships of soil moisture characteristics to the physical properties of soils. Water Resources Research, v. 20, p. 682-690, 1984.

CRAWFORD, J.W. The relationship between structure and the hydraulic conductivity of soil. European Journal of Soil Science, v. 45, p. 493-502, 1994.

CURI, N.; LARACH, J.A.I.; KAMPF, N.; MONIZ, A.C.; FONTES, L.E.F.. Vocabulário de ciência do solo. Campinas, 1993. 90p.

DOURADO NETO, D.; JONG VAN LIER, Q de.; BOTREL, T.A.; LIBARDI, P.L. Programa para confecção da água no solo utilizando o modelo de Genuchten. Engenharia Rural, v. 1, p. 92 - 102, 1990.

DRIESSEN, P.M.; DUDAL, R. The Major Soils of the World. Lecture notes on their geography formation, propieties and use. Agr. Univ. Wageningen, $1991.310 \mathrm{p}$.

DROZHZHINA, T.M.; VASIL'CHIKOVA, S.I. Effects of differential porosity on the nature of moisture migration and salt accumulation in soil (as exemplified by newly developed soils on Tadzhikistan). Soil Science, v. 16, p.109-115, 1984.

DUDAL, R. Na International Reference Base for Soil Classification. In: $14^{\mathrm{a}}$ congress soil science. Kyoto, v.5, p 38-43, 1990.

DUFFY, C.; WIERENGA, P.J.; KSELIK, R.A. Variations in infiltration rate based on soil survey information and field measurements. New México, 1981. 40p. (Bulletin, 680). 
ELLIES, A.; GREZ, R.; RAMIREZ, C. La conductividad hidrálica en fase saturada como herramienta para el diagnostico de la estructura del suelo. Agro Sur, v. 5, p. 51-56, 1997.

EMBRAPA. Serviço Nacional de Levantamento e Conservação de Solos. Sistema Brasileiro de Classificação de Solos. $2^{a}$ aproximação. Rio de Janeiro, EMBRAPA-CNPS, 1981. 107p.

EMBRAPA. Centro Nacional de Pesquisa Agroflorestal. Boletim Agrometeorológico. Manaus, EMBRAPA - UEPAE, 1984. (Documentos, 6).

EMBRAPA. Serviço Nacional de Levantamento e Conservação de Solos. Definição e notação de horizontes e camadas do solo. 2.ed. rev. atual. Rio de Janeiro, EMBRAPA - SNLCS, 1988. (Documentos, 3).

EMBRAPA. Centro Nacional de Pesquisa de Solos. Procedimentos Normativos de Levantamentos Pedológicos. Brasília, EMBRAPA - SPI, 1995. 101 p.

EMBRAPA. Centro Nacional de Pesquisa de Solos (Rio de Janeiro, RJ). Sistema Brasileiro de Classificação de Solos. $4^{\text {a }}$ aproximação. Rio de Janeiro, EMBRAPA-CNPS, 1997 a. 169p.

EMBRAPA. Centro Nacional de Pesquisa de Solos. Manual de Métodos de Análise de Solo. $2^{a}$ edição. rev. atual. Rio de Janeiro, 1997 b. 212p. (EMBRAPA-CNPS. Documentos; 1).

EMBRAPA. Centro Nacional de Pesquisa de Solos. Sistema Brasileiro de Classificação de Solos, Rio de Janeiro, EMBRAPA-CNPS, 1999. 412 p. 
ESTADOS UNIDOS. Departament of Agriculture. Natural Resources Conservation Service. Soil Survey Staff. Keys to soil taxonomy. 8. Ed. Washington, 1998. 326 p.

FAO. World reference base for soil resources. World Soil Resources Reports. Roma, n. $84-88,1998.88 \mathrm{p}$.

FELLER, C.; BEARE, M.H. Physical central of soil organic matter dynamics in the tropics. Geoderma, v. 79, p. 69-116, 1997.

FIELD, J.A.; PARKER, J.C.; POWELL, N.L. Comparasion of field and laboratory measured and predicted hydraulic properties of a soil with macropores. Soil Science, v.138, p.385-396, 1984.

FINKL, C.W. Soil Classification Benchmark papers in soil soil science. Pennsylvania, v.1, 1992. $400 \mathrm{p}$.

GARDNER, W.H. Water content. In: KLUTE, A. ed. Methods of soil analysis. Part I. Agronomy Monograph Séries no 9, Madison, Wisconsin, Cap.21, p.493-544, 1986.

GERMAN, P.; BEVEN, K. Water flow in soil macroporos. I. An experimental approach. Journal of Soil Science, v.32, n.1, p.1-13, 1981.

GISH, T.J.; STARR, J.L. Temporal variability of infiltration under field conditions. In: National Conference on Advances in Infiltration. Chicago, American Society of Agricultural Engineers, 1983, p. 122-131. (Publication advance in infiltration).

GREE, G.W.; BAUDER, J.C. Partile-size analysis. In: KLUTE, A. (Ed). Methods of soil analysis, I. physical and mineralogical methods. Madison. American Society of Agronomy, 1986. cap.15. p.383-411. 
GRIMALDI, M.; BOULET, R. Relation entre l' espace poral et le fonctionnement hydrodynamique d'une couverture pédologique sur socle de Guiyane française. Cahiers. ORSTOM, séries. Pédologie, v. XXV, n.3, p. 263-275, 1989.

GUEHL, J.M. Dynamique de I'eau dans le sol en forêt tropicale humide guyanaise. Influence de la couverture pédologique. Ann. Sci. For, v.41, n.2, p. 195-236, 1984 a.

GUEHL, J.M. Utilisation des méthodes tensioneutroniques pour I'étude des transferts hydriques dans le sol en milieu ferrallitique guyanais. Sci. Du Sol, $n^{0} 1$, p. 35-50, 1984 b.

GUERIF, J. L'analyse de la porosité: Application à étude du compactage des sols. In. MONIER, G.; GROSS, M.J. (Ed) Soil compaction and regeneration. Rooterdam: AAB, p. 122-131, 1987.

HARDY, D.H.; RAPER, C.D.; MINER, G.S. Chemical restrictons of roots in ultisol subsoils lessened by long-term management. Soil Science Society of American Journal., Madison, v. 54, p. 1657 - 1660, 1990.

HAVERKAMP, R.; PARLANGE, J.Y. Predicting the water-retention curve from particle-size distribution. Soil Science, v. 142, p.325-339, 1986.

HENDRICKX, J. M. H. Determination of hydraulic soil properties In: ANDERSON, M. G. \& BURT, T. P. Process Studies in Hillslope Hydrology. England, Cap. 3, p. 43-92, 1990.

HILLEL, D. Soil and water. Physical principles and processes. New York, Academic Press, 1971. 288p. 
HILLEL, D. Introduction to Soil Physics. New York, Academic Press, 1982. 365p.

HILLEL, D.; KRENTOS, V.D.; STYLIANOU, Y. Procedure and Test of an internal drainage method for measuring soil hydraulic characteristics in situ. Soil Science, v.114, p. 395-400, 1972.

HILL, J.N.S.; SUMNER, M.E. Effect of bulk density on moisture characteristics of soils. Soil Science, v. 103(4), p.234-238, 1967.

JARVIS, N. J. MACRO - A Model of Water Movement and Solute Transport in Macropous Soils, Monograph - Department of Soil Sciences, Reports and Dissertations 9, University of Agricultural Sciences. 1991. 58p

JENNY, H. Factors of soil formation. New York: Mc Graw-Hill, 1941.281p.

JORGE, J.A.; PRADO, H. Porosidade, consistência e propriedades hídricas de três Podzólicos Vermelho-Amarelos e uma Terra Roxa Estruturada. Revista Brasileira Ciência do Solo, v. 12, p. 1-6, 1988.

JURY, W.A.; RUSSO, D.; SPOSITO, G.; ELABD, H. The spatial variability of water and solute transport properties in unsaturated soil. Hilgardia, v. 55, n. 4, p. 1-31, 1987.

KENG, J.C.; LIN, C.S. A two line approximation of hydraulic conductivity for structured soils. Can. Agri. Eng., v. 24, p. 77-80, 1982.

KERTZMANN, F.F. Modificações na estrutura e no comportamento de um latossolo roxo provocadas pela compactação. São Paulo, 1996. 153p. Tese (Doutorado) Faculdade de Filosofia, Letras e Ciências Humanas, Universidade de São Paulo. 
KLUTE, A. Laboratory measurement of hidraulic conductivity of saturated soil. In: BLACK, C.A. Methods of soil analysis; I. physical and mineralogical properties, Including Statistics of Measurement and Sampling.. Madison: American Society of Agronomy, 1965. cap. 13, p. 210-221.

KLUTE, A. Water retention: laboratory methods. In: KLUTE, A. (Ed). Methods of soil analysis, I. physical and mineralogical methods. Madison. American Society of Agronomy, 1986. cap.26. p.635-662.

KLUTE, A.; DIRKSEN, C. Hydraulic Conductivity and diffusivity: Laboratory methods. In: KLUTE, A. (Ed.). Methods of soil analysis. I. physical and mineralogical methods. Madison, American Society of Agronomy, 1986. cap.28 , p.687-734.

KOOREVAAR, P.; MENELIK, G.; KIRKSEN, C. Elements of soil physics. Development of soil science 13, Amsterdam, Elsevier, 1983. 228p.

KOSUGUI, K. Three-parameter lognormal distribution model for soil water retention. Water Resources Research, v.30, n.4, p. 891-901, 1981

KRETZSCHMAR, R.; ROBARGE, W.P.; AMOOZEGAR, A. Filter efficiency of three saprolites for natural clay and iron oxide colloids. Environ. Sci. and Technology, v.28, p.1907-1915, 1994.

KUTILEK, M.; NIELSEN, D.R. Soil Hidrology. Alemania: Catena Verlag, 1994. 370p.

LAUREN, J.G.; WAGENET, R.J.; BOUMA, J.; WOSTEN, J.H.M. Variability of saturated hydraulic conductivity in a glossaquic hapludalf with macropores. Soil Science, v. 145, p. 20-28, 1988. 
LEMOS, R.C.; SANTOS, R.D. dos. Manual de descrição e coleta de solo no campo. $3^{\mathrm{a}}$ ed. Campinas, SP:SBCS/CNPS, 1996, 83p.

LETEY, J. The study of soil structure: science or art. Australian Journal of Soil Research, v.29, p.699-707, 1991.

LIBARDI, P.L.; REICHARDT. K. Características de 05 (cinco) solos do Estado de São Paulo. O solo, v. 1, p. 7-13, 1973.

LIBARDI, P.L. Dinâmica da água no solo. $2^{\mathrm{a}}$ edição. Piracicaba, 2000: o autor. 509p.

LIN, H.S.; MCINNES, K.J.; WILDING, L.P.; HALLMARK, C.T. Low tension water flow in structured soil. Canadian Journal Soil Science, v. 77, p. 649-654, 1997.

LIN, H.S.; MCINNES, K.J.; WILDING, L.P.; HALLMARK, C.T. Effects of soil morphology on hydraulic properties: I Quantification of soil morphology. Soil Science Society of American Journal, v. 63, p. 948 - 954, 1999.

LOGSDON, S.D.; JAYNES, D.B. Spatial variability of hydraulic conductivity in a cultivated field at different times. Soil Science Society of American Journal, Madison, v. 60, p. $703-709,1996$.

MALLANTS, D.; TSENG, PENG-H.; TORIDE, N.; TIMMERMAN, A.; FEYEN, J. Evaluation of multimodal hydraulic functions in characterizing a heterogeneous field soil. Journal of Hydrology, v. 195, p. 172-199, 1997.

MANFREDINI, S.; PADOVESE, P.P.; OLIVEIRA, J.B. Efeito da composição granulométrica da fração areia no comportamento hídrico de Latossolos de textura média e Areias Quartozosas. Revista Brasileira da Ciência do Solo, v. 8, p. 13$16,1984$. 
MARSHALL, T.J. A relation between permeability and size distribution of pores. Journal of Soil Science, v.9, n.1, p.1 - 8, 1958.

MCKEAGUE, J.A.; WANG, C.; TOPP, G.C. Estimating Saturated Hydraulic Conductivity from Soil Morphology. Soil Science Society of American Journal, v. 46, n.2, p.1239-1244, 1982.

MILLAR, A.A. Condutividade capilar de um suelo derivado de cenizas volcánicas. Turrialba, v.25, p.448-449, 1975.

MILLAR, A.A. Drenagem de terras agrícolas: bases agronômicas. São Paulo: McGraw-Hill do Brasil, 1978. 276p.

MILLINGTON, R.T.; QUIRK, J.P. Permeability of porous media. Nature, v.183, n.1, p.387 - 388, 1959.

MILLINGTON, R.T.; QUIRK, J.P. Transport in porous media. In: International Congress of Soil Science, 7, Madison: SSSA, v.1, n.3, p.97 - 106, 1960.

MOHANTY, B.P.; SKAGGS, T.H.; van GENUCHTEN, M.T. Impact of saturated hydraulic conductivity on the prediction on tile flow. Soil Science Society of America Journal, v. 62, p. 1522-1529, 1998.

MOORE, R.E. The relation of soil temperature to soil moisture pressure potential, retention and infiltration rate. Soil Science Society of American Journal,v. 5, p. 61-64, 1941. 
MORAES, S.O. Heterogeneidade hidráulica de uma terra roxa estruturada. Piracicaba, 1991. 141p. Tese (Doutorado) - Escola Superior de Agricultura Luiz de Queiroz, Universidade de São Paulo.

MUALEM, Y. A new model for predicting the hydraulic conductivity of unsaturated porous media. Water Resources Research, v.12, n.3, p.513 - 522, 1976.

NACHTERGAELE, F.O.; SPAARGAREN, O.; DECKERS, J.A.; AHRENS, B. New developments in soil classification World Reference Base for Soil Resources. Geoderma, v. 96, p. 345-357, 2000.

OLIVEIRA, L.B. Correlação entre a umidade a $1 / 3$ de atmosfera e o equivalente de umidade em solos do nordeste do Brasil. Pesquisa Agropecuária Brasileira, Série Agronômica. Brasilia, v.17(1), p. 125-129, 1982.

OLIVEIRA, J.B.; JACOMINE, P.K.T.; CAMARGO, M.N. Classes gerais de solos do Brasil: guia auxiliar para seu reconhecimento. Jaboticabal, FUNEP, 1992. 201p.

OTHMER, H.; DIEKKRUGER, B.; KUTLEK, M. Bimodal porosity and unsaturated hydraulic conductivity. Soil Science, v. 152, n.3, p. 139-150, 1991.

PETERSEN, G.W.; CUNNINGHAM, R.L.; MATELSKI, R.P. Moisture characteristics of Pennsylvania soils: II. Soil factors affecting moisture retention within a textural class silt-loam. Soil Science of American. Proceedings, v. 32, p. 866-870, 1968.

PHILIP, J.R. The theory of infiltration: The influence of initial moisture content. Soil Science, v. 84, p. 329-339, 1957.

PORTA, J.; LOPEZ, M.A.; ROQUERO, C. Edafologia paa la agricultura y el medio ambiente. $1^{\mathrm{a}}$ ed. Madrid, 1994. $803 \mathrm{p}$. 
PRADO, H. do. Manual de Classificação de Solos do Brasil. $2^{\text {a }}$ ed. Jaboticabal: FUNEP, 1996. 198p.

PREVEDELLO, C.L. Teoria do fluxo da água em solos não saturados: novos conceitos e aplicações. Piracicaba, 1987. 263p. Tese (Doutorado) - Escola Superior de Agricultura Luiz de Queiroz, Universidade de São Paulo.

RADAMBRASIL. Ministério das Minas e Energia. Dep. Nac. de Prod. Mineral. Folha SA-21 - Santárem. Rio de Janeiro, Projeto RADAMBRASIL, Rev. de Rec. Nat., v. 101, 1975. 510p.

RADAMBRASIL. Ministério das Minas e Energia. Levantamento dos recursos naturais: geologia, geomorfologia, pedologia, vegetação e uso potencial de terra. Folhas SF 23/24, Rio de Janeiro/Vitória, 1983, 780p.

REEVE, M.J; SMITH, P.D.; THOMASSON, A.J. The effect of density on water retention properties of field soils. Journal of Soil Science, Oxford, v.24, p.355$367,1973$.

REICHARDT, K. A água em sistemas agrícolas. São Paulo: Manole. 1987. 188p.

REICHARDT, K. Dinâmica da matéria e da energia em ecossistemas. $2^{\mathrm{a}}$ edição. Piracicaba, 1996. 505p.

RESENDE, M.; CURI, N.; SANTANA, D.P. Pedologia e Fertilidade do solo: Interações e Aplicações. Brasília, Ministério da Educação, 1988. 83p.

RESENDE, M.; SANTANA, D.P. Uso das relações $\mathrm{Ki}$ e $\mathrm{Kr}$ na estimativa da mineralogia para classificação de Latossolos. In: Reunião de classificação, 
correlação de solos e interpretação da aptidão agrícola. Rio de Janeiro, 1988. Anais. EMBRAPA-SNLCS/SBCS, p. 225-232.

RICHARDS, L.A. Capillary conduction of liquids through porous medium. Physics, v.1, p. 318-333, 1931.

RICHARDS, L.A.; FIREMAN, M. Pressure-plate apparatus for measuring moisture sorption and transmission by soils. Soil Science, New Brunswick, v. 56, p. 395 $404,1943$.

RIVERS, E.D.; SHIPP, R.F. Soil water retention as related to particle size in selected sands and Loamy sands. Soil Science. Baltimore, v. 126, p. 94-100, 1978.

ROBAIN, H.; CURMI, P. Rôle de la structure pédologique sur le comportement hydrique du sol aux faibles pF. Cahiers de. Recherche de la. Academie de. Sciences Paris, v.303, série I, n.6, p.509-514, 1986.

SALTER, P.J.; WILLIANS, J.B. The influence of texture on the moisture characteristics of soils. Part I: A critical comparison of techniques ofr determining the available water capacity and moisture characteristic curve of a soil. Journal of Soil Science, Oxford, v.16, p.1-15, 1965.

SAS Institute. SAS User's Guide: Statistics. $5^{\text {a }}$ ed. Cary, N.C. 1985. 956p.

SCOPEL, I.; COGO, N.P.; KLAMT, E. Infiltração da água em solos do litoral-norte do Rio Grande do Sul. Revista Brasileira de Ciência do Solo, v. 2, p. 167-170, 1978.

SENTELHAS, P.C.; MARIN, F.R.; PEREIRA, A.R.; ANGELOCCI, L.R.; VILLA NOVA, N.A.; BARBIERI, V. Análise dos dados climáticos e do balanço hídrico 
climatológico de Piracicaba (1917-1997). Piracicaba: DFM/ESALQ/USP. 1998. $81 \mathrm{p}$.

SHARMA, M.L.; UEHARA, G. Influence of soil structure on water relations in Low humic latosols. I. Water retention. Soil Science Society of America Proceedings, Madison, v.32, p.765-774, 1968.

SILVA, A.P. Variabilidade espacial de atributos físicos do solo. Piracicaba, 1988. 105p. Tese (Doutorado) - Escola Superior de Agricultura Luiz de Queiroz, Universidade de São Paulo.

SOIL SURVEY DIVISON STAFF. Soil Survey Manual. Handbook 18, US Govt. Printing Office, Washington, 1993.

SOIL SURVEY DIVISON STAFF. Keys to the soil taxonomy. Washington: USDA, Soil Conservation Service. 1996. 644p.

SOLLINS, P.; RADULOVICH, R. Effects of soil physical structure on solute transport in a weathered tropical soil. Soil Science Society of American Journal, v. 52, p. 1168-1173, 1988.

STARR, J.L. Spatial and temporal variation of ponded infiltration. Soil Science Society of American Journal, v. 54, p. 629-636, 1990.

THORNTHWAITE, C.W.; MATHER, J.R. The water balance. Publications in Climatology. New Jersey: Drexel Institute of Technology, 1955. 104p.

TIETJE, O.; HENNINGS, V. Accuracy of the saturated hydraulic conductivity prediction by pedo-transfer functions compared to the variability within FAO textural classes. Geoderma, v. 69, p. 71-84, 1996. 
TSUЛ, G.Y.; WATANABE, R.T.; SAKAI, W.S. Influence of soil microstructure on water characteristics of selected hawaiian soils. Soil Science Society of American Proceedings, v. 39, p. 28-33, 1975.

van GENUCHTEN, M. TH. A closed form equation for predicting the hidraulic conductivity for unsatureted soils. Soil Science Society of America Journal, v.44, n.5, p. 892-898, 1980.

VIEIRA, L.S. Manual de ciência do solo com ênfase em solos tropicais. $2^{\mathrm{a}}$ ed., Ed. Agronômica Ceres, 1988. 464p.

VILLELA, S.M.; MATTOS, A. Hidrologia aplicada. São Paulo, McGraw-Hill, 1975. $245 \mathrm{p}$.

VOMOCIL, J.A. Porosity. In: BLACK, C.A., ed. Methods of Soil Analysis. Wisconsin, American Society of Agronomy, nº9, p. 299-314, 1965.

WARRICK, A.W.; NIELSEN, D.R. Spatial variability of soil physical properties in the field. In: HILLEL, D. (Ed.) Applications of soil physics. New York: Academic Press,. cap. 13, p. 319-344. 1980

WOSTEN, J.H.M.; van GENUCHTEN, M. TH. Using texture and other soil properties to predict the unsaturated soil hydraulic functions. Soil Science Society of America Journal, v.52, p. 1762-1770, 1988.

YOUNGS, E.G. Hydraulic conductivity of saturated soils. In: SMITH, K.A.; MULLINS, C.E. (Ed). Soil analysis: physical methods. New York: Marcel Dekker. Cap. 4, p. 161-207, 1991. 